\title{
DEVELOPMENT OF CONTINUOUS SOLVENT EXTRACTION PROCESSES FOR COAL DERIVED CARBON PRODUCTS DE-FC26-03NT41873
}

\author{
Quarterly Report \\ PERIOD OF PERFORMANCE: \\ July 1, 2006 - September 30, 2006 \\ Submission date: \\ November 1, 2006
}

Principal Investigator:

Elliot B. Kennel

Co-Investigators:

Dady B. Dadyburjor, Gregory W. Hackett, Manoj Katakdaunde, Liviu Magean, Alfred H. Stiller, Robert C. Svensson, John W. Zondlo

West Virginia University Department of Chemical Engineering College of Engineering and Mineral Resources

PO Box 6102

Morgantown WV 26506

Subcontractors:

GrafTech International

12900 Snow Road

Parma, OH 44130

Koppers Inc. 1005 William Pitt Way Pittsburgh, PA 15238 


\section{DISCLAIMER:}

This report was prepared as an account of work sponsored by an agency of the United States Government. Neither the United States Government nor any agency thereof, nor any of their employees, makes any warranty, express or implied, or assumes any legal liability or responsibility for the accuracy, completeness, or usefulness of any information, apparatus, product, or process disclosed, or represents that its use would not infringe privately owned rights. Reference herein to any specific commercial product, process, or service by trade name, trademark, manufacturer, or otherwise does not necessarily constitute or imply its endorsement, recommendation, or favoring by the United States Government or any agency thereof. The views and opinions of authors expressed herein do not necessarily state or reflect those of the United States Government or any agency thereof. 


\section{TABLE OF CONTENTS}

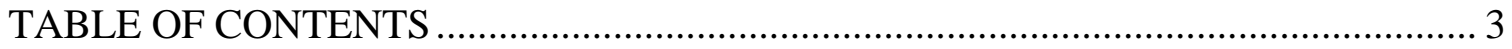

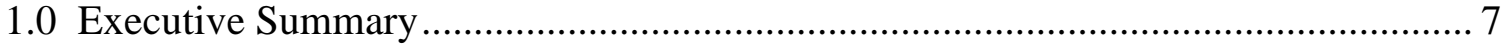

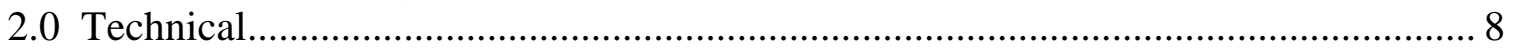

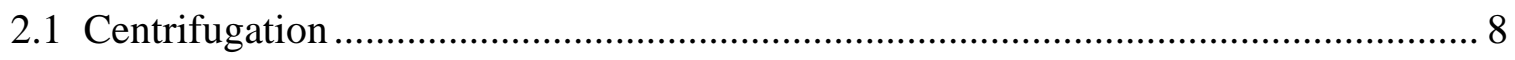

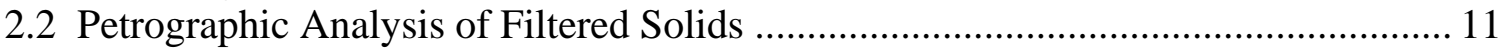

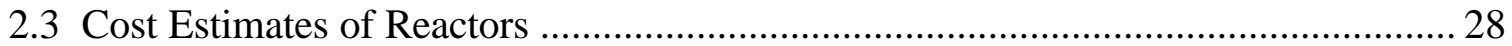

2.4 Carbon Materials for Use in a Direct Carbon Fuel Cell ......................................... 30

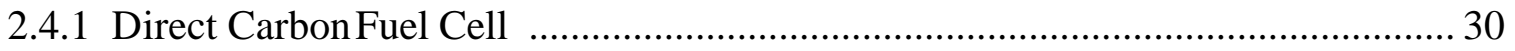

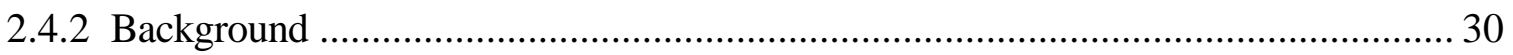

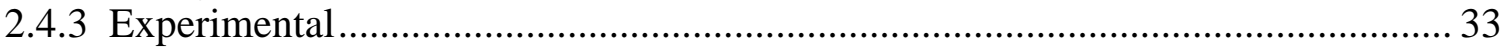

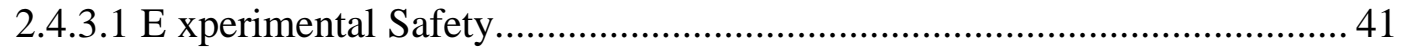

2.4.3.2 Carbon Rod Production.......................................................................... 42

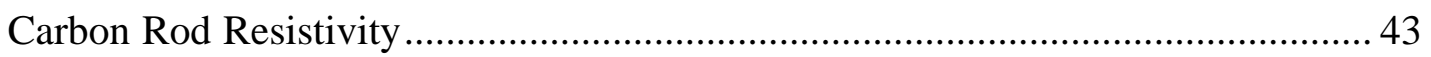

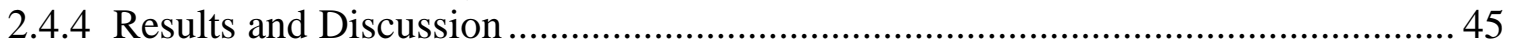

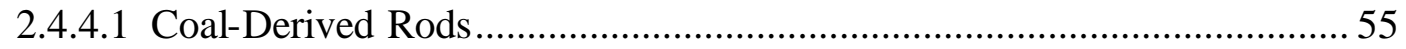

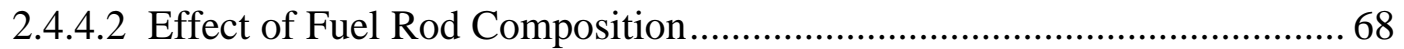

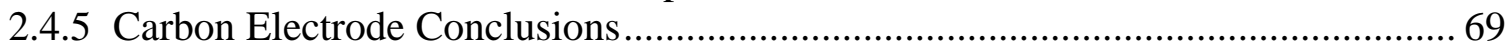

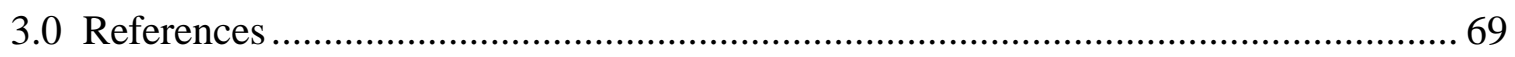




\section{LIST OF FIGURES}

Figure 1. Decanter-type centrifuge, similar to the unit used at WVU. ........................... 8

Figure 2. Spinner II Centrifuge, courtesy T. F. Hudgins. ............................................ 9

Figure 3. Centrifugation system, showing pressurized holding tank and centrifuge ..... 10

Figure 4. Close up of Oil Bath and Centrifuge. ........................................................... 10

Figure 5. Photomicrographs of Filtered Solid from WVU Extracted Sample RF-51... 13

Figure 6. Photomicrographs of Filtered Solid from WVU Extracted Sample RF-51..... 13

Figure 7. Photomicrographs of Filtered Solid from WVU Extracted Sample RF-51...... 14

Figure 8. Photomicrographs of Filtered Solid from WVU Extracted Sample RF-51 .... 14

Figure 9. Photomicrographs of Filtered Solid from WVU Extracted Sample RF-51_... 15

Figure 10. Photomicrographs of Filtered Solid from WVU Extracted Sample RF-51... 15

Figure 11. Photomicrographs of Filtered Solid from WVU Extracted Sample RF-51 .... 16

Figure 12. Photomicrographs of Filtered Solid from WVU Extracted Sample RF-51 .... 16

Figure 13. Photomicrographs of Filtered Solid from WVU Extracted Sample RF-51.... 17

Figure 14. Photomicrographs of Filtered Solid from WVU Extracted Sample RF-51.... 17

Figure 15. Photomicrographs of Filtered Solid from WVU Extracted Sample RF-51.... 18

Figure 16. Photomicrographs of Filtered Solid from WVU Extracted Sample RF-51.... 18

Figure 17. Photomicrographs of Filtered Solid from WVU Extracted Sample RF-51 ... 19

Figure 18. Photomicrographs of Filtered Solid from WVU Extracted Sample RF-51 .... 19

Figure 19. Photomicrographs of Filtered Solid from WVU Extracted Sample RF-51 .... 20

Figure 20. Photomicrographs of Filtered Solid from WVU Extracted Sample RF-51 .... 20

Figure 21. Photomicrographs of Filtered Solid from WVU Extracted Sample RF-51 _... 21

Figure 22. Photomicrographs of Filtered Solid from WVU Extracted Sample RF-51 .... 21

Figure 23. Photomicrographs of Filtered Solid from WVU Extracted Sample RF-51 .... 22

Figure 24. Photomicrographs of Filtered Solid from WVU Extracted Sample RF-51. .. 22

Figure 25. Photomicrographs of Filtered Solid from WVU Extracted Sample RF-51.... 23

Figure 26. Photomicrographs of Filtered Solid from WVU Extracted Sample RF-51... 23

Figure 27. Photomicrographs of Filtered Solid from WVU Extracted Sample RF-51... 24

Figure 28. Photomicrographs of Filtered Solid from WVU Extracted Sample RF-51_... 24

Figure 29. Photomicrographs of Filtered Solid from WVU Extracted Sample RF-51 .... 25

Figure 30. Photomicrographs of Filtered Solid from WVU Extracted Sample RF-51.... 25

Figure 31. Photomicrographs of Filtered Solid from WVU Extracted Sample RF-51.... 26

Figure 32. Photomicrographs of Filtered Solid from WVU Extracted Sample RF-51.... 26

Figure 33. Photomicrographs of Filtered Solid from WVU Extracted Sample RF-51.... 27

Figure 34. Photomicrographs of Filtered Solid from WVU Extracted Sample RF-51 .... 27

Figure 35. Photomicrographs of Filtered Solid from WVU Extracted Sample RF-51.... 28

Figure 36. Photomicrographs of Filtered Solid from WVU Extracted Sample RF-51... 28

Figure 37. ChemTech Hydrotreatment Pressure Vessel Design..................................29

Figure 38. Picture and Schematic Diagram of CellTech Design. .................................. 31

Figure 39. Schematic Diagram of Direct Carbon Fuel Cell ........................................... 34

Figure 40. Photograph of Constructed Direct Carbon Fuel Cell .................................... 35

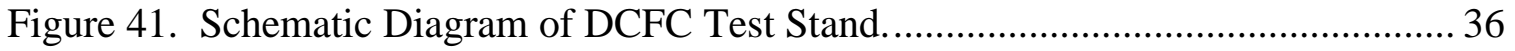

Figure 42. Photograph of Fuel Cell Test Stand Donated by the U.S. DOE. ................... 36

Figure 43. Photograph of Sparger Used for Bubbling Air Along the Cathode................ 37 
Figure 44. Generic Fuel Cell $i$-V Curves with Specific Regions Highlighted................. 39

Figure 45. Carbon Rod Resistivity Testing Apparatus ................................................. 44

Figure 46. Schematic Diagram of Four Point Method for Testing Resistivity ................ 44

Figure 47. Results of Initial Graphite Experiment Subject to the Conditions ................ 48

Figure 48. Results of Graphite Experiment Subject to the Conditions of Runs ............. 49

Figure 49. Results of Graphite Experiment Subject to the Conditions of Runs ............. 49

Figure 50. Results of Graphite Experiment Subject to the Conditions of Runs .............50

Figure 51. Results of Graphite Experiment Subject to the Conditions of Runs .............50

Figure 52. Long-Term Results for Graphite Experiment Subject to Condition ............. 51

Figure 53. Results of Graphite Experiment Subject to the Conditions of Runs ............. 51

Figure 54. Long-Term Results of Graphite Experiment Subject to the Conditions ....... 52

Figure 55. Results of Graphite Experiment Subject to the Conditions of Runs ..............52

Figure 56. Results of Graphite Experiment Subject to the Conditions of Run \#2 ......... 53

Figure 57. Long-Term Results for Graphite Experiment Subject to the Conditions ...... 54

Figure 58. Results of GrafTech Graphite Rod from Run \#19...................................... 54

Figure 59. Long-Term Results for GrafTech Graphite Rod from Run \#19 .................... 55

Figure 60. SEM Image of Carbon Fuel Rod with $\mathrm{C} / \mathrm{NaOH} / \mathrm{Fe}$ Buildup.........................56

Figure 61. Results of 100\% PetCoke Rod from Run \#13 ............................................ 57

Figure 62. Results of 100\% PetCoke Rod from Run \#14 ............................................ 58

Figure 63. Results of 100\% SECO Rod from Run \#18 ............................................... 58

Figure 64. Long Term Results for 100\% SECO Rod Run from Run \#18 ..................... 59

Figure 65. Results for 50\% SECO/ 50\% PetCoke Rod from Run \#16 ...........................59

Figure 66. Long Term Results for 50/50 SECO-PetCoke Rod Run from Run \#16........ 60

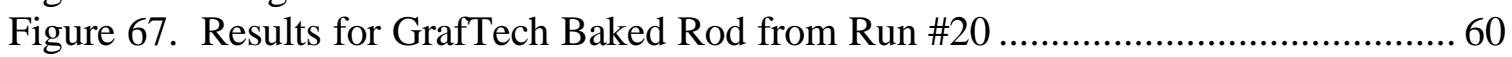

Figure 68. Long Term Results for GrafTech Non-Graphitized Rod Run from Run \#20 61

Figure 69. Reproducibility of Data Generated During the Same Run. ........................... 62

Figure 70. Reproducibility of Data Generated During Duplicate Runs .......................... 63

Figure 71. Effect of Temperature on Voltage Output and Power Density from Runs ...6 63

Figure 72. Effect of Temperature on Voltage Output and Power Density from Runs .... 64

Figure 73. Trends of Open Cell Voltage and Area Specific Resistance .........................6 65

Figure 74. Effect of Airflow Rate on Voltage Output and Power Density at $675{ }^{\circ} \mathrm{C} \ldots . . .66$

Figure 75. Effect of Airflow Rate on Voltage Output and Power Density at $600{ }^{\circ} \mathrm{C}$...... 66

Figure 76. Trends of Open Cell Voltage and Area Specific Resistance .........................67 67

Figure 77. Trends of Open Cell Voltage and Area Specific Resistance ......................... 68 


\section{LIST OF TABLES}

Table 1. Approximate Centrifugation Matrix......................................................... 11

Table 2. Petrographic Analysis of the Filtered Solids Sample RF-51 .......................... 12

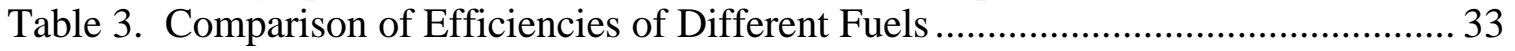

Table 4. Summary of Results from Experimental Design .......................................... 46

Table 5. Summary of Results for Runs Using Graphite Fuel Rods ............................... 47

Table 6. Summary of Results for Runs Using Coal-Derived Fuel Rods ......................... 56

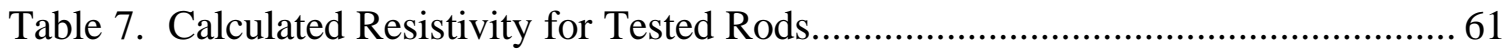

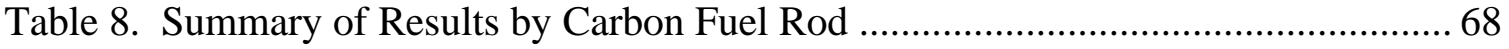




\subsection{Executive Summary}

In this reporting period, tonnage quantities of coal extract were produced but solid separation was not accomplished in a timely manner. It became clear that the originally selected filtration process would not be effective enough for a serious commercial process. Accordingly, centrifugation was investigated as a superior means for removing solids from the extract. Results show acceptable performance.

Petrographic analysis of filtered solids was carried out by $\mathrm{R} \& \mathrm{D}$ Carbon Petrography under the auspices of Koppers and consultant Ken Krupinski. The general conclusion is that the material appears to be amenable to centrifugation. Filtered solids shows a substantial pitch component as well as some mesophase, resulting in increased viscosity. This is likely a contributing reason for the difficulty in filtering the material.

Cost estimates were made for the hydotreatment and digestion reactors that would be needed for a 20,000 ton per year demonstration plants, with the aid of ChemTech Inc. The estimates show that the costs of scaling up the existing tank reactors are acceptable. However, a strong recommendation was made to consider pipe reactors, which are thought to be more cost effective and potentially higher performance in large scale systems.

The alternate feedstocks for coke and carbon products were used to fabricate carbon electrodes as described in the last quarterly report. Gregory Hackett successfully defended his MS Thesis on the use of these electrodes in Direct Carbon Fuel Cell (DCFC), which is excerpted in Section 2.4 of this quarterly report. 


\subsection{Technical}

\subsection{Centrifugation}

As described in last quarter's reports, methods for hydrotreating and coal digestion demonstrated marked improvement. Starting in the last week of August, weekly total coal digestion was 510, 510, 510, 630 and $630 \mathrm{lbs}$, or about an order of magnitude better than demonstrated performance during the spring. This brings the total inventory to nine 55-gallon drums, of which five have been filtered to a level of $0.5 \%$ ash or below.

The materials separation process was not adequate to handle the increase in throughput, however. Filtration has been low reliability and high downtime with difficult quality control. Owing partially to the difficulty in cleaning and removing pitch from the system, mass loss has been high and a reliable mass balance has not been obtained. In short, this process is not up to minimal engineering standards.

Earlier, centrifugation had been considered using a Sharples-Pennwalt decantertype unit donated by Koppers Inc. Centrifugation had been rejected because the ash levels in the output were no lower than $1 \%$. In retrospect, this decision was made prematurely. Pennwalt was consulted and recommended that a "polishing" centrifuge be used in series with the decanter centrifuge. This recommendation was not carried out, as filtration was believed to be an adequate alternative and produced results within specifications.

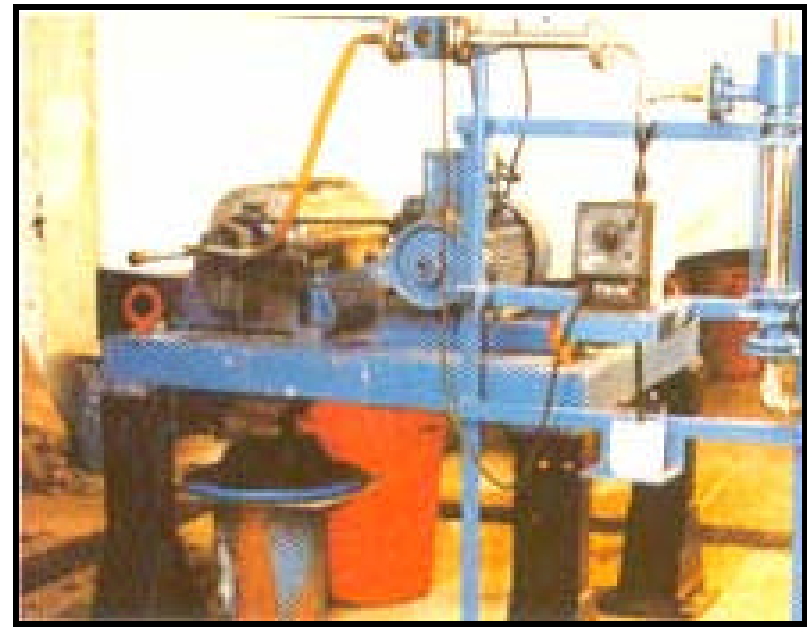

Figure 1. Decanter-type centrifuge, similar to the unit used at WVU. Photo courtesy Pennwalt India.

In the meantime however, chronic problems with clogging and intermittent down time have resulted in poor throughput capacity. Accordingly, it was decided to revisit this issue and to use a Sharples-Pennwalt decanter centrifuge to accomplish the initial ash 
reduction to about the $1 \%$ level, followed by a Spinner II centrifuge which would be used to bring the final ash level to meet the specification of $0.5 \%$ ash or lower (see Figure 2).

Testing was required to ensure that the Spinner II would meet the necessary specification. Feeding of the slurry to the centrifuge can be accomplished using a double diaphragm pump. This type of pump is virtually clog free. However, these devices are pulsed mode which is not optimal for the operation of the centrifuge. Accordingly, a pressurized holding tank is used as a buffer to supply coal liquids at constant pressure to the centrifuge. This arrangement is shown in Figure 3. The Spinner II centrifuge is partially submerged in an oil heating bath.

Preliminary results show that the ash level was reduced to $0.38 \%$, which is adequate for this purpose. Hence it is concluded that solids separation can be accomplished using this technique, and the next quarterly report will chronicle the process in greater detail.

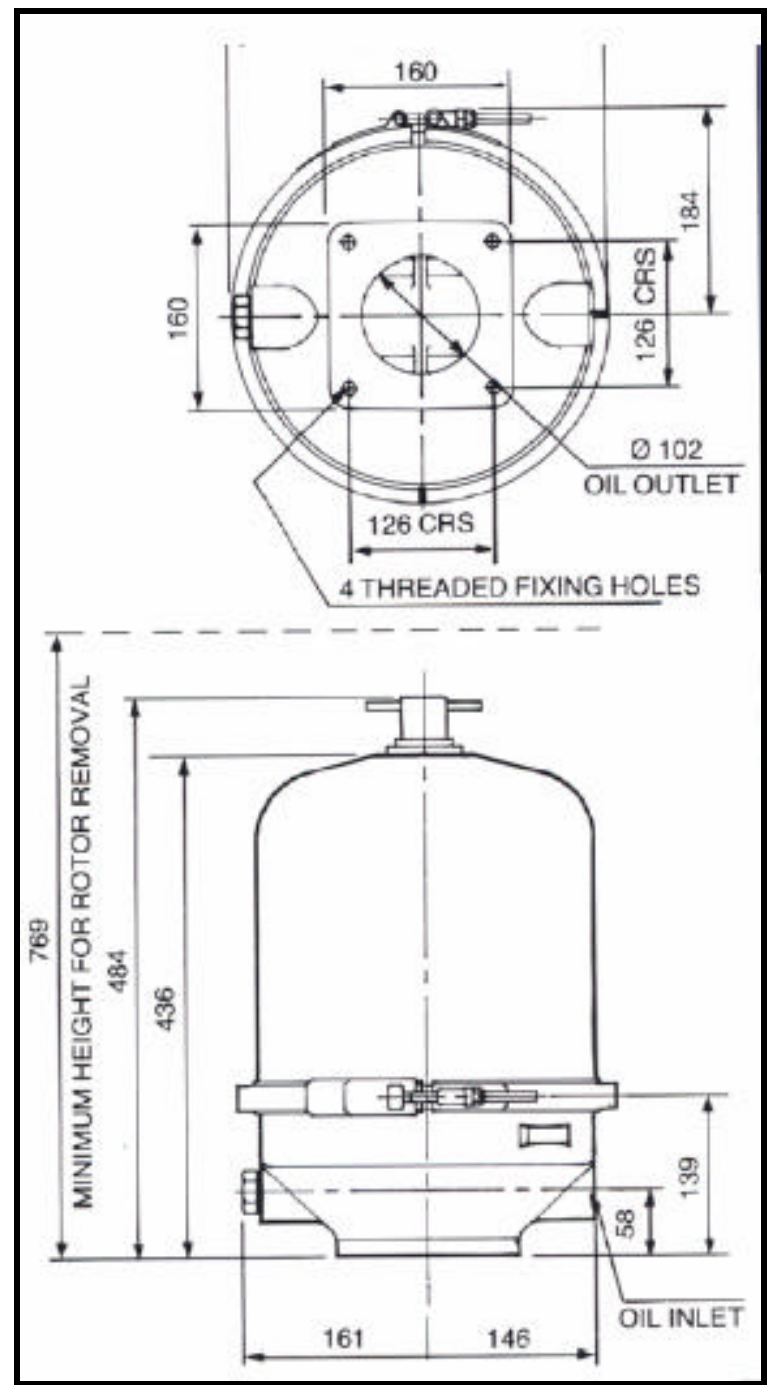

Figure 2. Spinner II Centrifuge, courtesy T. F. Hudgins. 


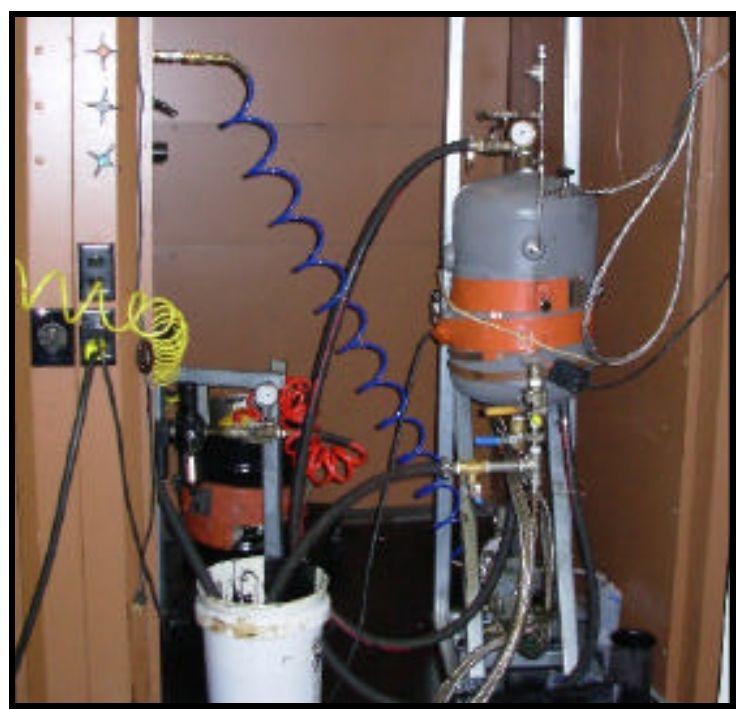

Figure 3. Centrifugation system, showing pressurized holding tank and centrifuge.

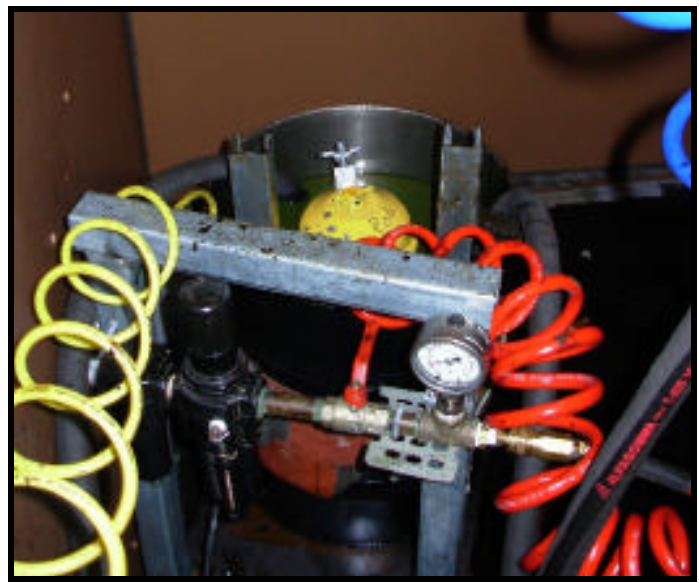

Figure 4. Close up of Oil Bath and Centrifuge.

Another aspect of the solids separation effort is the measurement of the ash level itself. Ash test procedures are now being estimated with ASTM proximate analysis, ASTM D-5142 using a LECO TGA701 unit. Earlier, an in-house method was used to estimate ash levels, which deviated from D5142 by using air at $700{ }^{\circ} \mathrm{C}$ rather than oxygen at $900{ }^{\circ} \mathrm{C}$. However, it was found that this method is not reliable and often produced higher estimates, probably due to incomplete oxidization.

Table 1 provides rough estimates (goals) for the ash level expected in the centrifugation process at different points in the process. 
Table 1. Approximate Centrifugation Matrix.

\begin{tabular}{|c|c|c|c|}
\hline Description & $\begin{array}{l}\text { Nominal } \\
\text { composition, } \\
\text { inlet }\end{array}$ & $\begin{array}{l}\text { Nominal } \\
\text { composition, } \\
\text { outlet }\end{array}$ & Disposition of outlet \\
\hline Raw unfiltered extract & $\begin{array}{l}8 \% \text { solids, } 4 \% \\
\text { ash }\end{array}$ & & $\begin{array}{l}\text { Blend with Sharples } \\
\text { Output 100:200 lbs }\end{array}$ \\
\hline $\begin{array}{l}\text { Sharples feedstock blend, } \\
\text { 100:200 blend of Sharples } \\
\text { output and raw unfiltered } \\
\text { extract }\end{array}$ & $\begin{array}{l}4 \% \text { solids, } 2 \% \\
\text { ash }\end{array}$ & $\begin{array}{l}2 \% \text { solids, } 1 \% \\
\text { ash }\end{array}$ & $\begin{array}{l}\text { Inlet to Spinner II, } \\
\text { blend with Spinner } \\
\text { Output } 20: 40 \text { pounds. }\end{array}$ \\
\hline Sharples tails & & $\begin{array}{l}15 \% \text { solids, } \\
8 \% \text { ash }\end{array}$ & $\begin{array}{l}\text { Use for Dick Wolfe } \\
\text { process or dispose of } \\
\text { as coal waste. }\end{array}$ \\
\hline $\begin{array}{l}\text { Spinner II feedstock blend } \\
\text { 20:40 blend of clean Spinner } \\
\text { output and Sharples output }\end{array}$ & $\begin{array}{l}1 \% \text { solids, } \\
0.5 \% \text { ash }\end{array}$ & $\begin{array}{l}0.4 \% \text { solids, } \\
0.2 \% \text { ash }\end{array}$ & Product for Koppers \\
\hline Spinner II Tails & & $\begin{array}{l}4 \% \text { solids } 2 \% \\
\text { ash }\end{array}$ & $\begin{array}{l}\text { Return to unfiltered } \\
\text { extract drum }\end{array}$ \\
\hline
\end{tabular}

\subsection{Petrographic Analysis of Filtered Solids}

A sample of filtered solids from the WVU extract of Kingwood coal was submitted through Koppers to R \&D Carbon Petrography for petrographic analysis, designated R \& D No. 1612 and RF-51 by Koppers consultant Ken Krupinski.

The sample of filtered solids was prepared for petrographic analysis and photographed in reflected light at $600 \mathrm{X}$ and at $1525 \mathrm{X}$ in oil. A total of 1000 point s were counted for the composite which consists of a pitch like binder phase material, angular and spherical anisotropic mesophase, coal inerts and mineral matter. In addition, 25 points of reflectance were measured on the pitch like binder phase material.

As described in Table 2, the filtered solid sample RF-51 has $74.2 \%$ by volume of a pitch like binder phase material, with $15.6 \%$ of total anisotropic carbon which consist of $13.8 \%$ spherical (individual and captured spheres) and $1.8 \%$ of angular fagments of anisotropic carbon which may be mosaic mesophase or pitch coke depending on the degree of carbonization as listed in Table 2 and shown in Figures 5 through 36. There is $4.4 \%$ of total coal inerts by volume which consist of $2.2 \%$ coal inerts which are less than 50 microns in size and $2.2 \%$ of coal inerts that are greater than 50 microns in size. There is $5.8 \%$ of total mineral matter by volume which consists mostly of fine sized disseminated clay, pyrite and angular mineral matter that is less than 50 microns in size with lesser amounts of angular mineral matter that is greater than 50 microns in size and quartz. To establish the degree of carbonization of the pitch like binder phase material 25 points of reflectance were measured for mean-maximum reflectance values. The meanmaximum reflectance for the binder phase material is $1.40 \%$. 
Table 2. Petrographic Analysis of the Filtered Solids Sample RF-51

\begin{tabular}{|l|l|}
\hline R \& D Carbon \# & 1612 \\
\hline KK \# & $\begin{array}{l}\text { Filtered Solids from } \\
\text { Pitch Extract } \\
\text { RF-51 }\end{array}$ \\
\hline Pitch Like Binder Phase Material & 74.2 \\
\hline \multicolumn{1}{|c|}{ Total Binder Phase } & 74.2 \\
\hline & \\
\hline Anisotripic Carbon: & \\
\hline $\begin{array}{l}\text { Mesophase Spheres and Captured } \\
\text { Aggregates }\end{array}$ & 13.8 \\
\hline $\begin{array}{l}\text { Angular Fragments of Mosiac } \\
\text { Mesophase or Pitch Coke }\end{array}$ & 1.8 \\
\hline \multicolumn{1}{|c|}{ Total Anisotropic Carbon } & 15.6 \\
\hline Total Coal Inerts & 4.4 \\
\hline Coal Inerts: & 2.2 \\
\hline Inerts <50 microns & 2.2 \\
\hline Inerts >50 microns & \\
\hline & 2.2 \\
\hline Mineral Matter: & 1.2 \\
\hline Disseminated Clay & 0.6 \\
\hline Angular Mineral Matter <50 microns & 1.6 \\
\hline Angular Mineral Matter >50 microns & 0.2 \\
\hline Pyrite & 5.8 \\
\hline Quartz & 100.0 \\
\hline & \\
\hline \multicolumn{1}{|c|}{ Total Mineral Matter } & \\
\hline Grand Total & \\
\hline
\end{tabular}




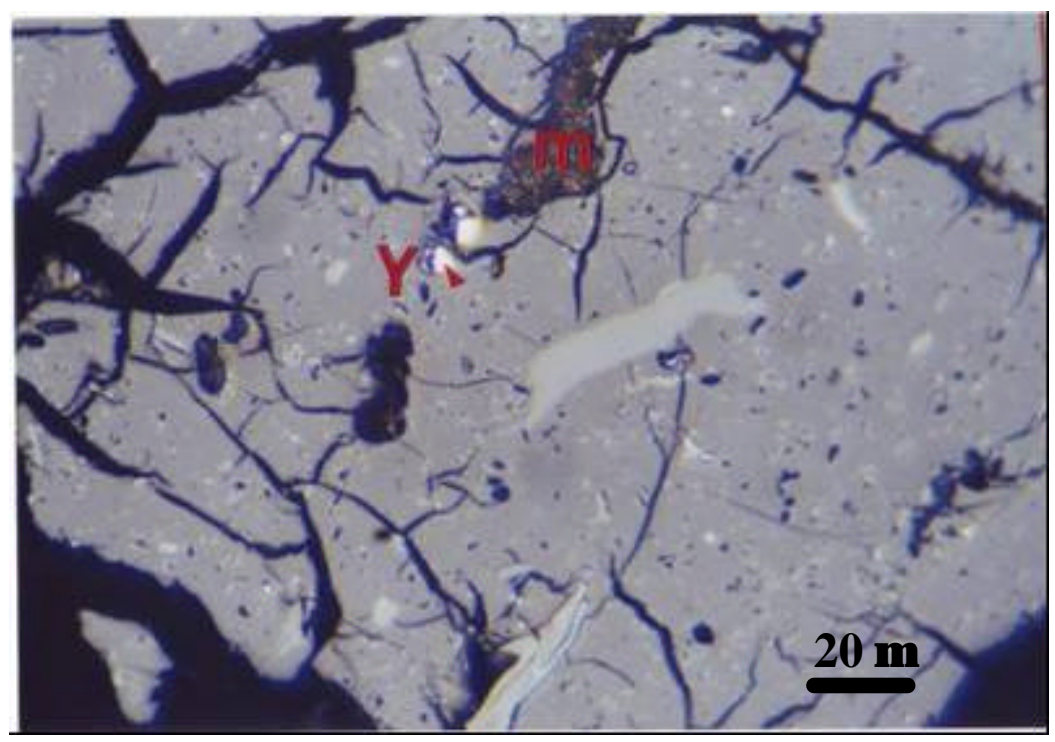

Figure 5. Photomicrographs of Filtered Solid from WVU Extracted Sample RF-51. Notes: $\quad$ M=Mineral Matter, Y=Pyrite. Reflected Light In Oil, X600.

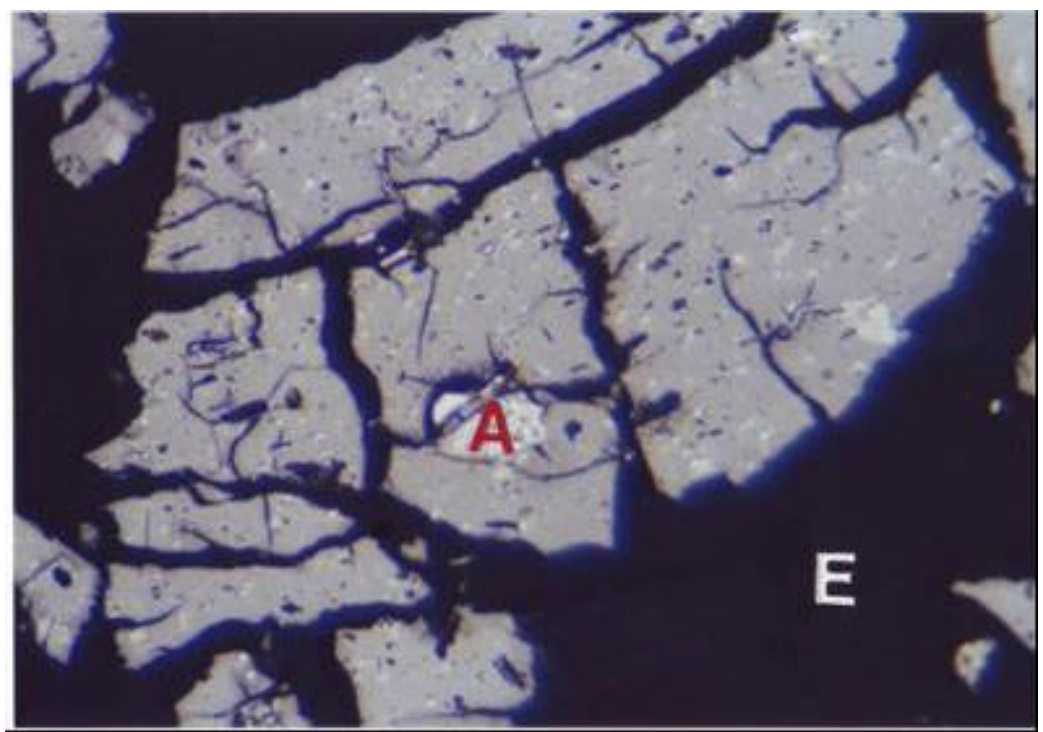

Figure 6. Photomicrographs of Filtered Solid from WVU Extracted Sample RF-51. Notes: A=Angular Particle of Anisotropic Mosaic Mesophase or Pitch Coke, E=Epoxy Mount Media. Reflected Light In Oil, X600. 


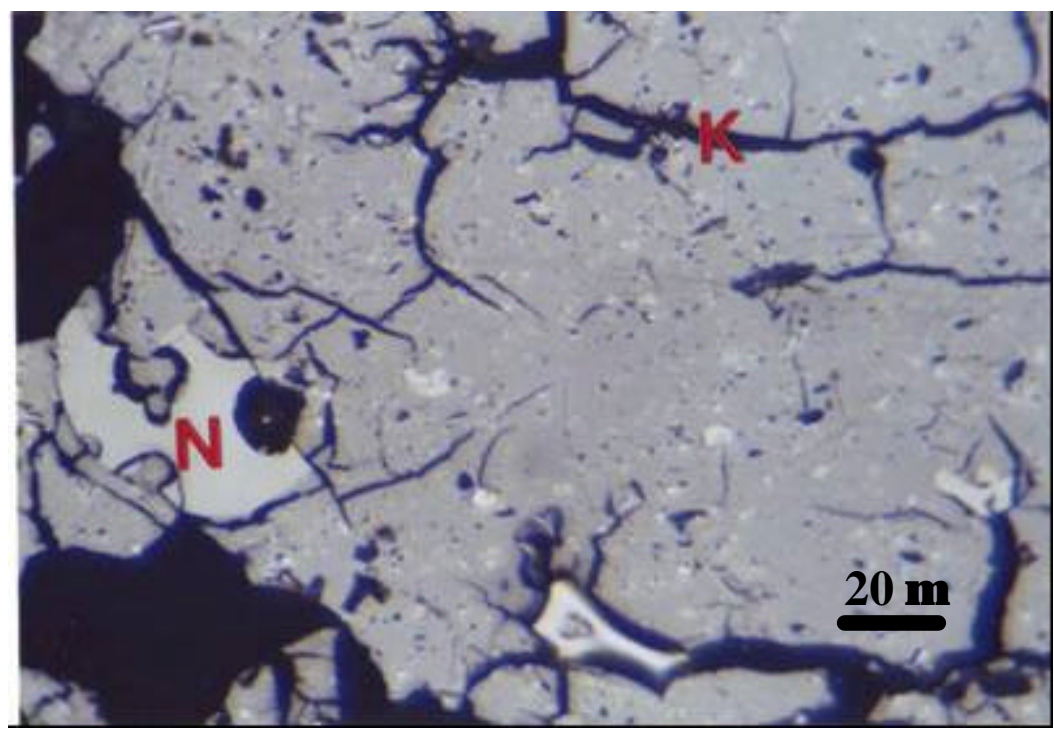

Figure 7. Photomicrographs of Filtered Solid from WVU Extracted Sample RF-51. Notes: $\quad \mathrm{N}=$ Coal Inert, $\mathrm{K}=$ Cracks from Drying and $\mathrm{E}=$ Epoxy Mount Media. Reflected Light In Oil, X600.

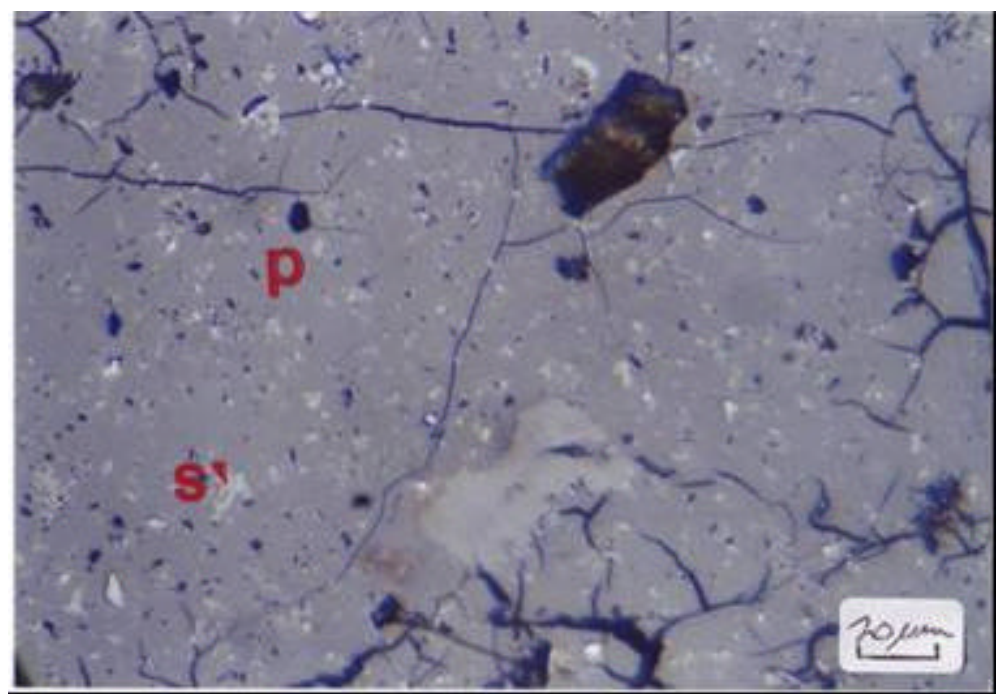

Figure 8. Photomicrographs of Filtered Solid from WVU Extracted Sample RF-51. Notes: P=Pitch Like Binder Phase Material, $\mathrm{S}=$ Anisotropic Mesophase Sphere. Reflected Light In Oil, X600. 


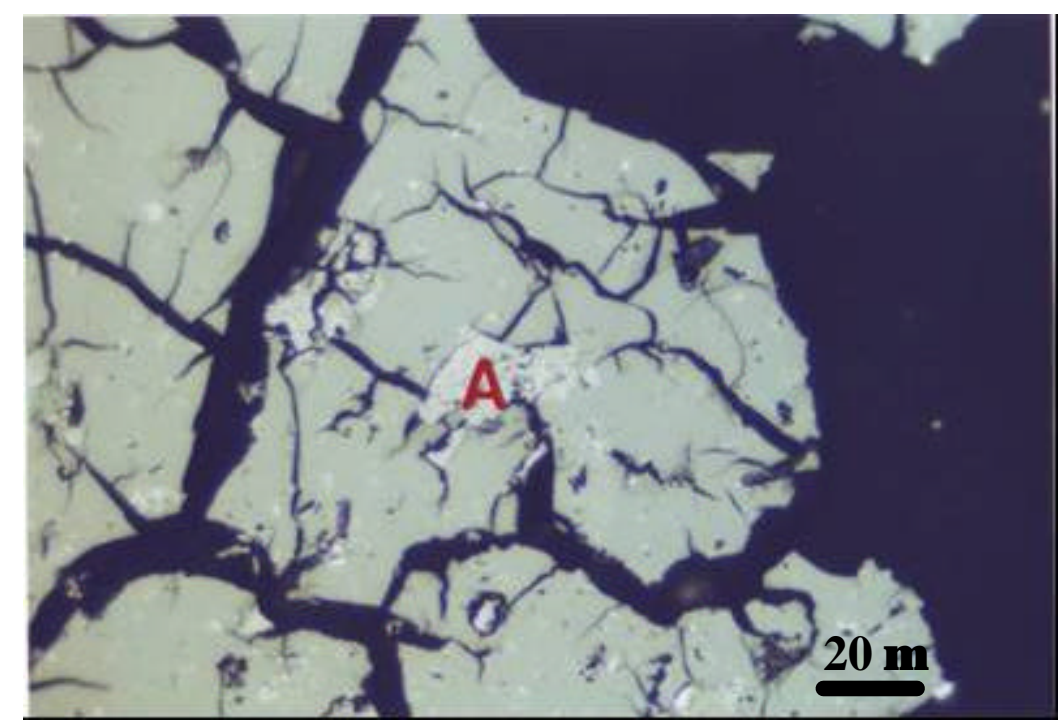

Figure 9. Photomicrographs of Filtered Solid from WVU Extracted Sample RF-51. Notes: A=Angular Particle of Anisotropic Mosaic Mesophase or Pitch Coke. Reflected Light In Oil, X600.

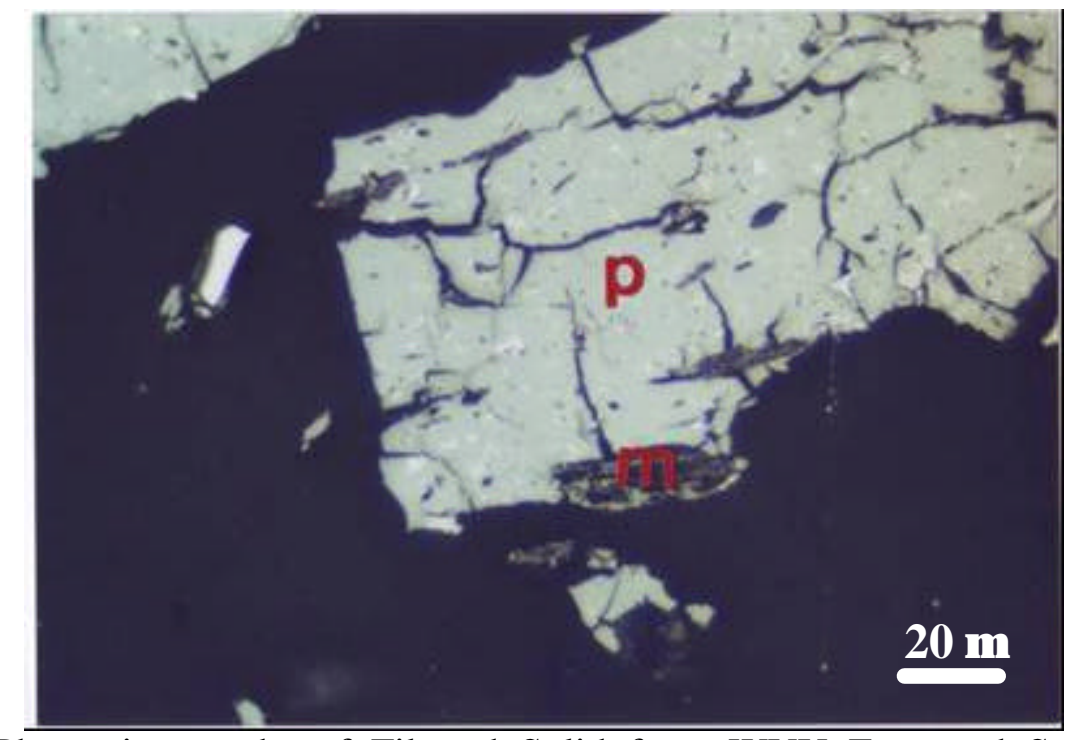

Figure 10. Photomicrographs of Filtered Solid from WVU Extracted Sample RF-51. Notes: P=Pitch Like Binder Phase Material, M=Mineral Matter. Reflected Light In Oil, X600. 


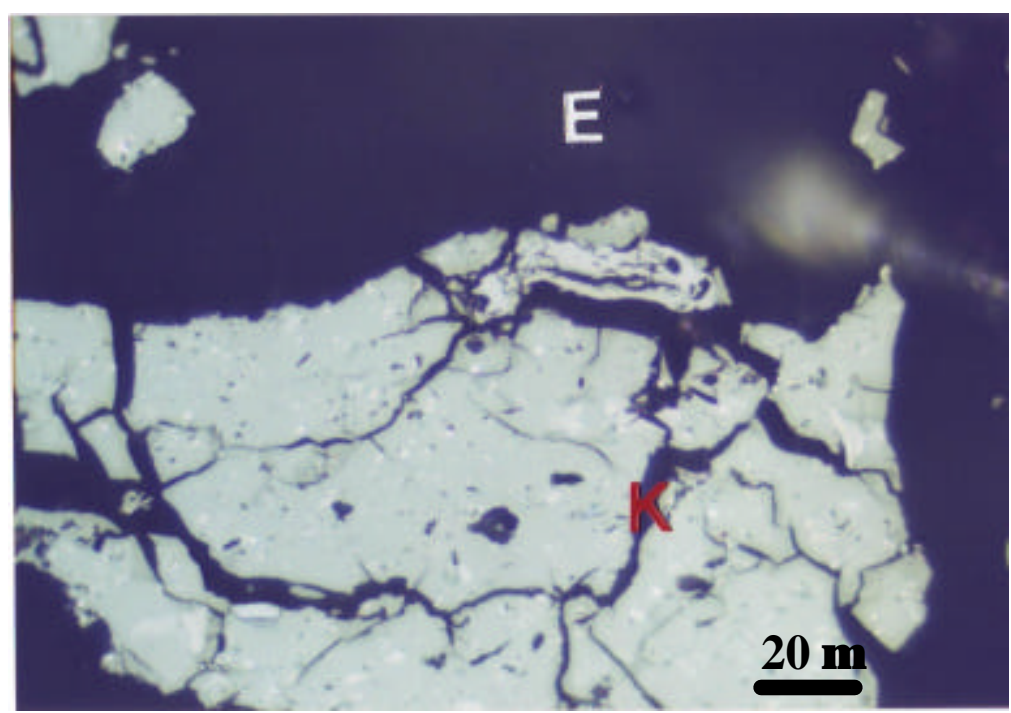

Figure 11. Photomicrographs of Filtered Solid from WVU Extracted Sample RF-51. Notes: E=Epoxy Mount Media. Reflected Light In Oil, X600.

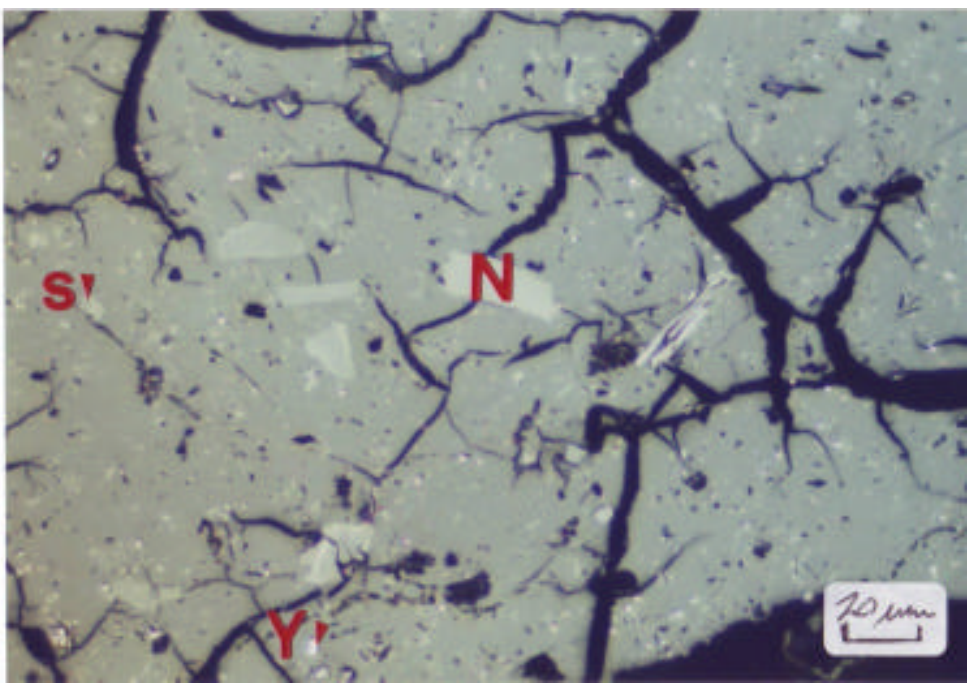

Figure 12. Photomicrographs of Filtered Solid from WVU Extracted Sample RF-51. Notes: N=Coal Inert, $\mathrm{S}=$ Anisotropic Mesophase Sphere, Y=Pyrite,. Reflected Light In Oil, X600. 


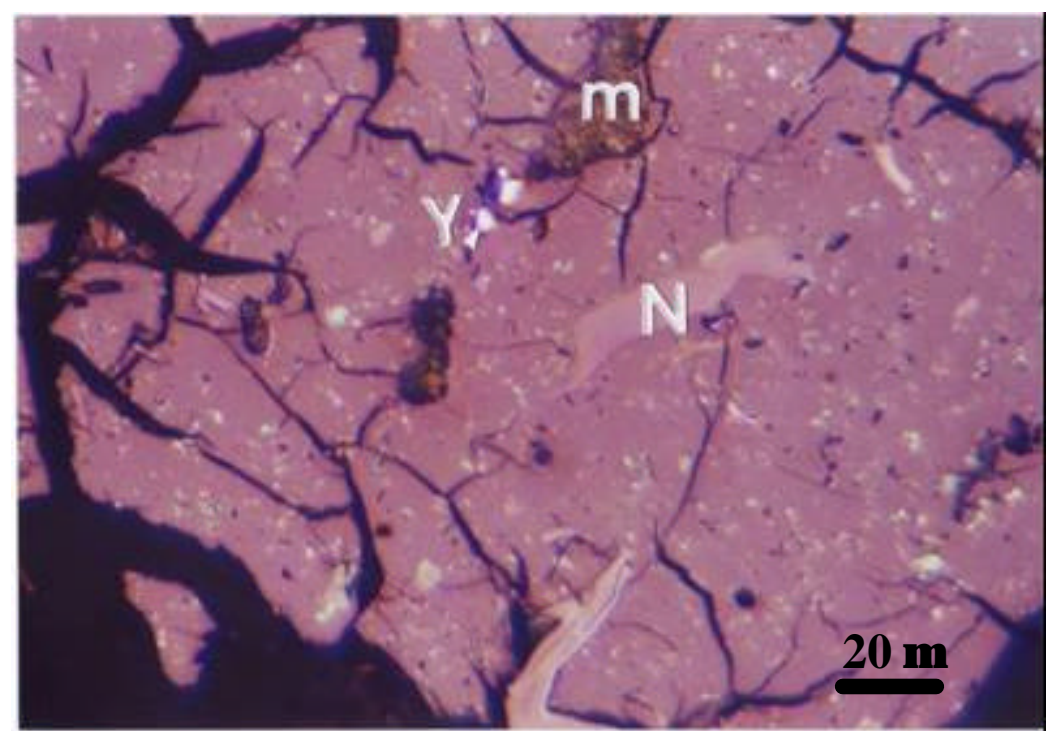

Figure 13. Photomicrographs of Filtered Solid from WVU Extracted Sample RF-51. Notes: N=Coal Inert, M=Mineral Matter, Y=Pyrite. Reflected Light In Oil, X600.

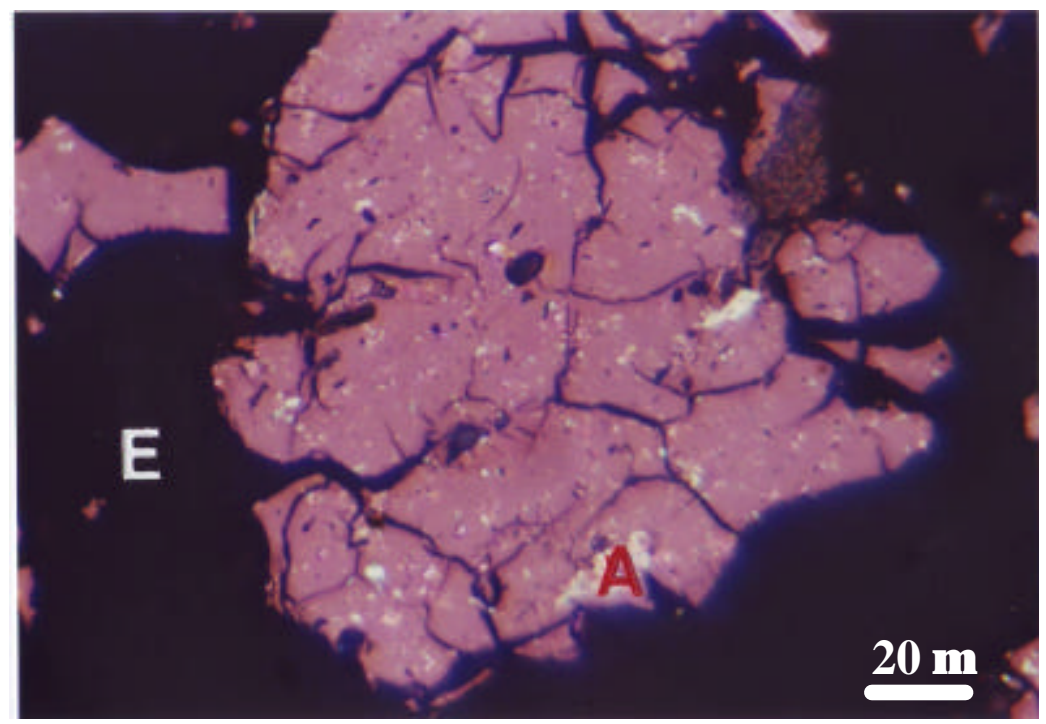

Figure 14. Photomicrographs of Filtered Solid from WVU Extracted Sample RF-51. Notes: P=Pitch Like Binder Phase Material, N=Coal Inert, S=Anisotropic Mesophase Sphere, A=Angular Particle of Anisotropic Mosaic Mesophase or Pitch Coke, $\mathrm{M}=$ Mineral Matter, $\mathrm{Y}=$ Pyrite, $\mathrm{K}=\mathrm{Cracks}$ from Drying and $\mathrm{E}=\mathrm{Epoxy}$ Mount Media. Reflected Light In Oil, X600. 


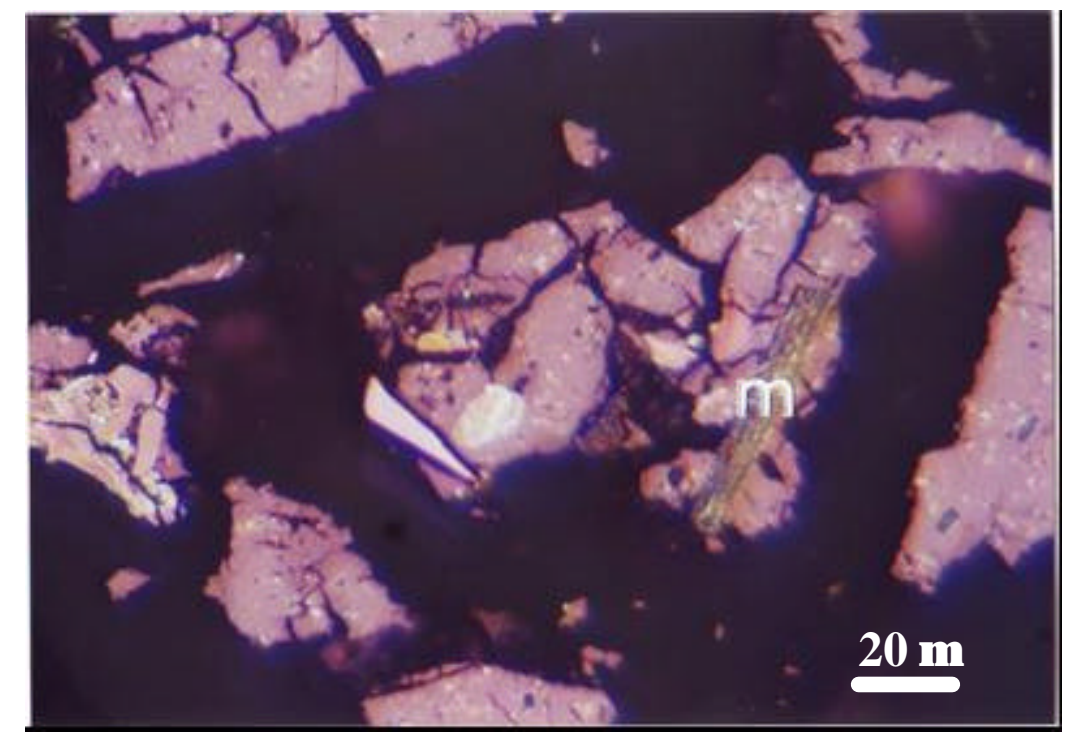

Figure 15. Photomicrographs of Filtered Solid from WVU Extracted Sample RF-51. Notes: M=Mineral Matter. Reflected Light In Oil, X600.

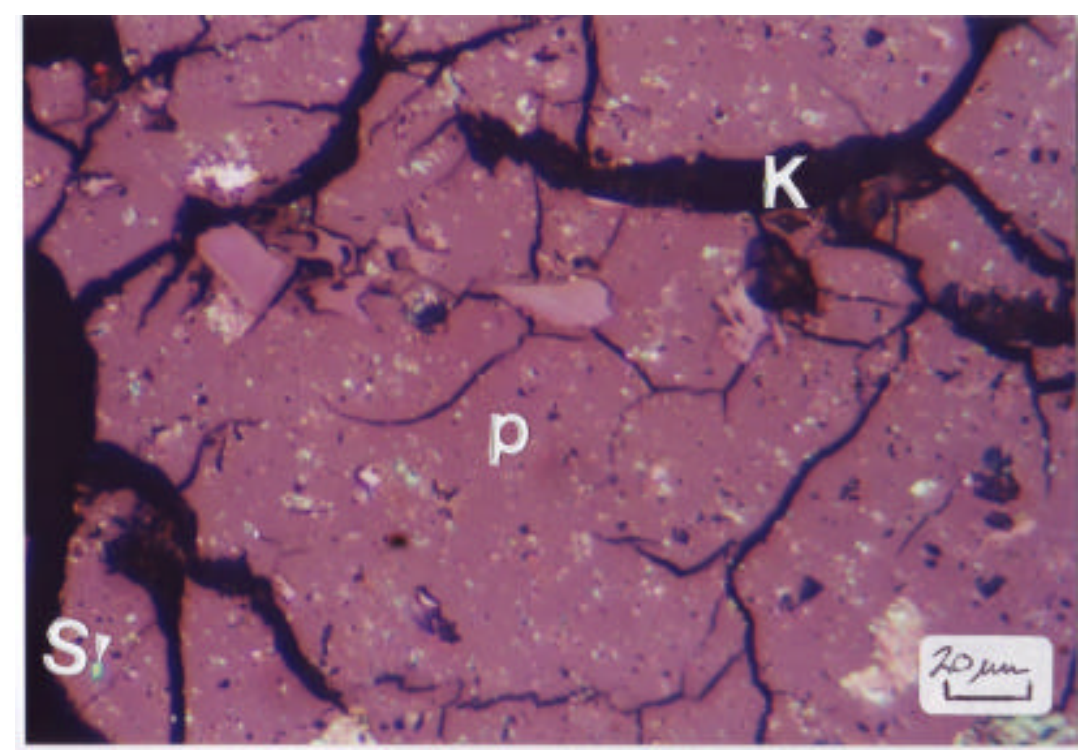

Figure 16. Photomicrographs of Filtered Solid from WVU Extracted Sample RF-51. Notes: $\mathrm{P}=$ Pitch Like Binder Phase Material, $\mathrm{S}=$ Anisotropic Mesophase Sphere, $\mathrm{K}=$ Cracks from Drying and E=Epoxy Mount Media. Reflected Light In Oil, X600. 


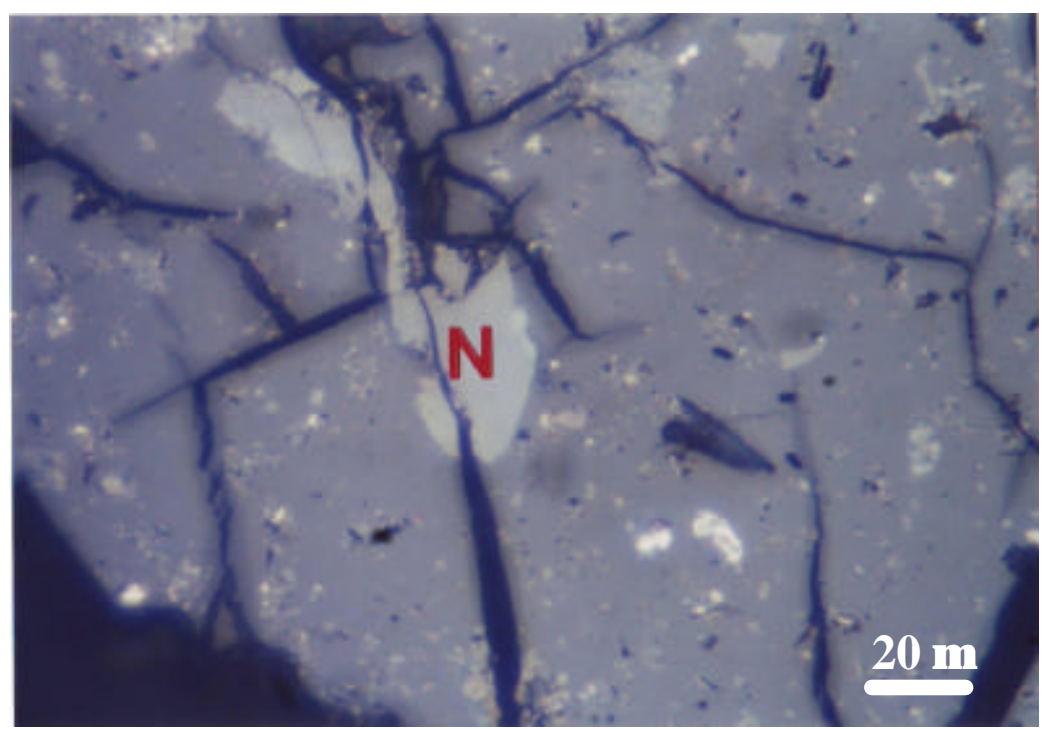

Figure 17. Photomicrographs of Filtered Solid from WVU Extracted Sample RF-51. Notes: N=Coal Inert. Reflected Light In Oil, X1525.

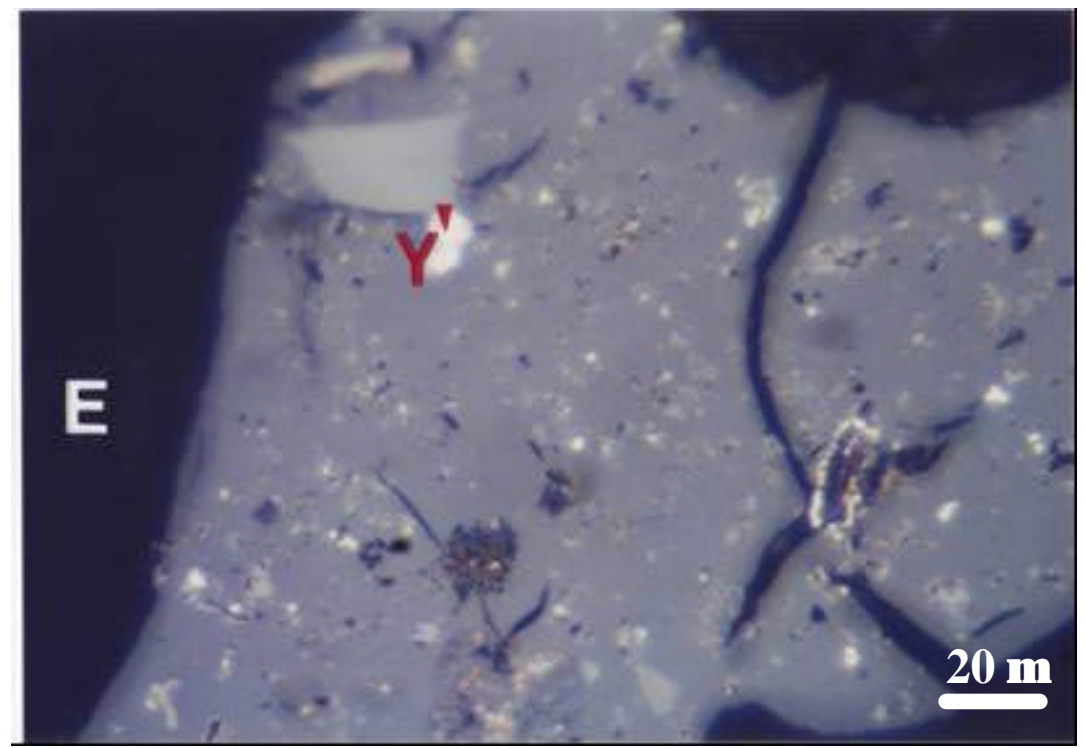

Figure 18. Photomicrographs of Filtered Solid from WVU Extracted Sample RF-51. Notes: $\mathrm{P}=$ Pitch Like Binder Phase Material, $\mathrm{N}=$ Coal Inert, $\mathrm{S}=$ Anisotropic Mesophase Sphere, A=Angular Particle of Anisotropic Mosaic Mesophase or Pitch Coke, $\mathrm{M}=$ Mineral Matter, $\mathrm{Y}=$ Pyrite, $\mathrm{K}=\mathrm{Cracks}$ from Drying and $\mathrm{E}=\mathrm{Epoxy}$ Mount Media. Reflected Light In Oil, X1525. 


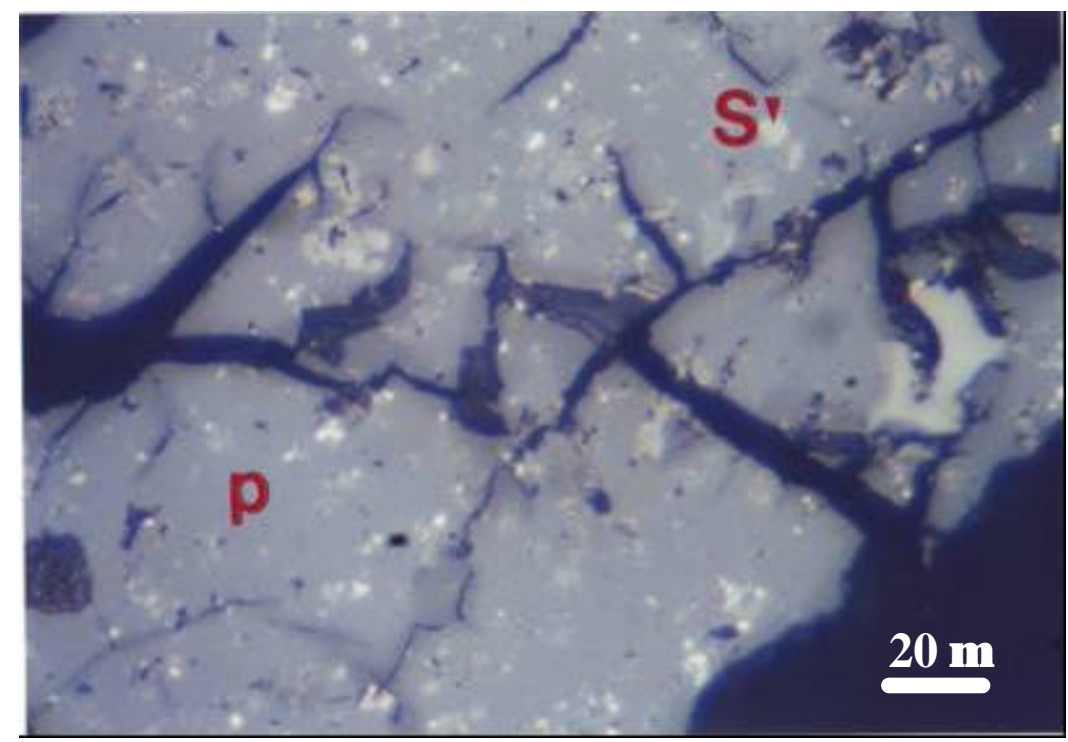

Figure 19. Photomicrographs of Filtered Solid from WVU Extracted Sample RF-51. Notes: P=Pitch Like Binder Phase Material, $S=$ Anisotropic Mesophase Sphere. Reflected Light In Oil, X600.

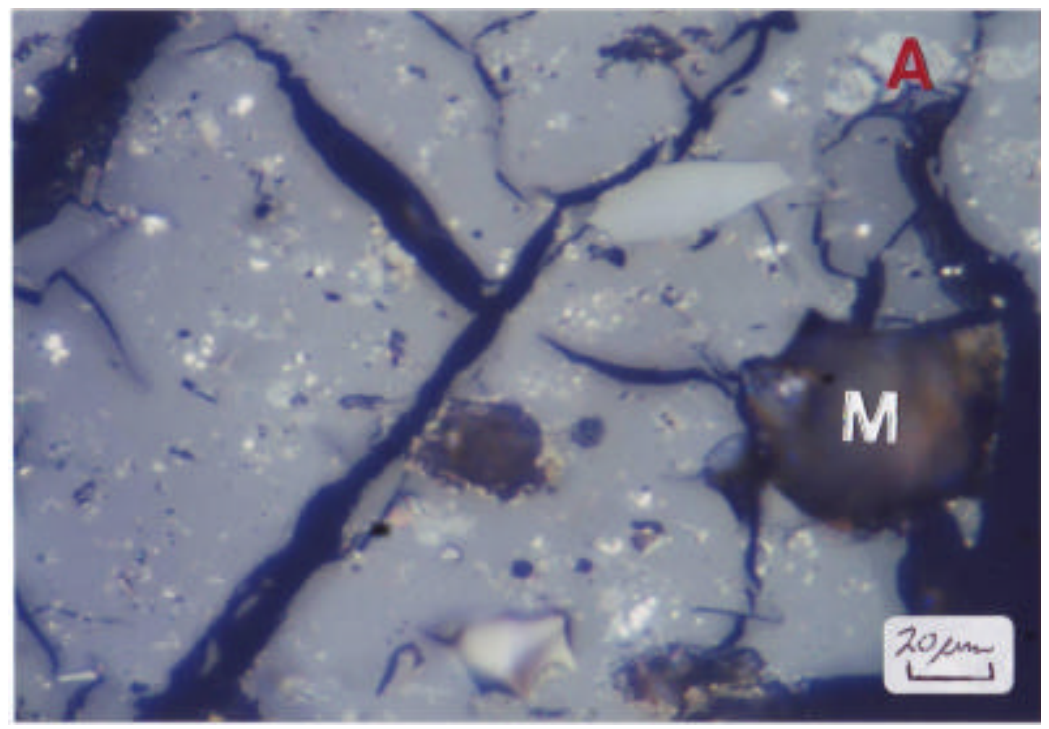

Figure 20. Photomicrographs of Filtered Solid from WVU Extracted Sample RF-51. Notes: $\mathrm{P}=$ Pitch Like Binder Phase Material, N=Coal Inert, $\mathrm{S}=$ Anisotropic Mesophase Sphere, A=Angular Particle of Anisotropic Mosaic Mesophase or Pitch Coke, $\mathrm{M}=$ Mineral Matter, $\mathrm{Y}=$ Pyrite, $\mathrm{K}=$ Cracks from Drying and $\mathrm{E}=$ Epoxy Mount Media. Reflected Light In Oil, X600. 


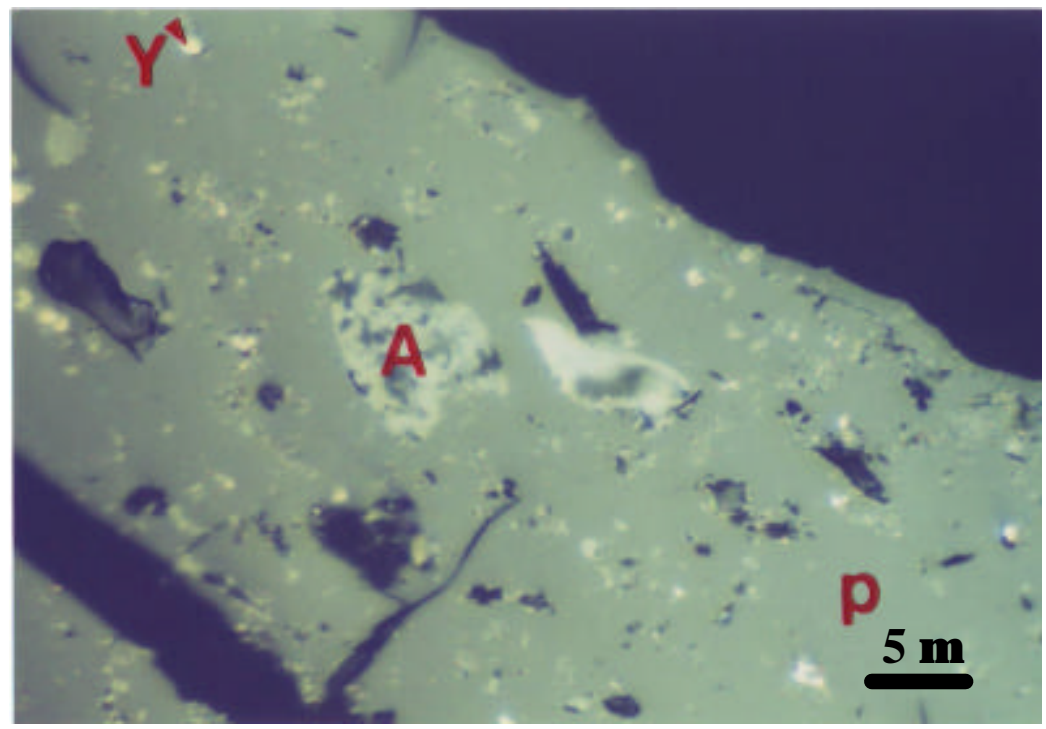

Figure 21. Photomicrographs of Filtered Solid from WVU Extracted Sample RF-51.

Notes: $\mathrm{P}=$ Pitch Like Binder Phase Material, $\mathrm{N}=\mathrm{Coal}$ Inert, $\mathrm{S}=$ Anisotropic Mesophase Sphere, A=Angular Particle of Anisotropic Mosaic Mesophase or Pitch Coke, $\mathrm{M}=$ Mineral Matter, Y=Pyrite, $\mathrm{K}=$ Cracks from Drying and E=Epoxy Mount Media. Reflected Light In Oil, X1525.

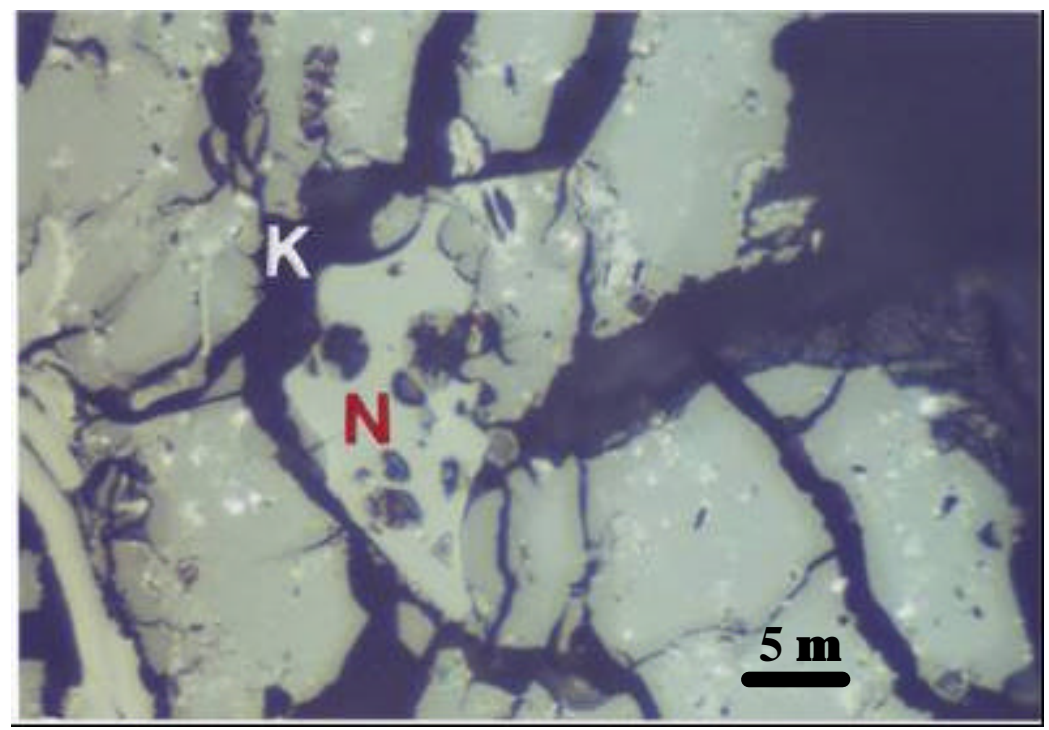

Figure 22. Photomicrographs of Filtered Solid from WVU Extracted Sample RF-51. Notes: P=Pitch Like Binder Phase Material, N=Coal Inert, S=Anisotropic Mesophase Sphere, A=Angular Particle of Anisotropic Mosaic Mesophase or Pitch Coke, $\mathrm{M}=$ Mineral Matter, $\mathrm{Y}=$ Pyrite, $\mathrm{K}=\mathrm{Cracks}$ from Drying and $\mathrm{E}=$ Epoxy Mount Media. Reflected Light In Oil, X1525. 


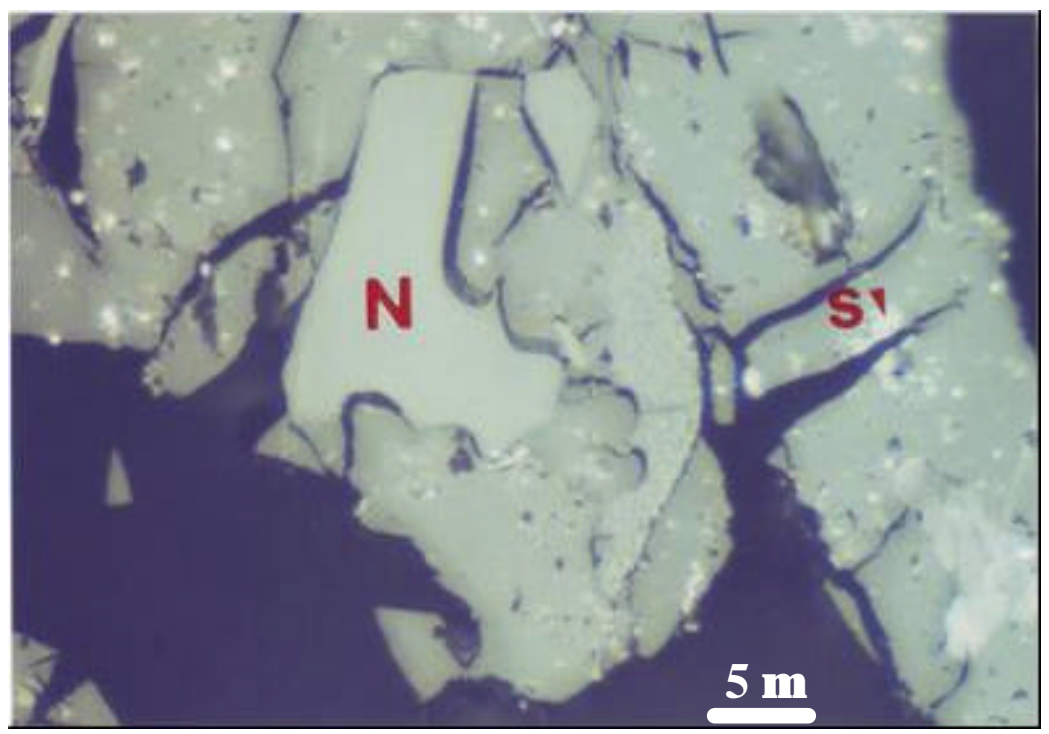

Figure 23. Photomicrographs of Filtered Solid from WVU Extracted Sample RF-51. Notes: $\mathrm{P}=$ Pitch Like Binder Phase Material, $\mathrm{N}=$ Coal Inert, $\mathrm{S}=$ Anisotropic Mesophase Sphere, A=Angular Particle of Anisotropic Mosaic Mesophase or Pitch Coke, $\mathrm{M}=$ Mineral Matter, $\mathrm{Y}=$ Pyrite, $\mathrm{K}=$ Cracks from Drying and $\mathrm{E}=$ Epoxy Mount Media. Reflected Light In Oil, X1525.

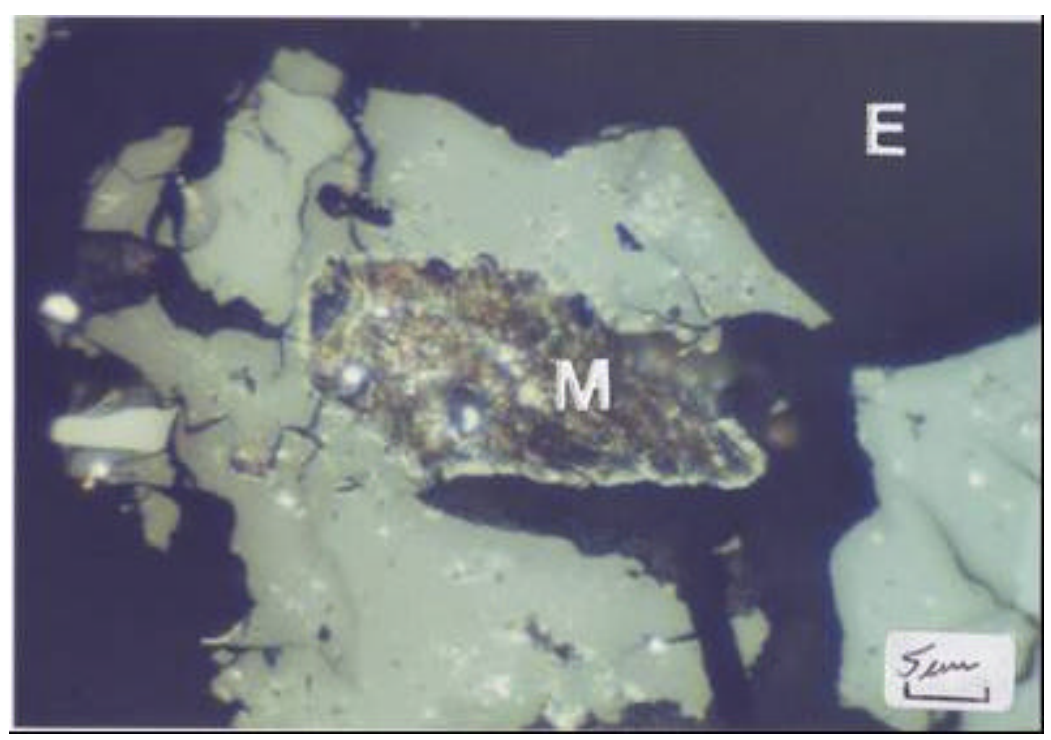

Figure 24. Photomicrographs of Filtered Solid from WVU Extracted Sample RF-51. Notes: $\mathrm{P}=$ Pitch Like Binder Phase Material, $\mathrm{N}=$ Coal Inert, $\mathrm{S}=$ Anisotropic Mesophase Sphere, A=Angular Particle of Anisotropic Mosaic Mesophase or Pitch Coke, $\mathrm{M}=$ Mineral Matter, $\mathrm{Y}=$ Pyrite, $\mathrm{K}=$ Cracks from Drying and $\mathrm{E}=\mathrm{Epoxy}$ Mount Media. Reflected Light In Oil, X1525. 


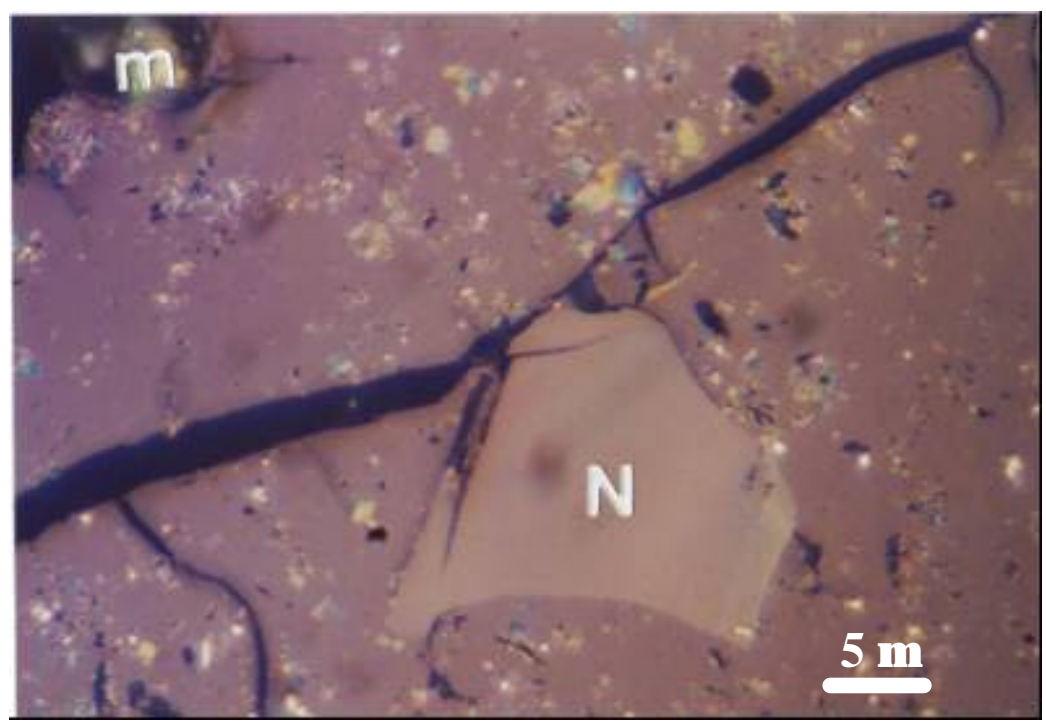

Figure 25. Photomicrographs of Filtered Solid from WVU Extracted Sample RF-51. Notes: N=Coal Inert, M=Mineral Matter. Reflected Light In Oil, X1525.

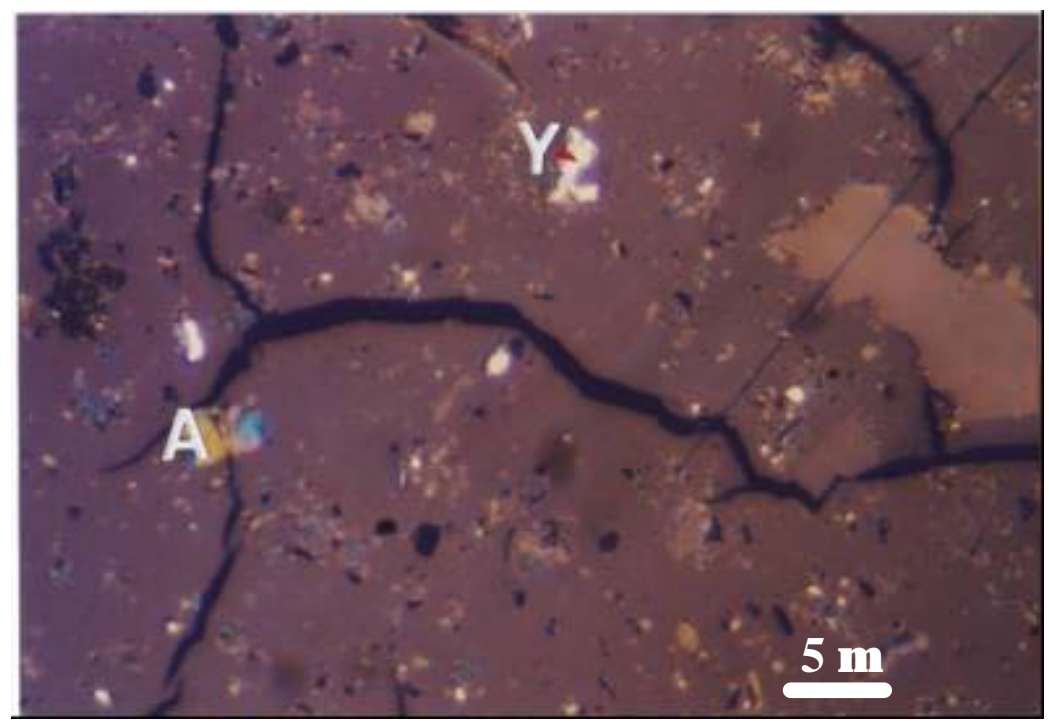

Figure 26. Photomicrographs of Filtered Solid from WVU Extracted Sample RF-51. Notes: A=Angular Particle of Anisotropic Mosaic Mesophase or Pitch Coke, Y=Pyrite. Reflected Light In Oil, X1525. 


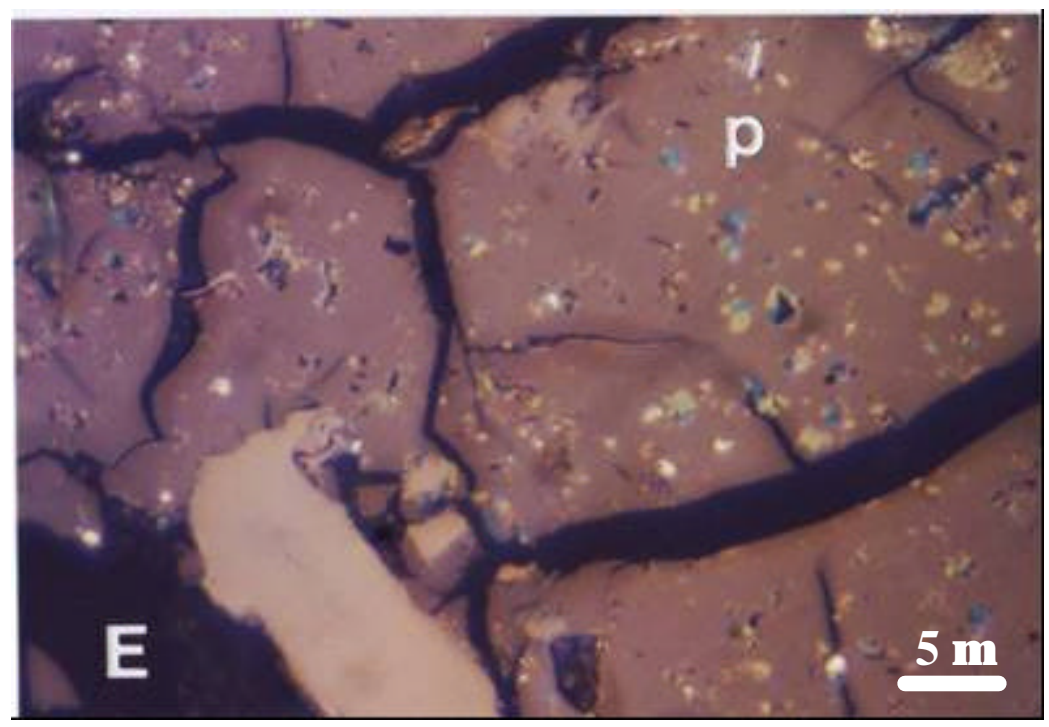

Figure 27. Photomicrographs of Filtered Solid from WVU Extracted Sample RF-51. Notes: P=Pitch Like Binder Phase Material, E=Epoxy Mount Media. Reflected Light In Oil, X1525.

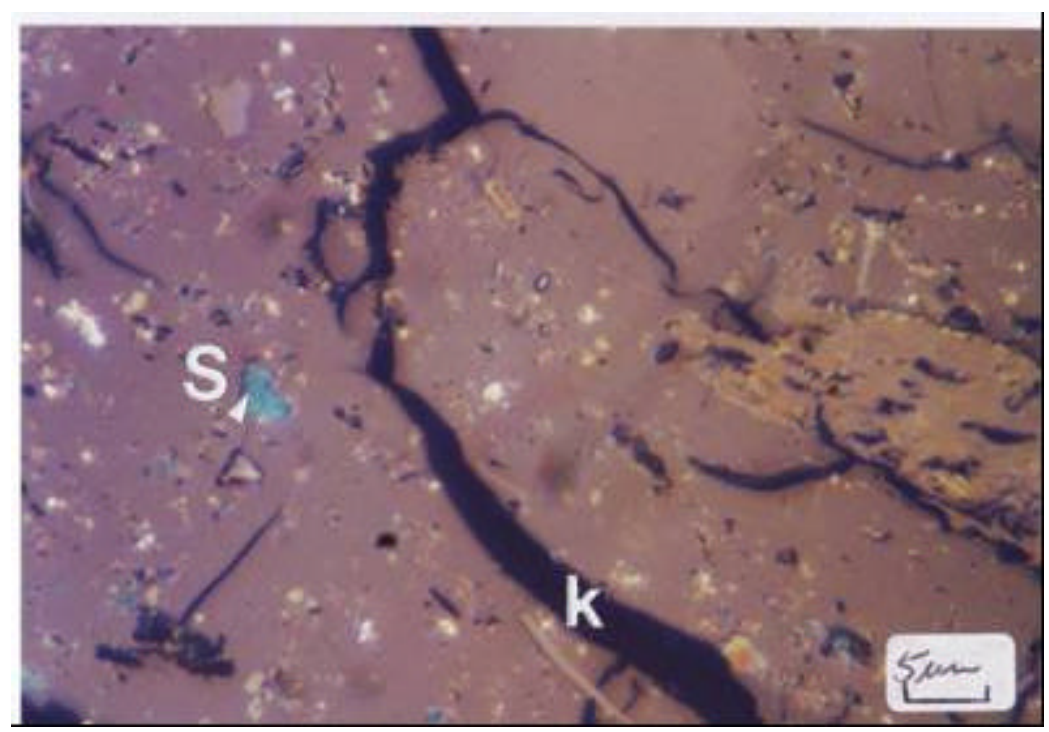

Figure 28. Photomicrographs of Filtered Solid from WVU Extracted Sample RF-51. Notes: $\mathrm{S}=$ Anisotropic Mesophase Sphere, $\mathrm{K}=\mathrm{Cracks}$ from Drying. Reflected Light In Oil, X1525. 


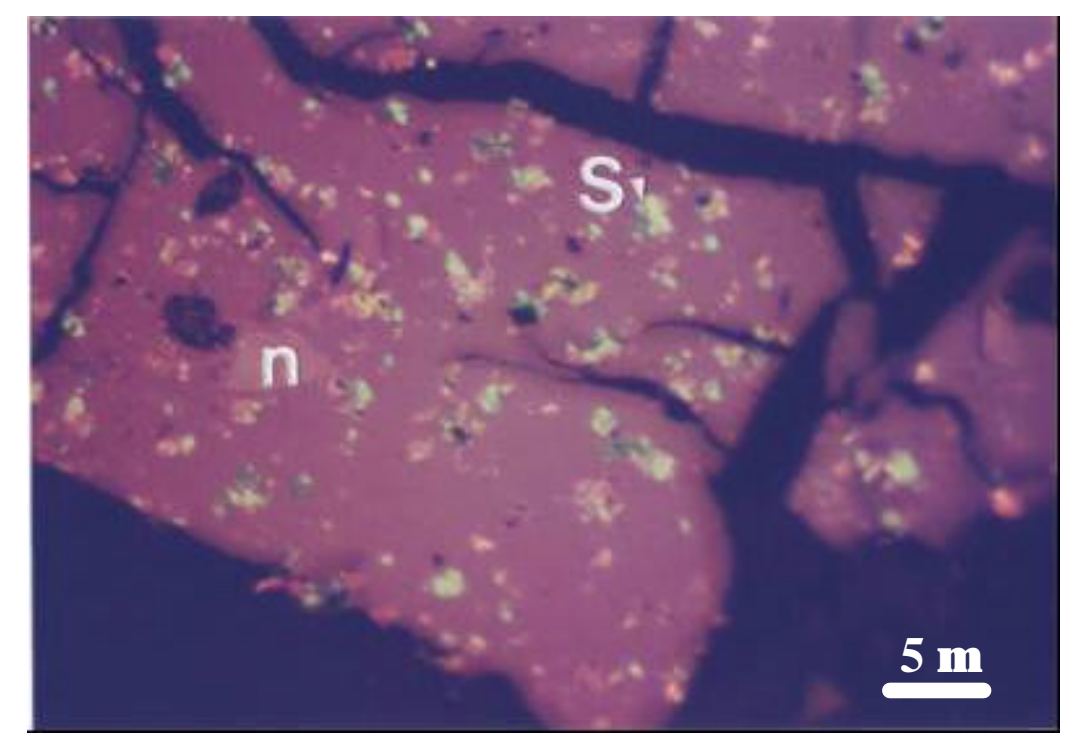

Figure 29. Photomicrographs of Filtered Solid from WVU Extracted Sample RF-51. Notes: N=Coal Inert, S=Anisotropic Mesophase Sphere. Reflected Light In Oil, X1525.

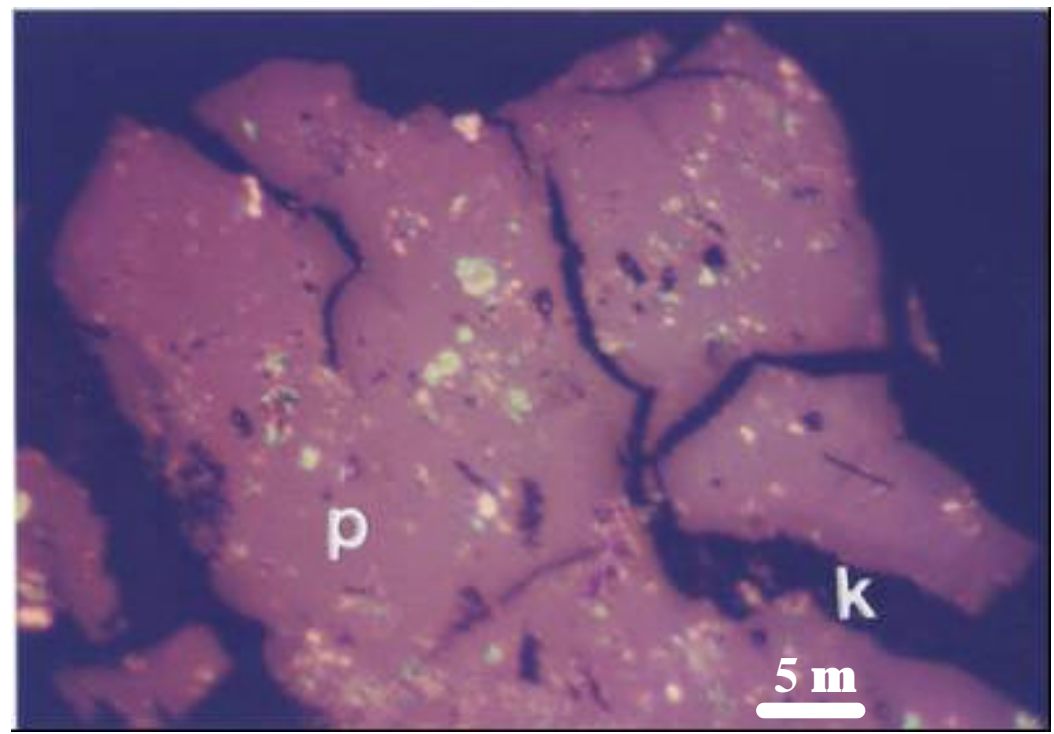

Figure 30. Photomicrographs of Filtered Solid from WVU Extracted Sample RF-51. Notes: $\mathrm{P}=$ Pitch Like Binder Phase Material, $\mathrm{K}=$ Cracks from Drying. Reflected Light In Oil, X1525. 


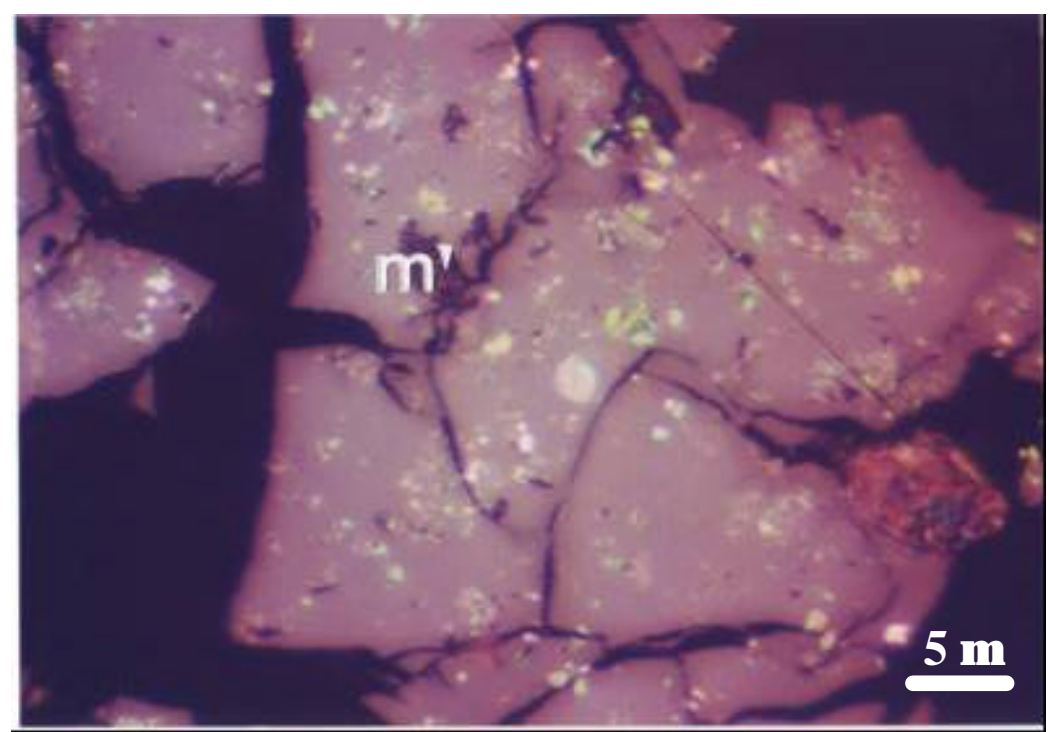

Figure 31. Photomicrographs of Filtered Solid from WVU Extracted Sample RF-51. Notes: M=Mineral Matter.. Reflected Light In Oil, X1525.

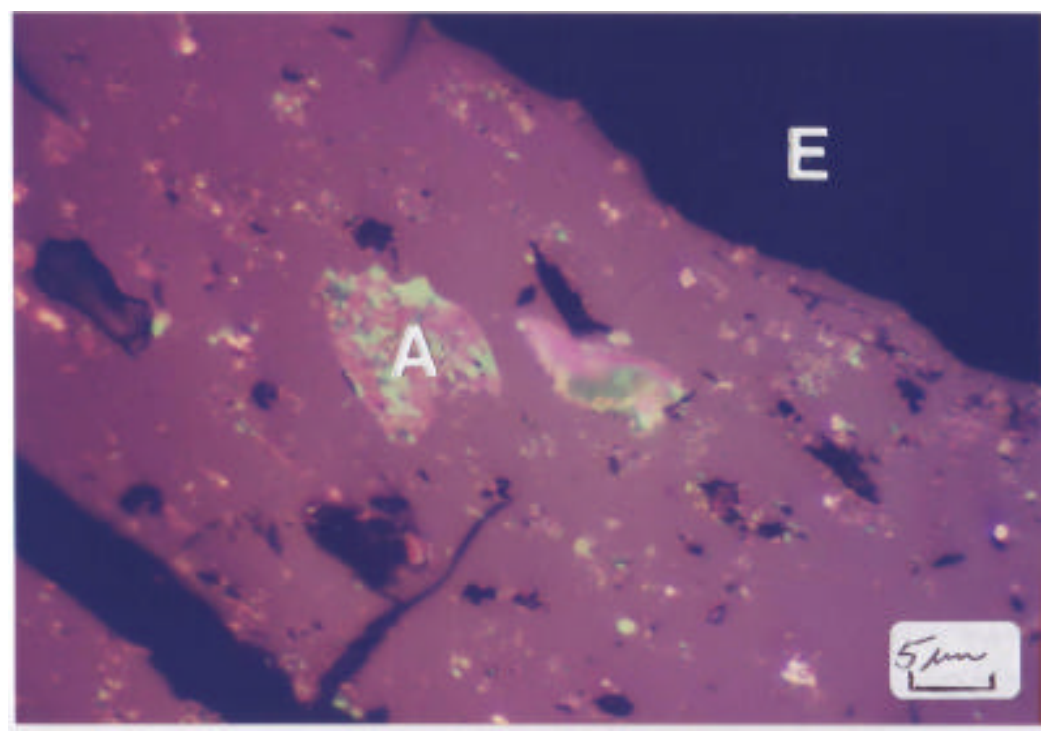

Figure 32. Photomicrographs of Filtered Solid from WVU Extracted Sample RF-51. Notes: A=Angular Particle of Anisotropic Mosaic Mesophase or Pitch Coke, E=Epoxy Mount Media. Reflected Light In Oil, X1525. 


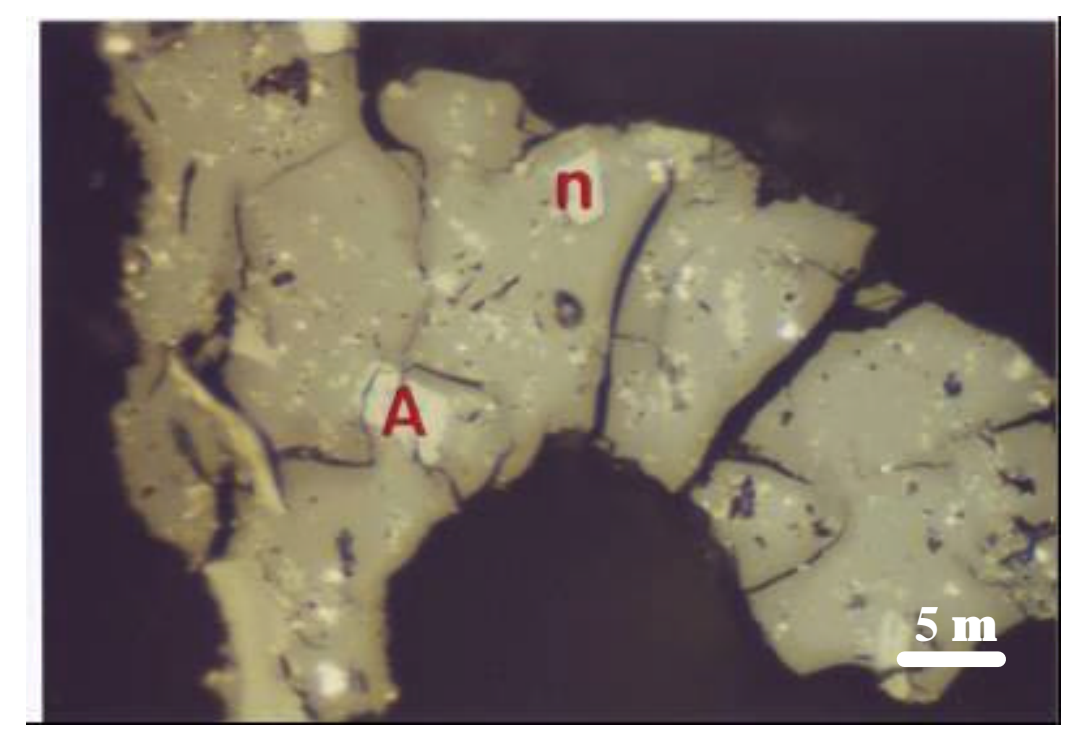

Figure 33. Photomicrographs of Filtered Solid from WVU Extracted Sample RF-51. Notes: N=Coal Inert, A=Angular Particle of Anisotropic Mosaic Mesophase or Pitch Coke. Reflected Light In Oil, X1525.

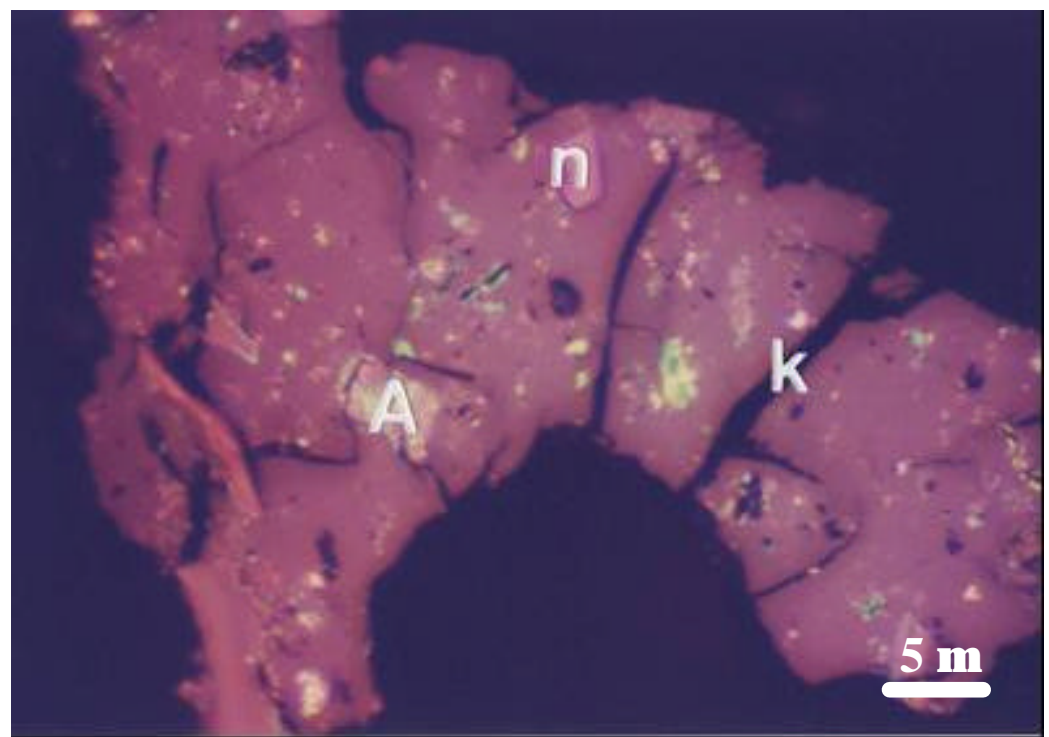

Figure 34. Photomicrographs of Filtered Solid from WVU Extracted Sample RF-51. Notes: $\mathrm{N}=\mathrm{Coa}$ Inert, $\mathrm{A}=$ Angular Particle of Anisotropic Mosaic Mesophase or Pitch Coke, $\mathrm{K}=$ Cracks from Drying. Reflected Light In Oil, X1525. 


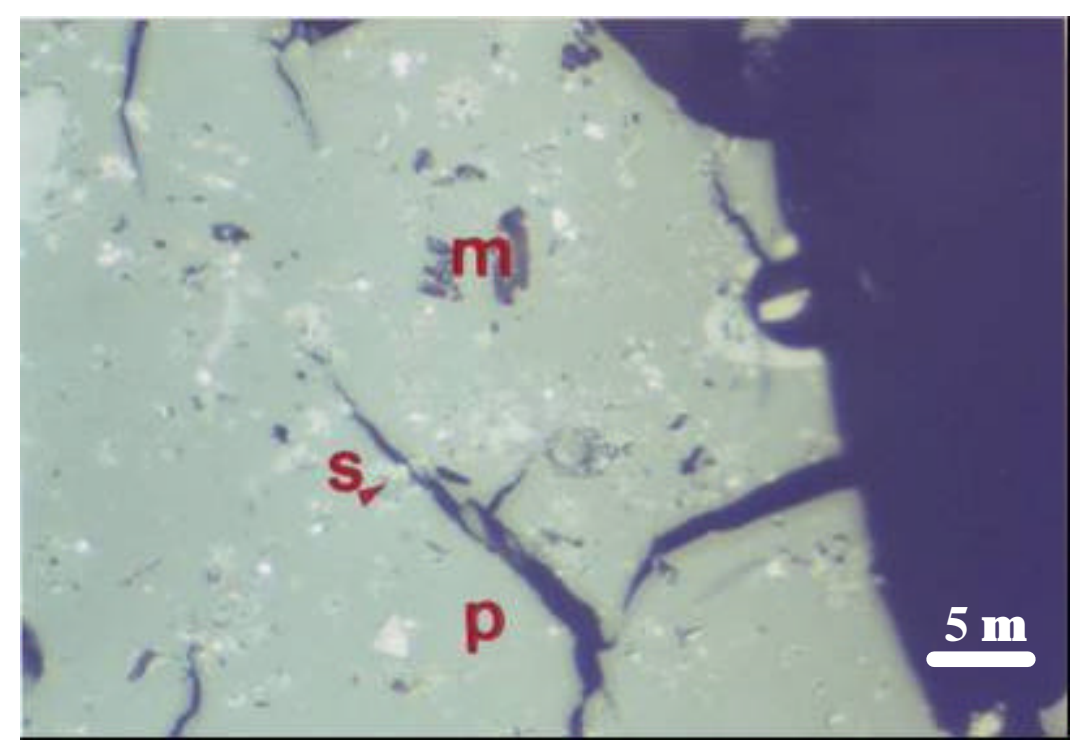

Figure 35. Photomicrographs of Filtered Solid from WVU Extracted Sample RF-51. Notes: P=Pitch Like Binder Phase Material, $\mathrm{S}=$ Anisotropic Mesophase Sphere, M=Mineral Matter. Reflected Light In Oil, X1525.

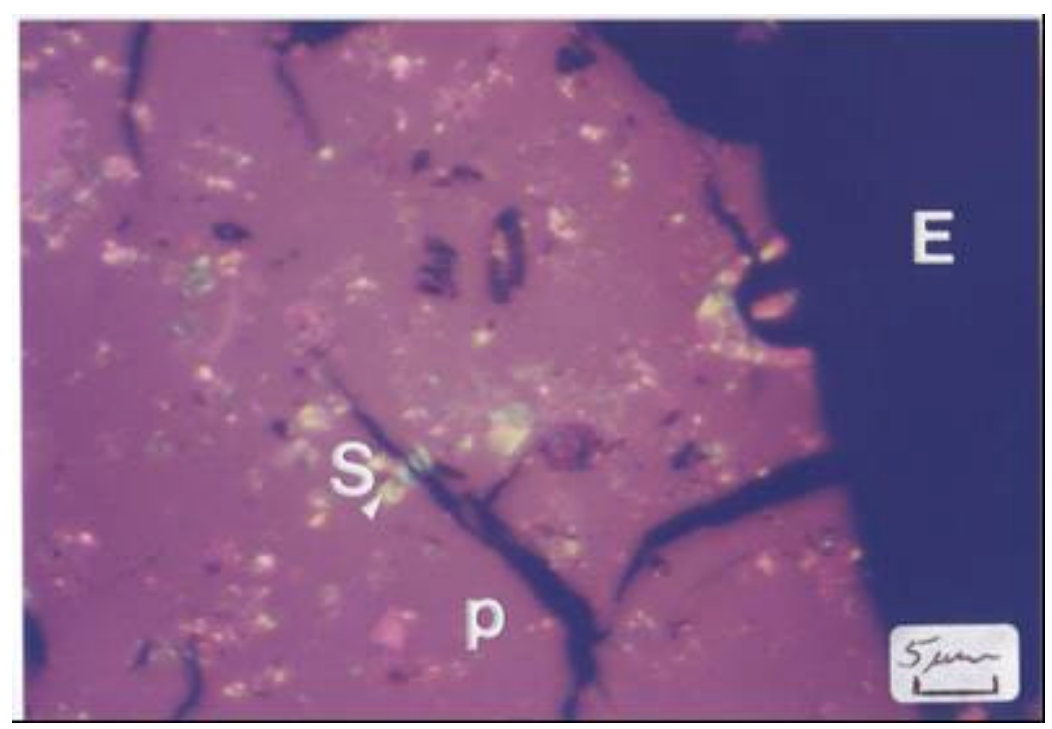

Figure 36. Photomicrographs of Filtered Solid from WVU Extracted Sample RF-51. Notes: $\mathrm{P}=$ =Pitch Like Binder Phase Material, $\mathrm{S}=$ Anisotropic Mesophase Sphere, E=Epoxy Mount Media. Reflected Light In Oil, X1525.

\subsection{Cost Estimates of Reactors}

Concern had been expressed about the financial feasibility of the hydrotreatment and coal digestion reactors for a 20,000 ton per year demonstration plant. Such units are 
not standard, and thus standard data bases are not adequate to estimate cost and delivery schedules. Accordingly, Koppers Inc hired ChemTech Inc (David Catena, PI) to estimate the cost of these units.

The results are approximately in line with previous estimates according to the Capcost ${ }^{\mathrm{TM}}$ model. Based on an operating point of $415{ }^{\circ} \mathrm{C}$ and $1500 \mathrm{psig}$ and one hour residence time, a vessel was designed with SS 321 cladding. Vessel diameter is 5.5' and height is 12 feet.

The quoted cost was $\$ 660,000$ for the 79,000 pound liquefaction reactor and $\$ 525,000$ for the 61,000 pound hydrogenation reactor. Delivery time was estimated at 50 to 58 weeks.

The uncertainty is considered high since this would be a custom unit. In addition, ChemTech was not able to identify more than a single potential supplier. Thus, even though the costs are considered to be quite acceptable for this application, it was strongly recommended that pipe reactors be considered as an alternative at much lower cost and better performance.

In particular, it is hypothesized that the tank-type reactor provides poor contact between the hydrogen, catalyst and fluid, thus resulting in an unnecessarily long residence time.

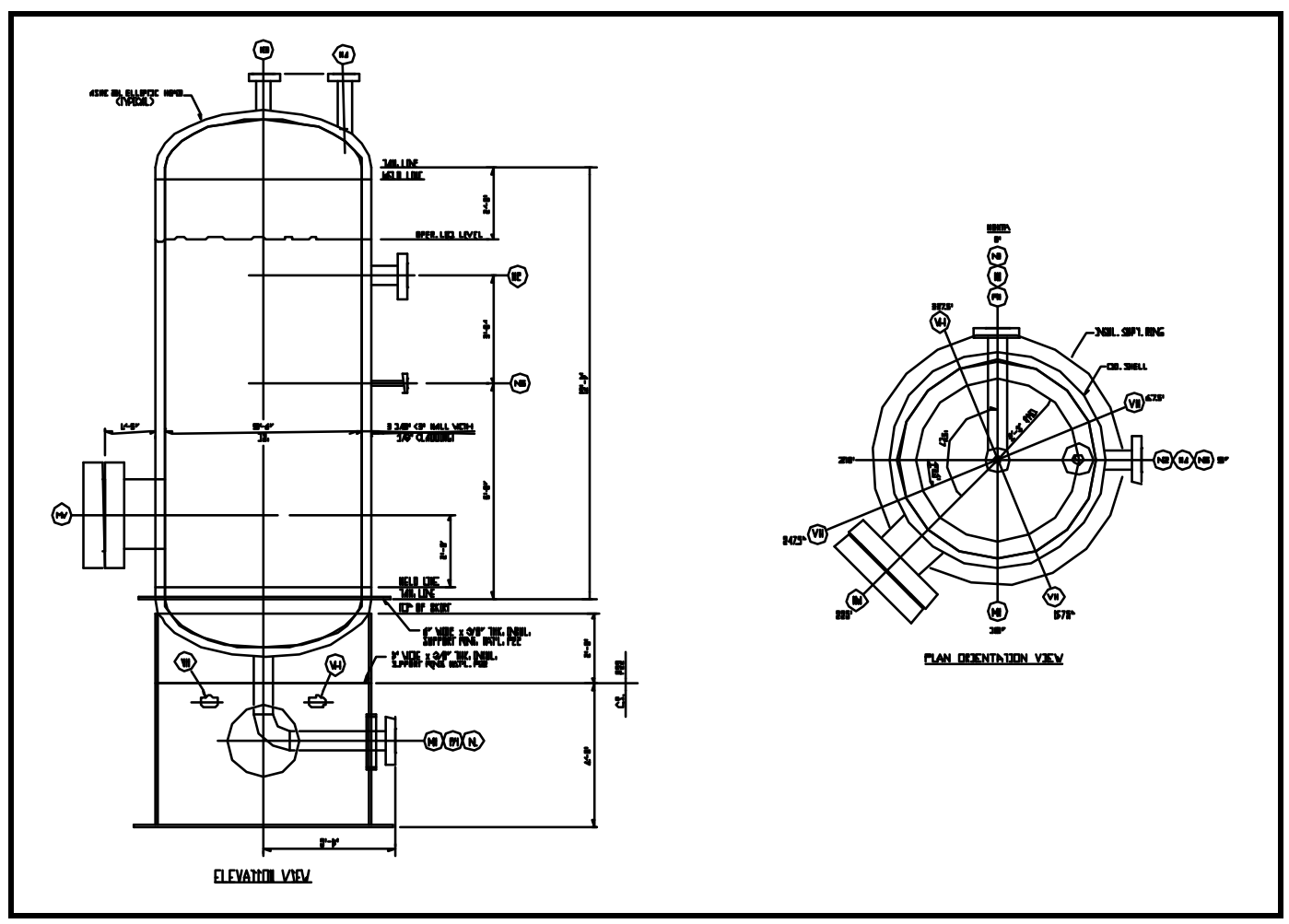

Figure 37. ChemTech Hydrotreatment Pressure Vessel Design. 


\subsection{Carbon Materials for Use in a Direct Carbon Fuel Cell}

\subsubsection{Direct Carbon Fuel Cell (DCFC)}

The Direct Carbon Fuel Cell (DCFC) has the potential to convert the chemical energy of carbon directly into electricity without the need for gasification or moving machinery. Moreover, these fuel cells are twice as fuel-efficient as coal-fired power plants, resulting in reduced carbon dioxide emissions per unit of electricity generated. These advantages, and the favorable thermodynamics of direct oxidation, result in thermodynamic efficiencies between 80 and $90 \%$. The process produces almost pure carbon dioxide, which can be easily collected for downstream disposal using methods such as carbon sequestration. Carbon is not burned in air; therefore, the exhaust is free of nitrogen oxides $\left(\mathrm{NO}_{\mathrm{X}}\right)$, eliminating many pollution issues caused by coal combustion.

The problem of converting chemical energy from solid fuels directly into electrical energy, without passing through the intermediate stages of thermal to mechanical and from mechanical to electrical energy, has been a popular topic for years. Coal-derived cokes are among the resources that can be used to test this direct conversion procedure.

The purpose behind this research is to compare the performance of different types of carbon materials for operation in a direct carbon fuel cell. The National Energy Technology Laboratory (NETL) provided two surplus fuel cell test stands for research purposes, one of which was used for this project. Because the NETL test stands were originally designed for investigation of solid-oxide fuel cells, modifications were needed to adapt them for use with the DCFC. Some of the equipment was replaced and updated. For example, the load cell (discussed later) was replaced and an electronic airflow mass flow controller (MFC) was installed. To make the process more user-friendly, the data acquisition phase of the experimentation was computerized. Using the provided data logger, readings taken from the fuel cell were interfaced to the computer through LabView 6.0 software for realtime data acquisition. The construction material of the fuel cell was based on electrical conductivity, corrosion resistance, and availability. The fuel cell was constructed at WVU with help from Mr. James H. Hall.

Once constructed, it was necessary to test the equipment to make sure that everything is operating as expected. The airflow was measured independently to create a calibration for the airflow rotometer. The system was vigorously tested for leaks. The voltages were carefully measured at different points in the system to assess various voltage drops. The safety features of the design were thoroughly examined.

Finally, graphite and different compositions of coal-derived fuel rods were evaluated and their performance recorded. The performance of these fuel rods was tested under varying conditions such as airflow rate, fuel cell operating temperature, and different types of molten electrolyte.

\subsubsection{Background}

William W. Jacques was the first person known to have obtained a patent for "Method of Converting Potential Energy of Carbon into Electrical Energy" on March 3, 
1896. ${ }^{1}$ Philip V. Pesavento patented a DCFC variant, used in this study, which was assigned to Scientific Application \& Research Associates, Inc. (SARA). ${ }^{2}$ In this design they claim to use an "anode basket" in which to place pulverized coal. They also use several molten electrolytes such as the hydroxides of aluminum, calcium, cesium, lithium, potassium, sodium, rubidium, strontium, and mixtures thereof. Along the same lines as Jacques, a "bubbler" is used to supply the oxygen to the cathode side of the cell. The addition of the anode basket relieves the requirement that the coal be machined into rods, a more efficient method of operation.

Other groups have studied variants of the Jacques cell. One design from SARA separates the electrolyte around the anode from the electrolyte around the cathode. The transport of hydroxide ions is allowed across an electrically insulating but ionically conducting separator. Also, a metallic basket type current collector is used along with particulate carbon fuel. This is accomplished using a porous ceramic or sintered porous metal basket that is isolated from the cathode. The basket also acts as the anode in this case. Thus different reactions can occur at each the anode and cathode without the electrolyte mixing.

Lawrence Livermore National Laboratory (Cooper et al.) developed the direct conversion of carbon fuels in a cell with a molten carbonate electrolyte, the molten carbonate fuel cell, or MCFC. This method may be beneficial because of the ability of the reactions to consume carbonate at the anode and produce it at the cathode in the same mole ratio without any hindering side reactions.

CellTech Power has developed metal electrode cells that can oxidize carbon and other materials. ${ }^{3}$ A test cell is shown below.

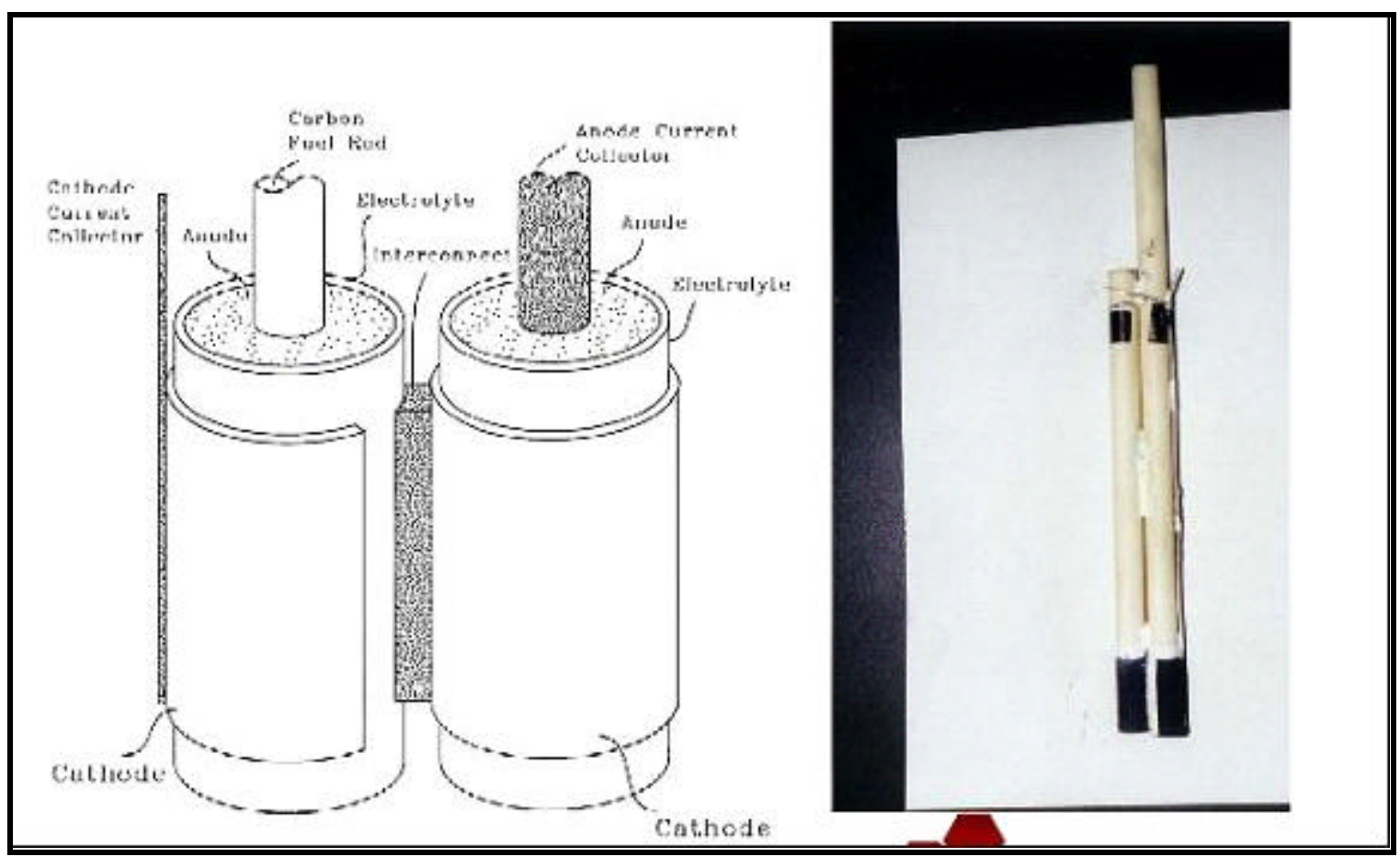

Figure 38. Picture and Schematic Diagram of CellTech Design. Illustration credit: CellTech Inc. 
The element carbon has an affinity for combining electrically with a large number of other chemical elements under a variety of conditions. In the DCFC, the exothermic reaction of carbon and oxygen is used to provide the necessary electrons from the system. Using a hydroxide electrolyte, the recognized chemical reactions that occur with a carbon-based fuel in the DCFC are as follows:

$$
\begin{aligned}
\mathrm{C}+\mathrm{O}_{2} & \rightarrow \mathrm{CO}_{2} \\
\mathrm{C}+4 \mathrm{OH}^{-} & \rightarrow \mathrm{CO}_{2}+2 \mathrm{H}_{2} \mathrm{O}+4 e^{-} \\
4 e^{-}+\mathrm{O}_{2}+2 \mathrm{H}_{2} \mathrm{O} & \rightarrow 4 \mathrm{OH}^{-} \\
\mathrm{CO}_{2}+2 \mathrm{OH}^{-} & \rightarrow \mathrm{CO}_{3}{ }^{2-}+\mathrm{H}_{2} \mathrm{O}
\end{aligned}
$$

Equation 1 is the overall reaction, and is the direct oxidation of carbon. Equation 2 is the reaction between the carbon fuel and the molten hydroxide electrolyte that occurs at the anode, showing that four electrons are produced per mole of carbon. Equation 3 represents the cathode reaction between the oxygen, water, and electrons that replenishes the hydroxide electrolyte. Moreover, the addition of water vapor increases the ionic conductivity in the electrolyte by adding polar molecules. Equation 4 is an undesired side reaction that consumes the electrolyte producing the carbonate ion. The carbonate ion will eventually poison the electrolyte as it increases in concentration relative to the hydroxide, causing the cell to fail. The occurrence of this reaction is minimized by the addition of excess water vapor, which will hydrolyze the carbonate atom, reforming the previously consumed hydroxide.

The maximum electrical energy that can be obtained from Equation 1 can be calculated from the free energy change involved in the reaction. For example, graphitic carbon reacts with gaseous oxygen at standard temperature and pressure (1atm, $25{ }^{\circ} \mathrm{C}$ ) resulting in the voltage given by the following relation:

$$
\begin{gathered}
\frac{\Delta G^{\circ} \times 4.18}{N F}=E^{\circ} \\
E_{\text {cell }}=E^{\circ}-\frac{R T}{N F} \cdot \ln \frac{\left[\mathrm{CO}_{2}\right]}{\left[\mathrm{O}_{2}\right]}
\end{gathered}
$$

where $\Delta G^{\circ}$ is the standard free energy change of Reaction $2.1,-94,260 \mathrm{cal} / \mathrm{mol} ;{ }^{4} 4.18$ is the constant relating calories and watt-seconds; $N$ is the number of unit charges (moles of electrons) involved, four in this case; $F$ is the Faraday constant, 96,494 coulombs per unit charge (moles of electrons), and $E^{\circ}$ is the standard voltage of a carbon cell, $1.01 \mathrm{~V}$. However, a more practical available voltage, $\mathrm{E}_{\text {cell, }}$, as calculated by J.F. Cooper, is about $0.8 \mathrm{~V}$, yield ing a total efficiency of $0.80 .^{5}$ Table 3 is a comparison of carbon, hydrogen, and methane, which are fuels used in various types of fuel cells. $E^{\circ}$ is the theoretical limit for oxidizing each of the listed reactants. The utilization energy is defined as the fraction of fuel consumed in practical operation. $e_{v}$ is the fraction of the voltage available 
at the practical rate. When these values are multiplied, an actual efficiency results, showing carbon to be the most efficient of the three.

Changing the temperature of the cell will not affect the voltage much because the value of $\Delta G$ (replaces $\Delta G^{\circ}$ in Equation 5 for non-standard conditions) is only different from $\Delta G^{\circ}$ by 16 calories at $1000{ }^{\circ} \mathrm{C}$ and only about 10 calories at $600{ }^{\circ} \mathrm{C},{ }^{6,7}$ which is the standard operating temperature for the cell in this project.

\section{Table 3. Comparison of Efficiencies of Different Fuels}

\begin{tabular}{|c|c|c|c|c|}
\hline Fuel & $\begin{array}{c}\text { Theoretical Limit } \\
\Delta \mathbf{G}^{\circ}(\mathbf{T}) / \Delta \mathbf{H}^{\circ}{ }_{\text {std }}\end{array}$ & $\begin{array}{c}\text { Utilization } \\
\text { Energy, } \mu\end{array}$ & $\begin{array}{c}\mathbf{V}(\mathbf{i}), \mathbf{V}(\mathbf{i}=\mathbf{0})= \\
\varepsilon_{\mathbf{v}}\end{array}$ & $\begin{array}{c}\text { Actual Efficiency }= \\
{\left[\Delta \mathbf{G}^{\circ}(\mathbf{T}) / \Delta \mathbf{H}^{\circ}{ }_{\text {std }}\right](\mu)\left(\varepsilon_{\mathbf{v}}\right)}\end{array}$ \\
\hline $\mathrm{C}$ & 1.003 & 1.00 & 0.80 & 0.80 \\
\hline $\mathrm{CH}_{4}$ & 0.895 & 0.80 & 0.80 & 0.57 \\
\hline $\mathrm{H}_{2}$ & 0.700 & 0.80 & 0.80 & 0.45 \\
\hline
\end{tabular}

Usually, the reactants are oxidized at the anode and reduced at the cathode, with platinum wire being used as an electrode. However, carbon does not ionize, and oxygen ionizes extremely slowly. These reactants can, however, react with ions in a molten electrolyte, in this case hydroxide (ionized) as shown in Equations 2 and 3. Often, platinum, iron, nickel, silver, copper, or some oxide is used as the cathode with the carbon used as the anode. In this research an iron-titanium alloy (98\%-2\%) was selected as the cathode material. This metal is ideal because of the small content of titanium that forms a complex with the ferrous oxides, preventing corrosion.

\subsubsection{Experimental}

A detailed schematic diagram of the designed fuel cell is shown in Figure 38. An actual photograph of the constructed cell is shown below in Figure 40. A schematic diagram of the fuel cell test stand is shown in Figure 40 along with a photograph of the test stand in Figure 41. 


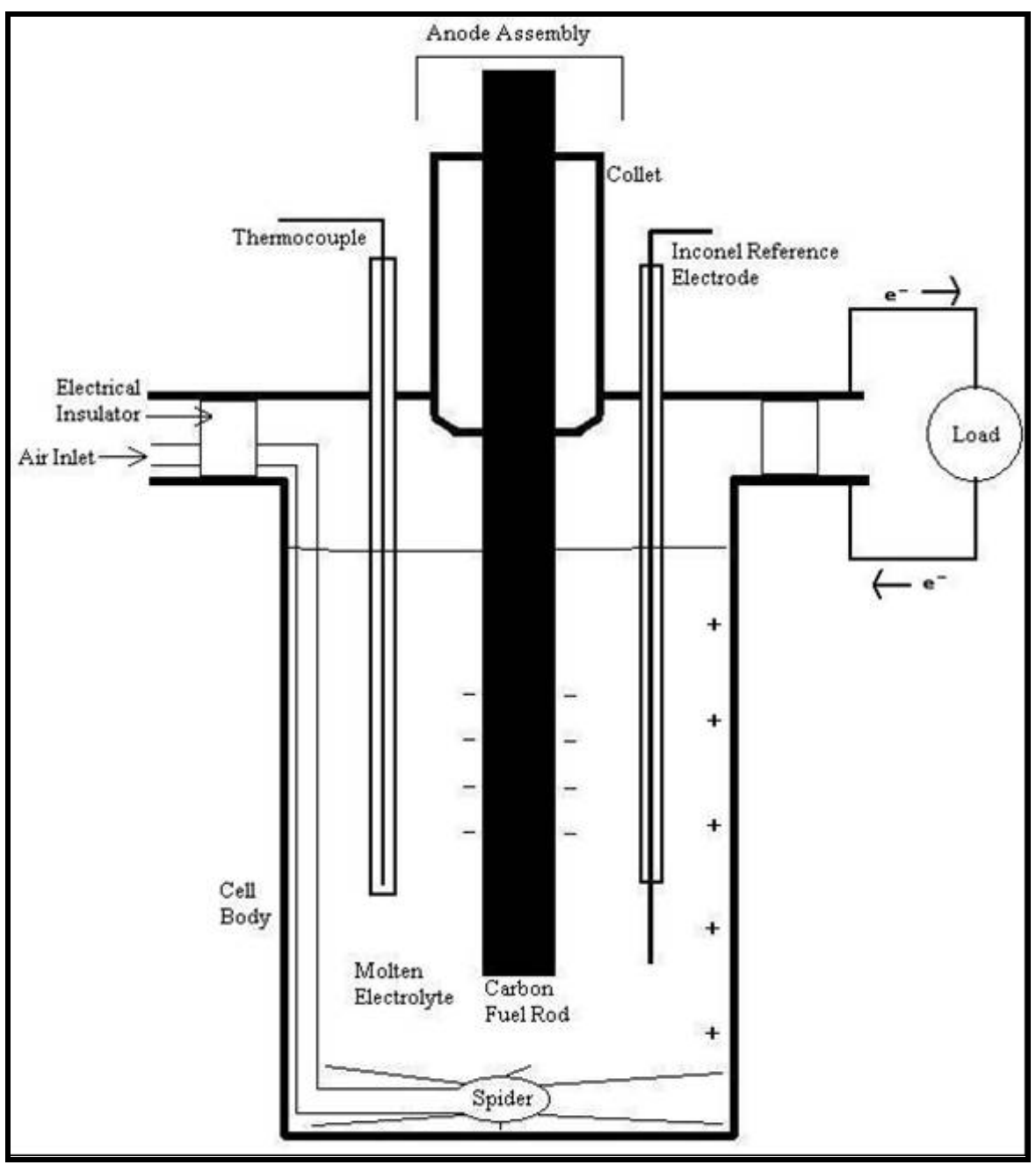

Figure 39. Schematic Diagram of Direct Carbon Fuel Cell 


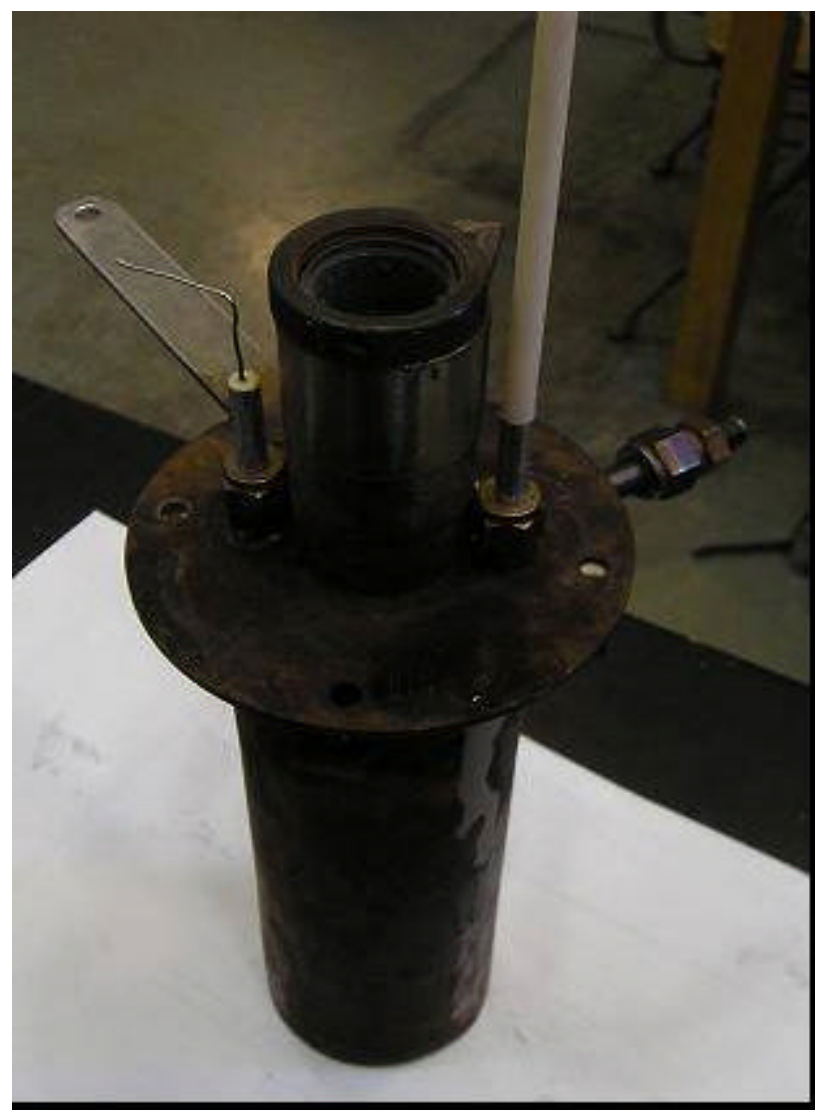

Figure 40. Photograph of Constructed Direct Carbon Fuel Cell

As previously mentioned, the DCFC design, in the most basic sense, consists of a cathode and an anode. More specifically, carbon rods are used as the anode while an irontitanium alloy (98\%-2\%) is used as the cathode. In this case, a molten electrolyte of sodium hydroxide $(\mathrm{NaOH})$ supplies the hydroxide ions necessary for the anode halfreaction(Equation 2). The electrolyte is surrounded by the cathode, which is shaped into a can. 


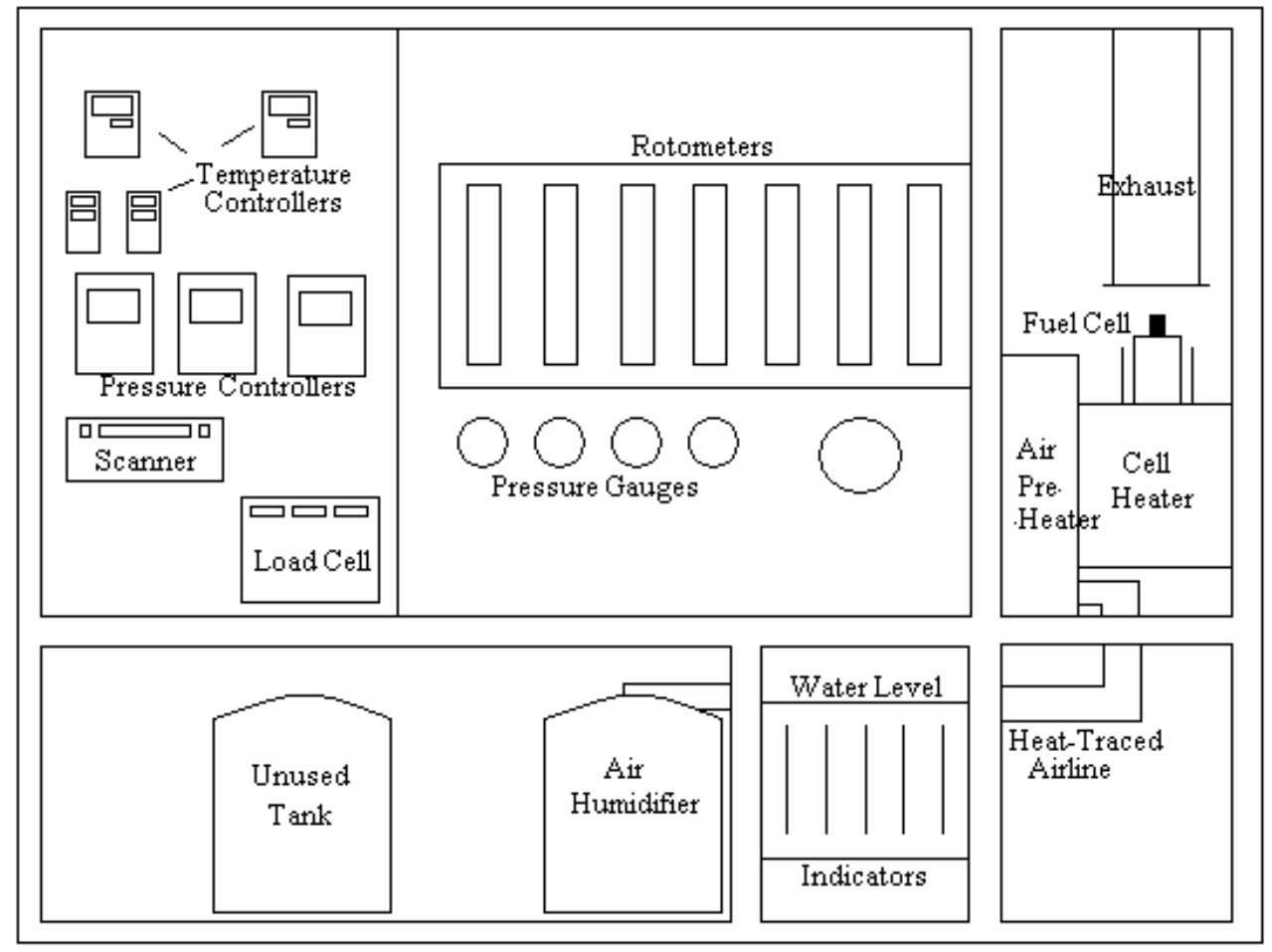

Figure 41. Schematic Diagram of DCFC Test Stand.

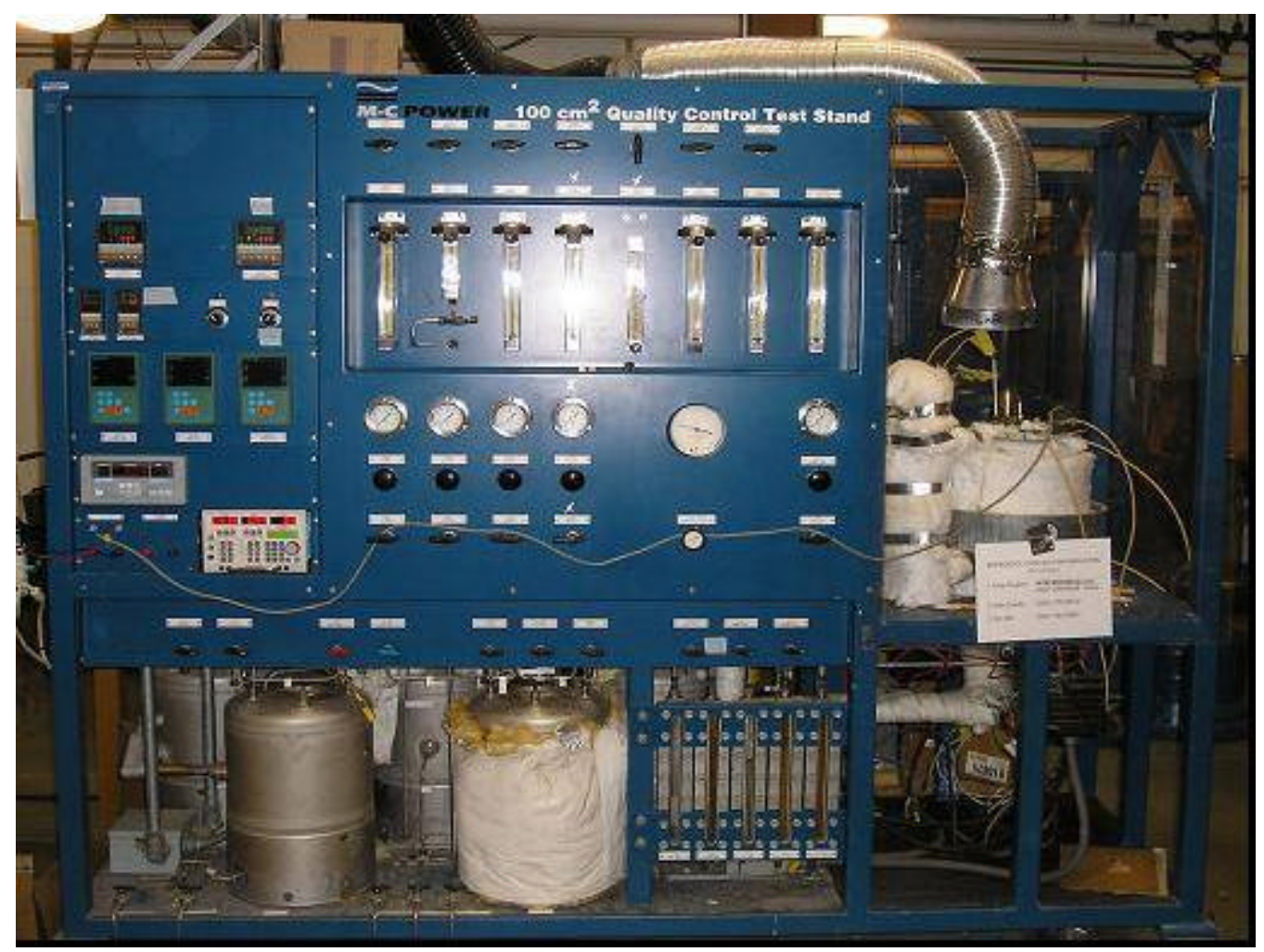

Figure 42. Photograph of Fuel Cell Test Stand Donated by the U.S. DOE. 
The oxygen supply, humidified air at $70{ }^{\circ} \mathrm{C}$, is pre-heated to the fuel cell operating temperature, and then is distributed to the cathode by means of a "spider-type" sparger. The spider (Figure 43) takes the air inlet and directs it toward the inner surface area of the can, supplying small bubbles of needed oxygen and water to the cathode halfreaction (Equation 3). An inconel wire (.041-inch OD) is used as a reference electrode for separate anode and cathode voltage measurements. A type- $\mathrm{K}$ thermocouple is placed in a ceramic thermal well (Omega Engineering, Inc. models KQIN-11611-12 and ORX11614-6, respectively) to measure the electrolyte temperature for control purposes.

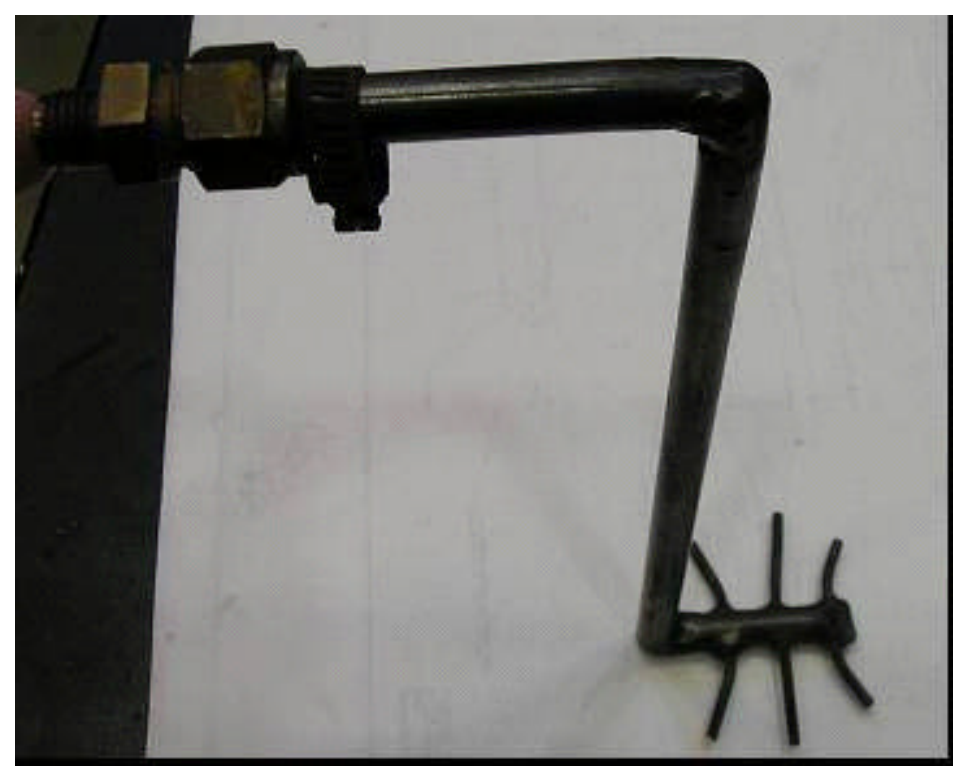

Figure 43. Photograph of Sparger Used for Bubbling Air Along the Cathode.

The fuel cell is heated to the desired operating temperature by means of two $1.25 \mathrm{~kW}$ ceramic fiber heaters, supplied by Watlow, Inc. These are labeled "Cell Heaters" in Figure 41. The fuel cell and the preheated air tubing, "Air Pre-Heater" are well insulated to help prevent thermal losses.

The main objective of this research is to investigate the effects of different types of carbon-based fuel rods on fuel cell performance. In addition, the operating conditions were changed while using the same type of carbon rod. This allowed an assessment of both the effect of the rod type as well as the operating conditions. Most of the experiments were conducted with graphite rods. These rods were tested multiple times to investigate process variables such as air flow rate, fuel cell temperature, electrolyte changes and additives, and fuel cell modifications. The graphite rods were used more extensively than the others because more were available for use and were manufactured previously.

The experimental design is summarized below:

1. Graphite rod, $\mathrm{T}=600^{\circ} \mathrm{C}$, Air Flow $=0.25 \mathrm{SLPM}, \mathrm{NaOH}$ electrolyte

2. Graphite rod, $\mathrm{T}=600^{\circ} \mathrm{C}$, Air Flow $=0.50$ SLPM, NaOH electrolyte

3. Graphite rod, $\mathrm{T}=600^{\circ} \mathrm{C}$, Air Flow $=0.75 \mathrm{SLPM}, \mathrm{NaOH}$ electrolyte 
4. Graphite rod, $\mathrm{T}=600^{\circ} \mathrm{C}$, Air Flow $=0.90 \mathrm{SLPM}, \mathrm{NaOH}$ electrolyte

5. Graphite rod, $\mathrm{T}=625^{\circ} \mathrm{C}$, Air Flow $=0.50 \mathrm{SLPM}, \mathrm{NaOH}$ electrolyte

6. Graphite rod, $\mathrm{T}=650^{\circ} \mathrm{C}$, Air Flow $=0.50$ SLPM, NaOH electrolyte

7. Graphite rod, $\mathrm{T}=675^{\circ} \mathrm{C}$, Air Flow $=0.25$ SLPM, NaOH electrolyte

8. Graphite rod, $\mathrm{T}=675^{\circ} \mathrm{C}$, Air Flow $=0.50 \mathrm{SLPM}, \mathrm{NaOH}$ electrolyte

9. Graphite rod, $\mathrm{T}=675^{\circ} \mathrm{C}$, Air Flow $=0.75 \mathrm{SLPM}, \mathrm{NaOH}$ electrolyte

10. Graphite rod, $\mathrm{T}=700^{\circ} \mathrm{C}$, Air Flow $=0.50 \mathrm{SLPM}, \mathrm{NaOH}$ electrolyte

11. Graphite rod, $\mathrm{T}=600^{\circ} \mathrm{C}$, Air Flow $=0.50 \mathrm{SLPM}, \mathrm{Li}_{2} \mathrm{CO}_{3}+\mathrm{Na}_{2} \mathrm{CO}_{3}$ electrolyte

12. Graphite rod, $\mathrm{T}=600^{\circ} \mathrm{C}$, Air Flow $=0.50 \mathrm{SLPM}, \mathrm{NaOH}+\mathrm{LiOH}$ electrolyte

13. Petcoke Rod \#11, $\mathrm{T}=600^{\circ} \mathrm{C}$, Air Flow $=0.50$ SLPM, NaOH electrolyte

14. Petcoke Rod $\# 10, \mathrm{~T}=600^{\circ} \mathrm{C}$, Air Flow $=0.50 \mathrm{SLPM}, \mathrm{NaOH}$ electrolyte

15. $25 \%$ SECO, $75 \%$ PetCoke Rod, $\mathrm{T}=600^{\circ} \mathrm{C}$, Air Flow $=0.50$ SLPM, NaOH el.

16. $50 \%$ SECO, $50 \%$ PetCoke Rod, $\mathrm{T}=600^{\circ} \mathrm{C}$, Air Flow $=0.50$ SLPM, $\mathrm{NaOH}$ el.

17. $75 \%$ SECO, $25 \%$ PetCoke Rod, $\mathrm{T}=600^{\circ} \mathrm{C}$, Air Flow $=0.50$ SLPM, NaOH el.

18. $100 \%$ SECO, $\mathrm{T}=600^{\circ} \mathrm{C}$, Air Flow $=0.50 \mathrm{SLPM}, \mathrm{NaOH}$ electrolyte

19. GrafTech graphite rod, $\mathrm{T}=600^{\circ} \mathrm{C}$, Air Flow $=0.50 \mathrm{SLPM}, \mathrm{NaOH}$ electrolyte

20. GrafTech baked rod, $\mathrm{T}=600^{\circ} \mathrm{C}$, Air Flow $=0.50 \mathrm{SLPM}, \mathrm{NaOH}$ electrolyte

The carbon rods are different both in their composition and in the way that they were manufactured. The investigation will include a good sampling of rods that vary in one or both of these characteristics.

Some of the experiments were completed during the same experimental run. As long as the carbon rod and the electrolyte remain the same, the airflow rate and fuel cell temperature are variable during the experiment. This helps in keeping the supply cost down as well as the time necessary to complete the experimental phase of the research. Most tests were done with the sodium hydroxide electrolyte, but Runs \#11 and \#12 were made with mixed carbonate and hydroxide electrolytes.

The generated cell voltage $(\mathrm{V})$ is plotted versus the current density $\left(\mathrm{mA} / \mathrm{cm}^{2}\right)$ drawn from the cell. Current density is the current drawn over the surface area of the rod exposed to the electrolyte, divided by the surface area. This is used to normalize the data for rods of different diameter and surface area. Similarly, the power density is plotted versus the current density to assess the maximum power generated. Fuel cells are designed to operate at or below the power density maximum. At current densities below the power density maximum, voltage efficiency improves but power density falls. At current densities above the maximum, both voltage efficiency and power density fall. The slope of the cell voltage versus the current density curve in the central region of the data supplies a value for the ohmic resistance of the fuel cell, the so-called Area Specific Resistance (ASR). The ASR is an area-normalized resistance. It accounts for the fact that fuel cell resistance scales with area, thus allowing different size fuel cells to be compared. 
A typical $i$-V curve is shown in Figure 44. A few points to notice about the curve are as follows: ${ }^{8}$

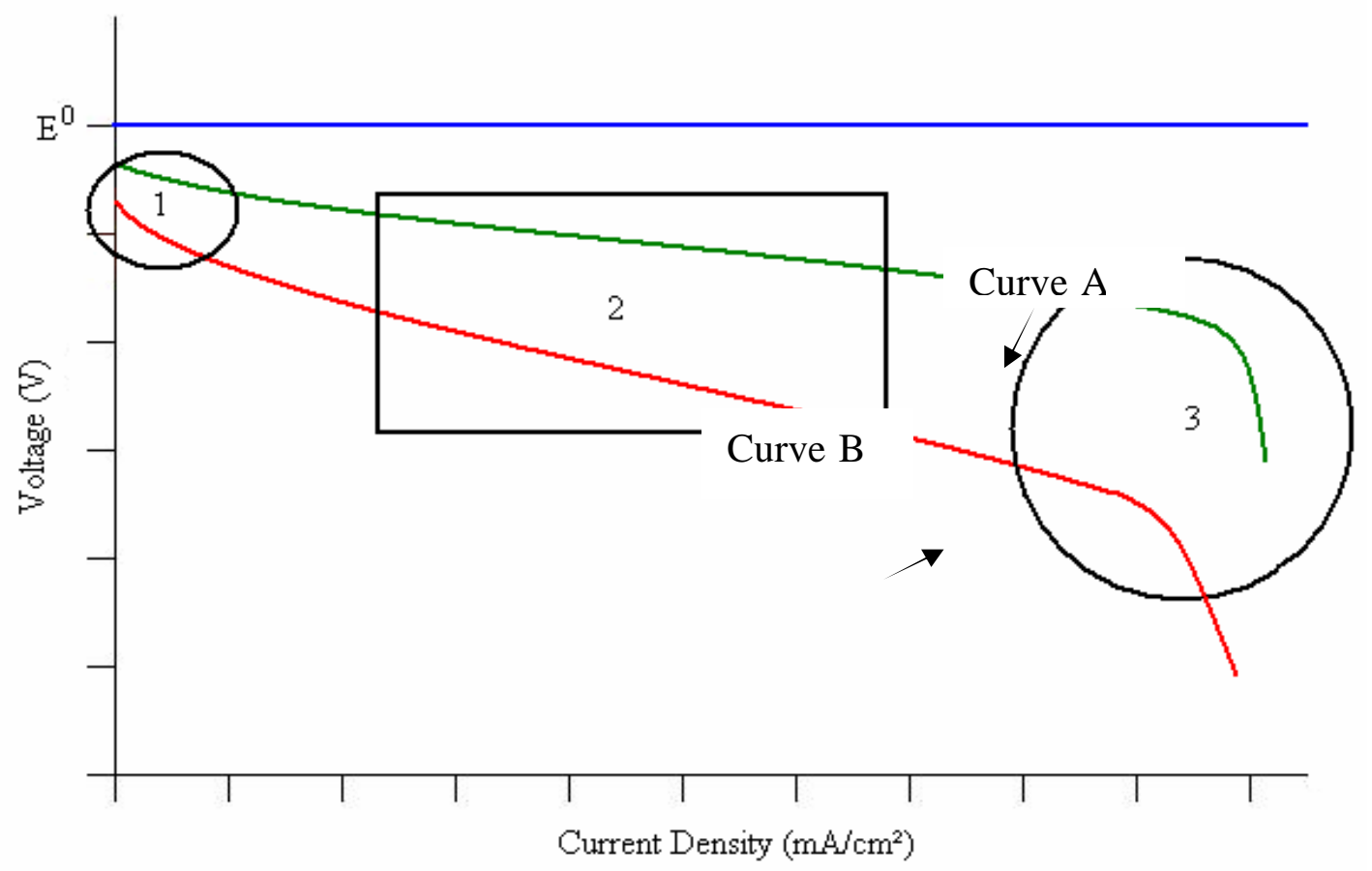

Figure 44. Generic Fuel Cell $i$-V Curves with Specific Regions Highlighted.

- The open circuit voltage (OCV) is the cell voltage at zero current.

- The initial decrease is due to the activation resistance.

- The voltage then falls less rapidly, and more linearly, and is due to ohmic resistance.

- There is usually a higher current density at which the voltage falls more rapidly, and is due to mass transport resistance.

In the first region, where the initial decrease is slightly steeper, the electrochemical reactions are slow at the electrode surface. When current densities are small, then the voltage losses are dominated by the slowness of the electrochemical reactions. This is called activation resistance. This is voltage lost in driving the chemical reaction that transfers the electrons to or from the electrode. In Figure 44, Curve A has faster electrochemical reactions than Curve B.

In the second, more linear region, the ohmic resistance of the fuel cell is controlling. This region also has activation losses but it is dominated by the fact that the fuel cell has some resistance. This resistance is mostly found in the electrolyte and electrodes of the fuel cell. When the ohmic resistance is high, ionic and electronic conduction is hindered, which lowers the cell voltage. Electrons will travel more slowly through the fuel cell and more heat will be generated. The rest of these losses can be found in the electrode material and the interconnections of the cell. Curve A has a lower ohmic resistance than Curve B. 
In the third, much steeper region, the reactants cannot get to the reaction site quickly enough, the so-called mass transport or diffusion resistance. If the reactants cannot get to the reaction site fast enough, then the rate of the electrochemical reactions is once again limited, due to the low concentration of reactant at the electrode surface. At very high current densities, more reactant has to be supplied so that more electrons can be generated. The difference in the curves is explained by the relative ease of the transport of reactants.

Equation 7 summarizes how the cell voltage is obtained after losses.

$$
V=E^{0}-\eta_{A C T}-\eta_{\text {OHMIC }}-\eta_{\text {DIFF }}
$$

Here, $V$ is the cell voltage, $E^{0}$ is the thermodynamic cell voltage, $\eta_{A C T}$ is the activation voltage bsses, $\eta_{\text {OHMIC }}$ is the ohmic voltage losses, and $\eta_{\text {DIFF }}$ is the concentration voltage losses.

The actual experiments were conducted in the following manner at West Virginia University. The method described in this section is the basic operating procedure for a typical experiment and is not absolute. Different experiments may have required more attention to certain aspects of the procedure than others.

Because of the high heat capacity of water, the first order of business is to begin to heat the water tank used for humidification of the feed air, from room temperature to 70 ${ }^{\circ} \mathrm{C}$. This tank provides the water vapor to the airline required by the reaction at the cathode. The line from the humidifier to the pre-heater is heat-traced at $70{ }^{\circ} \mathrm{C}$ to prevent the water from condensing.

While the tank is heating, the carbon rod apparatus is prepared. Careful attention must be paid so that the rod is not broken during this process. The metal surfaces on this apparatus are buffed with emery paper to ensure good electrical contact with a fresh metal surface. The cell is similarly cleaned (usually the day before) and the inside is buffed with a wire brush to remove any corroded or rusted portions of the interior. The spider is cleaned to remove any residual electrolyte that may have gotten caught in the openings during the previous run. The carbon rod is tightened into the apparatus using a collet fitted to the top plate of the fuel cell. The size of the collet depends on the outer diameter of the rod (usually $3 / 4$ "). Because electrical contact is very important in this experiment, the collet is firmly tightened using a vice and lever arm tool.

The fuel cell body is then mounted in the test stand and the airline is connected. The area around the cell and heaters is well insulated to minimize the heat loss from the cell. The airflow is then set to a predetermined rate by means of the electronic flow controller. Once it is confirmed that air is flowing, the solid electrolyte is added to the cell. The temperature controllers for both the air pre-heater and the cell heaters are set to the desired operating temperature and powered on.

When the solid electrolyte has melted (usually about 30 minutes), the carbon rod, previously mounted in the collet, is slowly immersed into the liquid electrolyte and then removed in order to record the submerged length of the rod. This is done because the height of the electrolyte varies from experiment to experiment. This value is then used to calculate the nominal surface area of the carbon rod, the side and bottom areas of a cylinder, which is exposed to the electrolyte, which, in turn, is used to normalize the 
current. Once the length is obtained, the rod is replaced into the cell. The rod is submerged at an extremely slow rate to alleviate some of the thermal shock from the temperature difference of the room temperature rod and the molten electrolyte.

Once the apparatus is assembled, the proper wires are connected to the anode, cathode, and reference electrode respectively with the other ends being connected to the load cell and the data collection devices. Before any experimental data are collected, it is confirmed that the proper temperatures have been reached and are steady, the cell voltage is in equilibrium and the equipment is functioning properly.

After everything has been checked for proper operation, the experimental data can be collected. The experimental parameters are set and the system is allowed time to reach equilibrium once more. Because most of the tests involve the evaluation of voltage versus current density curves, the current drawn is increased in a step-wise manner from zero amps (open cell) to some maximum value determined by the experiment. Each datum point is recorded after 30 seconds of equilibrium time since it was found that the cell voltage and current stabilize very quickly, usually within a few seconds of being changed. The incremental change of the current drawn is usually $0.1-0.2 \mathrm{~A}$ every 30 seconds and is adjusted on the load cell manually. Once the maximum value is reached (determined by a $0.200 \mathrm{~V}$ reading at the cathode), the current is ramped down at about 0.5 $-1.0 \mathrm{~A}$ every 30 seconds. The reason a value of $0.200 \mathrm{~V}$ at the cathode signifies the maximum obtainable current is due to the fact that the cell voltage rapidly decreases at that point even with just a small increase in current. This is due to the transport limitations described earlier.

After again reaching open cell, the system is allowed time to recover (15-20 minutes) and another experiment can then be performed as long as the system is still functioning properly. If an experiment is to be run long term, the desired current is set and the cell is checked hourly to ensure proper operation so that it can be left unattended overnight.

After all the experiments have been completed on a particular carbon rod, the shutdown and cleanup procedure begins. The heaters are turned off and the air is allowed to flow to prevent the electrolyte from backing up into the air supply line. Once the fuel cell has cooled to a temperature near the melting point of the electrolyte (approximately $300{ }^{\circ} \mathrm{C}$ for sodium hydroxide), the carbon rod apparatus is removed and the molten electrolyte is dumped into a tray so that it can solidify and be properly disposed of. Great care must be taken in this procedure, as the cell is still extremely hot $\left(300^{\circ} \mathrm{C}\right)$. Proper clothing, hand protection, eye protection, and face shielding must be worn.

After everything has been taken apart, the cell is once again cleaned and all the parts are prepared for the next experiment. With this procedure, it is possible to run an experiment every $1-2$ days.

\subsubsection{Experimental Safety}

The described experiment poses several serious safety concerns that can be readily alleviated through proper procedures and precautions. Material safety and data sheets for all the chemicals in this study are included in the appendix.

First, proper eyewear and protective gloves should be worn at all times when dealing with corrosive chemicals such as sodium hydroxide. When handling the hot fuel 
cell, it is extremely important to wear high temperature heat resistant gloves. Severe burns occur when skin is exposed to temperatures around $600{ }^{\circ} \mathrm{C}$.

Second, when dealing with molten chemicals, there is always a risk of spatter or spilling. Acrylic panels have been placed around the fuel cell testing area shown in Figure 42, located on the right side of the diagram. These are removable when it is necessary to adjust the fuel cell. While in operation, these shields are always to be in place. Molten sodium hydroxide, other than being at $600+{ }^{\circ} \mathrm{C}$, is highly corrosive and will cause damage upon exposure to skin or nearby equipment.

Third, an emergency electrical shut-off switch is installed. Some of these experiments require long-term runs. Therefore, if something malfunctions in the middle of the night, the emergency shut-off is clearly labeled so that anyone can shut down the system immediately.

Fourth, exhaust fumes may contain sodium hydroxide vapors or other potential hazards. A fan-powered duct has been routed from just above the fuel cell to the nearest fume hood to insure that none of these fumes escapes into the surrounding air in the laboratory.

Fifth, to prevent the heaters from overshooting the set point by an extreme amount, the temperature controllers include an over temperature protection system that will immediately shut off the heaters in the event that the preset high-limit temperature is reached. Also, to prevent the water from condensing in the airlines, heat tapes and insulation have been wrapped around the line carrying the humidified air from the humidification tank to the air pre-heater to keep it at the proper temperature.

Finally, when dealing with electricity, one must be sure not to short out the system or touch any exposed wires that have a current running through them. Although measures are taken to insulate any wires from exposure, there is always the possibility of an exposed connection. Therefore, users must heed caution and always be able to see where their hands are being placed. Safety is very important in any experimental process and was not taken lightly in these experiments.

\subsubsection{Carbon Rod Production}

The graphite rods tested in these experiments were remaining from a previous project and were found in a large quantity at WVU. The place or method of manufacture is not known. The only thing known about these is the resistivity (discussed later) and that the rods are well made.

The coal-derived rods were made at WVU using a combination of Solvent Extracted Carbon Ore (SECO), petroleum coke (PetCoke), and a coal tar binder pitch that binds the SECO and PetCoke together. SECO is a low-ash extract material that is produced at WVU by solvent extraction of raw coal using $\mathrm{N}$-methyl pyrrolidone as the solvent. Petroleum coke is an anisotropic carbon produced in a delayed coker at the refinery. It has a low electrical resistivity, making it ideal for use as an anode material. Some of the rods were created as pure PetCoke (no SECO in mixture) at a composition of ( $80 \%$ PetCoke $/ 20 \%$ binder pitch). These rods were pressed in a heated mold at $200{ }^{\circ} \mathrm{C}$ and then calcined to $1000{ }^{\circ} \mathrm{C}$. They were used in Runs \#13 and \#14. Other rods were made by the same procedure and included different compositions of SECO and PetCoke, using a $15 \%$ coal tar binder pitch to hold the mixture together. It should be noted that the 
rods produced in this manner had visible cracks in the surface and had some variation in their quality. The production of these rods was the subject of a previous M.S. thesis at WVU. $^{9}$

The GrafTech rods were either baked or graphitized and were produced by GrafTech, Inc., which specializes in the production of synthetic graphite. West Virginia University has a good working relationship with GrafTech and these rods were provided free of charge by Mr. Doug Miller. The rods produced by GrafTech did not have any visible cracks and were well made. The baked rods were made from premium petroleum coke and binder pitch. They were baked at $1000{ }^{\circ} \mathrm{C}$ but not graphitized.

\section{Carbon Rod Resistivity}

In the fuel cell design used for this work, the carbon rod is both the fuel and the anode. Therefore, it must be able to carry electricity fairly well in order for the system to work. The resistivity of the rods is the physical parameter that indicates how well they are able to carry electricity in comparison to each other. The resistivity of a representative rod of each type was measured and recorded using a standard four-point apparatus available at WVU. This apparatus contains a power supply, a current meter, a variable resistor, a voltmeter, and a carbon rod holder consisting of two copper plates on both ends to make electrical contact with the rod. With this information, the resistivity of the rod can be calculated. A picture of the resistivity apparatus is shown below in Figure 45 .

A Keithley Model 2000 multi-meter (in current mode) in series with the carbon fuel rod measures the current. The voltage drop across the rod is measured with a second digital multi-meter (same model, in voltage mode) that is connected to the rod by two pointed contact pins over a precisely measured distance. The variable resistor allows for control of the current in the circuit. A schematic diagram of this method is shown in Figure 46. The resistivity is given by

$$
\rho=\left(\frac{V}{I}\right)\left(\frac{A_{C S}}{L}\right)\left(10^{3}\right),
$$

where $\rho$ is the resistivity, $(\mu \Omega \cdot \mathrm{m}) V$ is the voltage $(\mathrm{V})$ to current, $I$ is the current (A) A $A_{C S}$ is the cross-sectional area $\left(\mathrm{m}^{2}\right)$, and $L$ to the length between contact points $(\mathrm{m})$. 


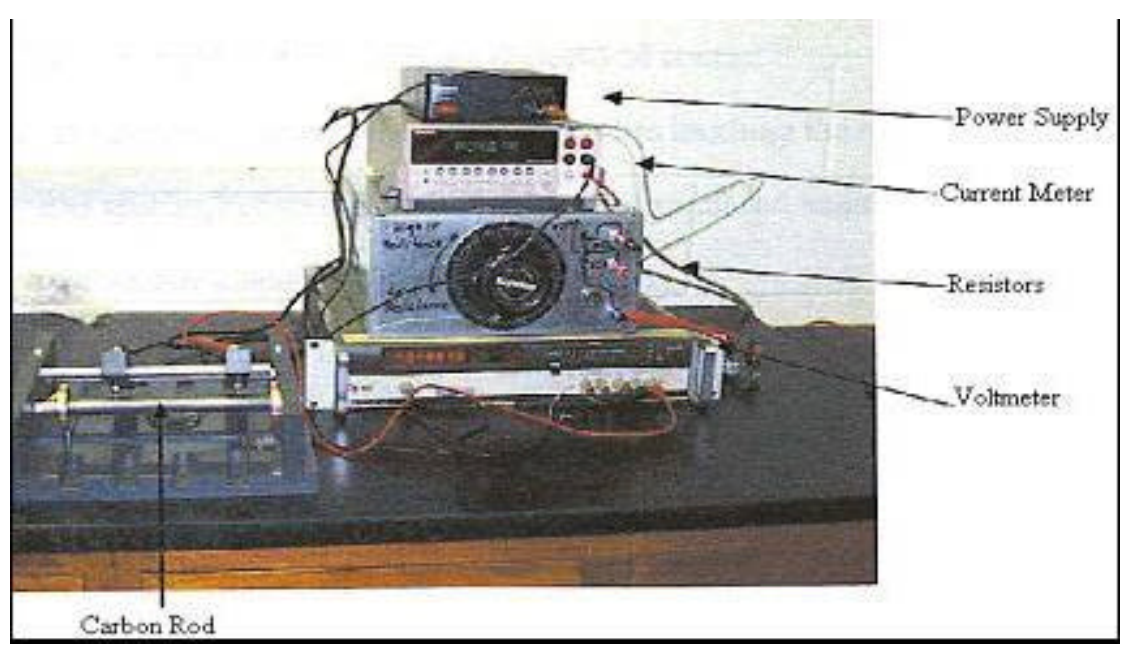

Figure 45. Carbon Rod Resistivity Testing Apparatus

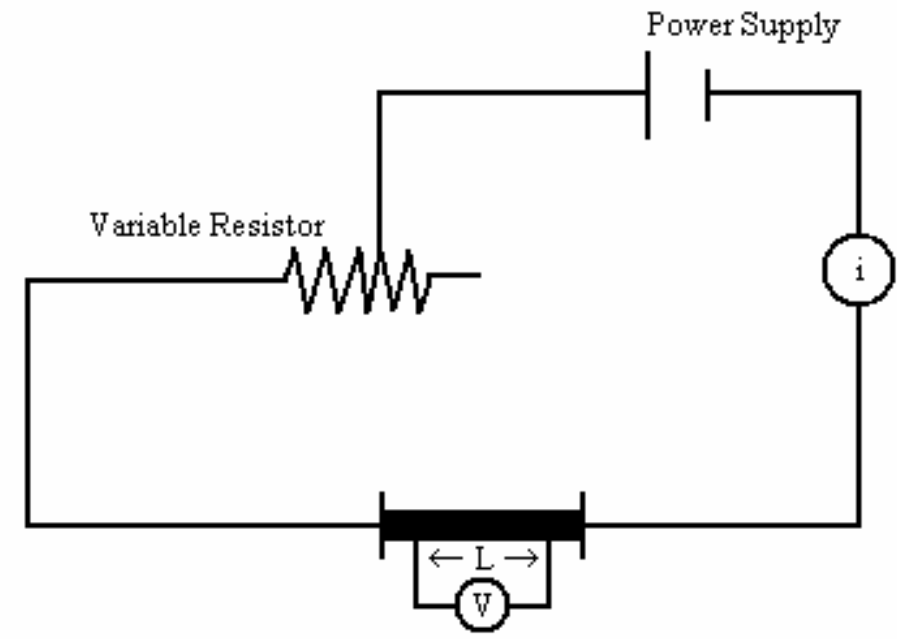

Figure 46. Schematic Diagram of Four Point Method for Testing Resistivity 


\subsubsection{Results and Discussion}

The test stand was successfully modified from a solid-oxide fuel cell to a direct carbon fuel cell. The equipment that was replaced (as discussed previously) all functioned properly. After experimenting with the test stand for an extended period of time, it became easier to manipulate the system to meet the needs of the project. The computer system allowed data points to be collected electronically, saving a lot of time compared to hand written data.

The data were accurate because several conditions of the cell could be monitored simultaneously, giving a clearer sense of what was occurring within the cell at a specific moment, as opposed to reading meters and recording values individually. In this sense, human error was alleviated for the data collection.

During a few runs, the molten electrolyte erupted out of the cell. The cause of this is not well understood. One hypothesis for this occurrence could be an air pressure buildup. At the time of the first occurrence, the air was fed from the "house air" line at WVU that is connected to all of the laboratories in the building. The remedy for this was to install a breathing quality air cylinder and pressure regulator directly to the system to alleviate any pressure buildups. This would also take care of any purity issues, as it was suspected that excess moisture was in the house airline. However, this solution did not solve the problem.

A second hypothesis is that while the load cell was set to a current of zero, a static charge built up between the anode and the cathode. This would likely happen because with the load cell turned off, the flow of electrons is stopped. The chemical reactions were ongoing and electrons were still being produced and consumed at the anode and cathode respectively. After the charges increased to a certain point, it is believed that a spark may have formed causing the major disruption within the cell, which led to molten electrolyte being expelled up to 15 feet away from the experiment. This prompted the installation of acrylic sheets around the cell for shielding. As a remedy to this problem, the load cell was never actually turned off, but set at the lowest possible current setting. By keeping the electrons flowing, the static charge should not build up. After using this method, only one further eruption occurred and it was small in comparison.

A summary of all results from the experimental setup discussed previously is given below as Table 4 . 
Table 4. Summary of Results from Experimental Design

\begin{tabular}{|c|c|c|c|c|c|c|}
\hline Run & $\begin{array}{l}\text { Open Cell } \\
\text { Voltage (V) }\end{array}$ & $\begin{array}{c}\text { Maximum } \\
\text { Current } \\
\text { Density } \\
\left(\mathrm{mA} / \mathrm{cm}^{2}\right) \\
\end{array}$ & $\begin{array}{c}\text { Maximum } \\
\text { Power Density } \\
\left(\mathrm{W} / \mathrm{cm}^{2}\right)\end{array}$ & $\begin{array}{c}\text { Area Specific } \\
\text { Resistance } \\
\left(\Omega \times \mathrm{cm}^{2}\right) \\
\end{array}$ & $\begin{array}{c}\text { Active Surface } \\
\text { Area }\left(\mathrm{cm}^{2}\right)\end{array}$ & Resistance $(\Omega)$ \\
\hline 1 & 0.751 & 230 & 0.066 & 2.91 & 50.5 & 0.058 \\
\hline 2 & 0.767 & 207 & 0.068 & 2.75 & 49.5 & 0.056 \\
\hline 3 & 0.779 & 175 & 0.065 & 2.74 & 50.5 & 0.054 \\
\hline 4 & 0.788 & 105 & 0.048 & 2.50 & 54.5 & 0.046 \\
\hline 5 & 0.757 & 133 & 0.057 & 2.00 & 51.9 & 0.039 \\
\hline 6 & 0.760 & 170 & 0.073 & 1.60 & 51.9 & 0.031 \\
\hline 7 & 0.773 & 183 & 0.062 & 2.60 & 51.9 & 0.050 \\
\hline 8 & 0.735 & 185 & 0.048 & 3.00 & 51.9 & 0.058 \\
\hline 9 & 0.770 & 197 & 0.084 & 1.60 & 51.9 & 0.031 \\
\hline 10 & 0.729 & 214 & 0.062 & 2.20 & 51.9 & 0.042 \\
\hline 11 & \multicolumn{6}{|c|}{ NO DATA COLLECTED } \\
\hline 12 & \multicolumn{6}{|c|}{ NO DATA COLLECTED } \\
\hline 13 & 0.963 & 53 & 0.033 & 4.30 & 60.6 & 0.071 \\
\hline 14 & 0.981 & 48 & 0.032 & 4.20 & 43.7 & 0.096 \\
\hline 15 & \multicolumn{6}{|c|}{ ROD BROKE OFF AT ELECTROLYTE SURFACE } \\
\hline 16 & 0.963 & 31 & 0.020 & 8.10 & 71.7 & 0.113 \\
\hline 17 & \multicolumn{6}{|c|}{ ROD DID NOT SURVIVE EXPERIMENT PREPARATION } \\
\hline 18 & 1.044 & 35 & 0.024 & 7.55 & 66.5 & 0.114 \\
\hline 19 & 0.705 & 107 & 0.041 & 2.20 & 41.3 & 0.053 \\
\hline 20 & 0.972 & 38 & 0.026 & 4.20 & 65.2 & 0.064 \\
\hline
\end{tabular}

The graphite rods operated very well in the DCFC. The method in which they were manufactured allowed for reliable experiments to be conducted. Also, because of their stability, it was possible to run multiple types of experiments, changing the process variables without the rod degrading. The graphite rods left the electrolyte fairly clear after finishing an experiment, which shows that not much particulate carbon was dissolving into the electrolyte. Any carbon that was missing from the surface of the rod was therefore, reacting with the hydroxide to form electrical power.

The maximum open-circuit voltage (OCV) from a graphite rod was a value of $0.788 \mathrm{~V}$. This value for the graphite rods was not as high as obtained from the coal derived rods, as previously noted in the literature. A summary of the runs involving graphite fuel rods is given below in Table 5 . 
Table 5. Summary of Results for Runs Using Graphite Fuel Rods

\begin{tabular}{|c|c|c|c|c|c|c|}
\hline Run & $\begin{array}{c}\text { Open Cell } \\
\text { Voltage (V) }\end{array}$ & $\begin{array}{c}\text { Maximum } \\
\text { Current Density } \\
\left(\mathrm{mA} / \mathrm{cm}^{2}\right)\end{array}$ & $\begin{array}{l}\text { Maximum } \\
\text { Power Density } \\
\left(\mathrm{W} / \mathrm{cm}^{2}\right)\end{array}$ & $\begin{array}{l}\text { Area Specific } \\
\text { Resistance } \\
\left(\Omega \times \mathbf{c m}^{2}\right)\end{array}$ & $\begin{array}{c}\text { Active Surface } \\
\text { Area }\left(\mathrm{cm}^{2}\right)\end{array}$ & Resistance $(\Omega)$ \\
\hline 1 & 0.751 & 230 & 0.066 & 2.91 & 50.5 & 0.058 \\
\hline 2 & 0.767 & 207 & 0.068 & 2.75 & 49.5 & 0.056 \\
\hline 3 & 0.779 & 175 & 0.065 & 2.74 & 50.5 & 0.054 \\
\hline 4 & 0.788 & 105 & 0.048 & 2.50 & 54.5 & 0.046 \\
\hline 5 & 0.757 & 133 & 0.057 & 2.00 & 51.9 & 0.039 \\
\hline 6 & 0.760 & 170 & 0.073 & 1.60 & 51.9 & 0.031 \\
\hline 7 & 0.773 & 183 & 0.062 & 2.60 & 51.9 & 0.050 \\
\hline 8 & 0.735 & 185 & 0.048 & 3.00 & 51.9 & 0.058 \\
\hline 9 & 0.770 & 197 & 0.084 & 1.60 & 51.9 & 0.031 \\
\hline 10 & 0.729 & 214 & 0.062 & 2.20 & 51.9 & 0.042 \\
\hline 11 & \multicolumn{6}{|c|}{ NO DATA COLLECTED } \\
\hline 12 & \multicolumn{6}{|c|}{ NO DATA COLLECTED } \\
\hline 19 & 0.705 & 107 & 0.041 & 2.20 & 41.3 & 0.053 \\
\hline
\end{tabular}

Conditions for Runs \#1, \#2, and \#3 were repeated throughout the experimentation process. Therefore, several values were obtained that are not recorded in Table 5. The area specific resistance (ASR), active surface area, and resistance are reported as average values of these repetitions. The active surface area is the amount of the fuel rod that is in contact with the electrolyte, where the anode reaction occurs, and is used to normalize the ASR data because the various runs had different active surface areas.

The results of the graphite runs are shown in Figures 47-56. All of the graphite runs have similar shapes for their $i-\mathrm{V}$ curve. The curves all drop quickly at the smaller currents due to the activation resistance. They continue to decrease in a linear fashion due to the ohmic resistance of the cell. Finally, the voltage decreases drastically at high currents due to the concentration or transport limitation being reached. The fuel cell power density increases with increasing current density, reaches a maximum, and then falls at still higher current densities.

These results, which all showed the same trend, were sometimes very different in magnitude. The run shown as Figure 47 was the first attempt and was terminated prior to reaching the maximum power density. This explains why the basic trend was not obtained. The run displayed in Figure 48, produced the most current, and therefore, produced a high power density. Each of these runs showed slightly different results and this may be due to some coating of the rods (which is discussed later), poisoned electrolyte (due to cell corrosion), etc. What is important to note is that the trends are similar and produce nearly the same voltages and power.

Long-term runs for some graphite experiments were conducted to investigate the long-term effects of the DCFC. These results are given in Figure 52, Figure 54, Figure 57, and Figure 59. In Figure 52, a constant current of 2.0A was set and the cell is allowed to run for an extended period of time ( $\sim 17$ hours). This graphite rod held up well and only degraded slightly after 17 hours. It should be noted that for the long-term testing, the active surface area of the rod was assumed to remain constant over the entire 
course of the test. In reality, this is not the case as the rod diameter decreases as more carbon reacts. Since there is no easy way to follow the change in area, it was taken as constant.

In Figure 54, a constant current of 2.0A was also set. However, in this case, the cell voltage degrades much quicker. There was a coating on the surface of this rod that most likely hindered the reaction at the rod's surface. Therefore, the reaction could not take place at this current. After shutting off the load (current), the cell recovered to $0.700 \mathrm{~V}$. Once the current was turned back on, cell voltage decreased drastically. This reinforces the idea that the coating of the anode that was causing the problem.

In Figure 57, a constant current of 1.5A was set. After a small initial decrease, the cell recovered and produced a constant voltage over the remaining 15 hours. This run proved to be the most stable of the long-term runs as the voltage decrease over time was minimal.

In Figure 59, a constant current of 1.0A was set. The cell seems to struggle throughout the long term run, holding steady for the first 12 hours and slowly decreasing cell voltage over the next 9 hours. During this long-term run, a large pressure buildup was noticed and the airflow rate was stuck at 0.075 SLPM, which was below the set point of 0.50 SLPM.

Cell Voltage and Power Density versus Current Density Graphite Rod, $\mathrm{T}=600^{\circ} \mathrm{C}, 11 / 22 / 05$

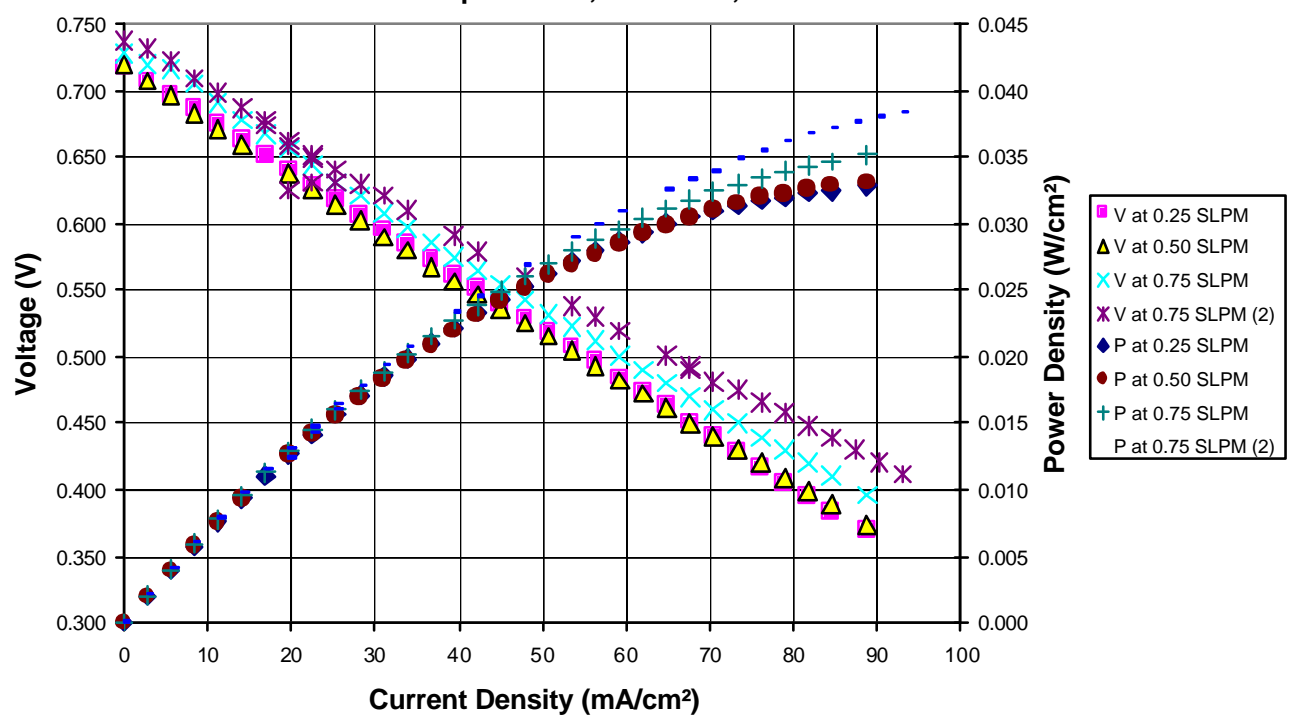

Figure 47. Results of Initial Graphite Experiment Subject to the Conditions of Runs \#1, $\# 2$, and \#3 


\section{Cell Voltage and Power Density versus Current Density}

Graphite Rod, $T=600^{\circ} \mathrm{C}, 12 / 6 / 05$

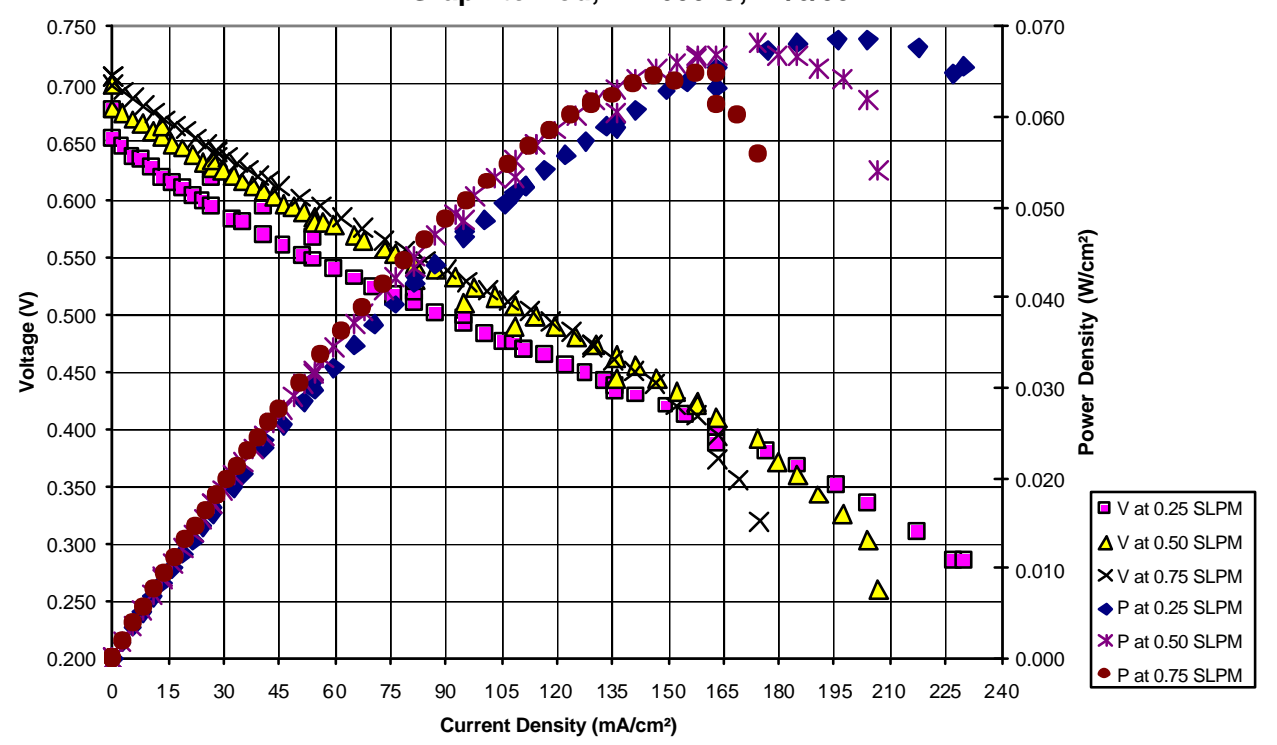

Figure 48. Results of Graphite Experiment Subject to the Conditions of Runs \#1, \#2, and \#3

\section{Cell Voltage and Power Density versus Current Density Graphite Rod, $\mathrm{T}=600^{\circ} \mathrm{C}, 12 / 14 / 05$}

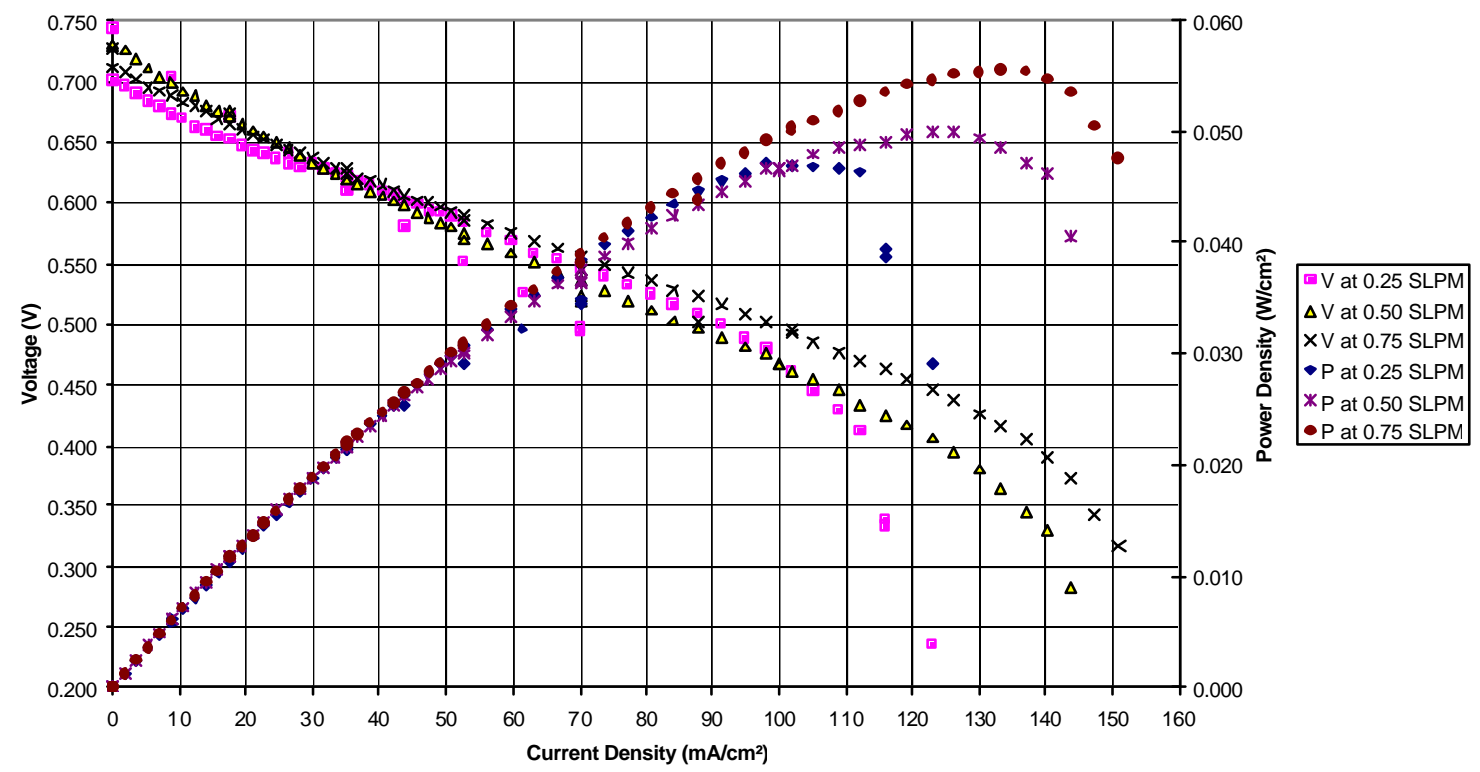

Figure 49. Results of Graphite Experiment Subject to the Conditions of Runs \#1, \#2, and \#3 


\section{Cell Voltage and Power Density versus Current Density \\ Graphite Rod, $\mathrm{T}=600^{\circ} \mathrm{C}, 1 / 12 / 06$}

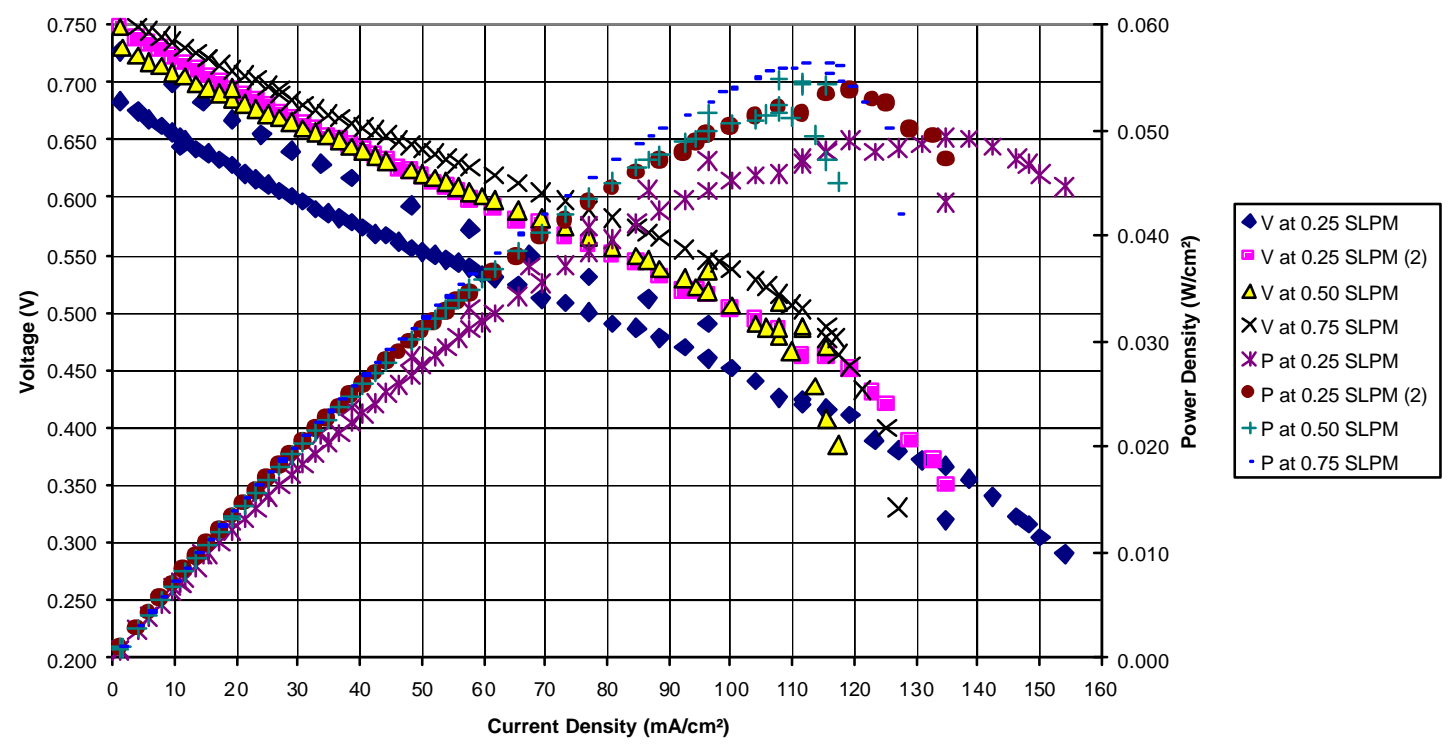

Figure 50. Results of Graphite Experiment Subject to the Conditions of Runs \#1, \#2, and \#3

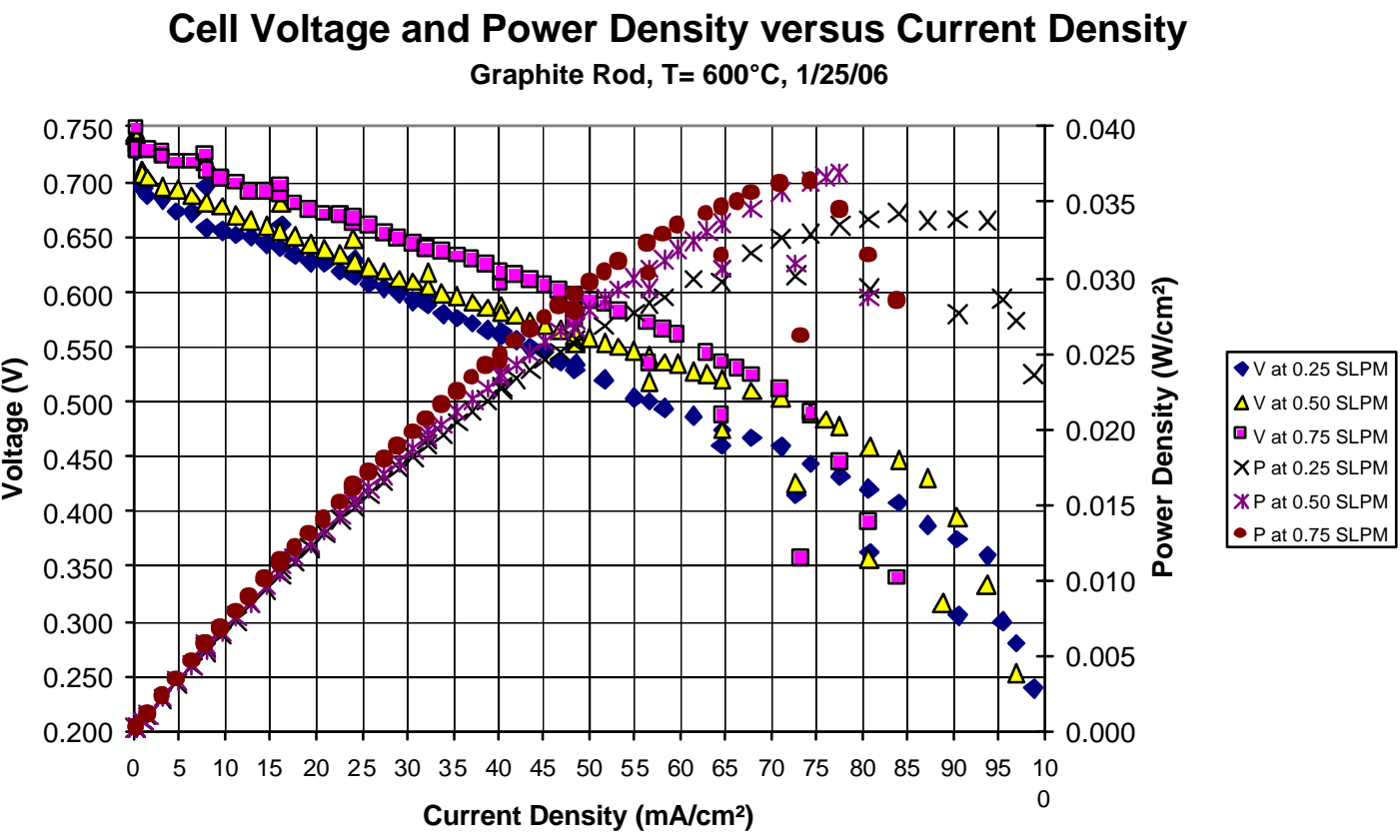

Figure 51. Results of Graphite Experiment Subject to the Conditions of Runs \#1, \#2, and \#3 


\section{Cell Voltage over Time}

Graphite Rod, Airflow $=0.25$ SLPM, $\mathrm{T}=600^{\circ} \mathrm{C}, 1 / 25 / 06$

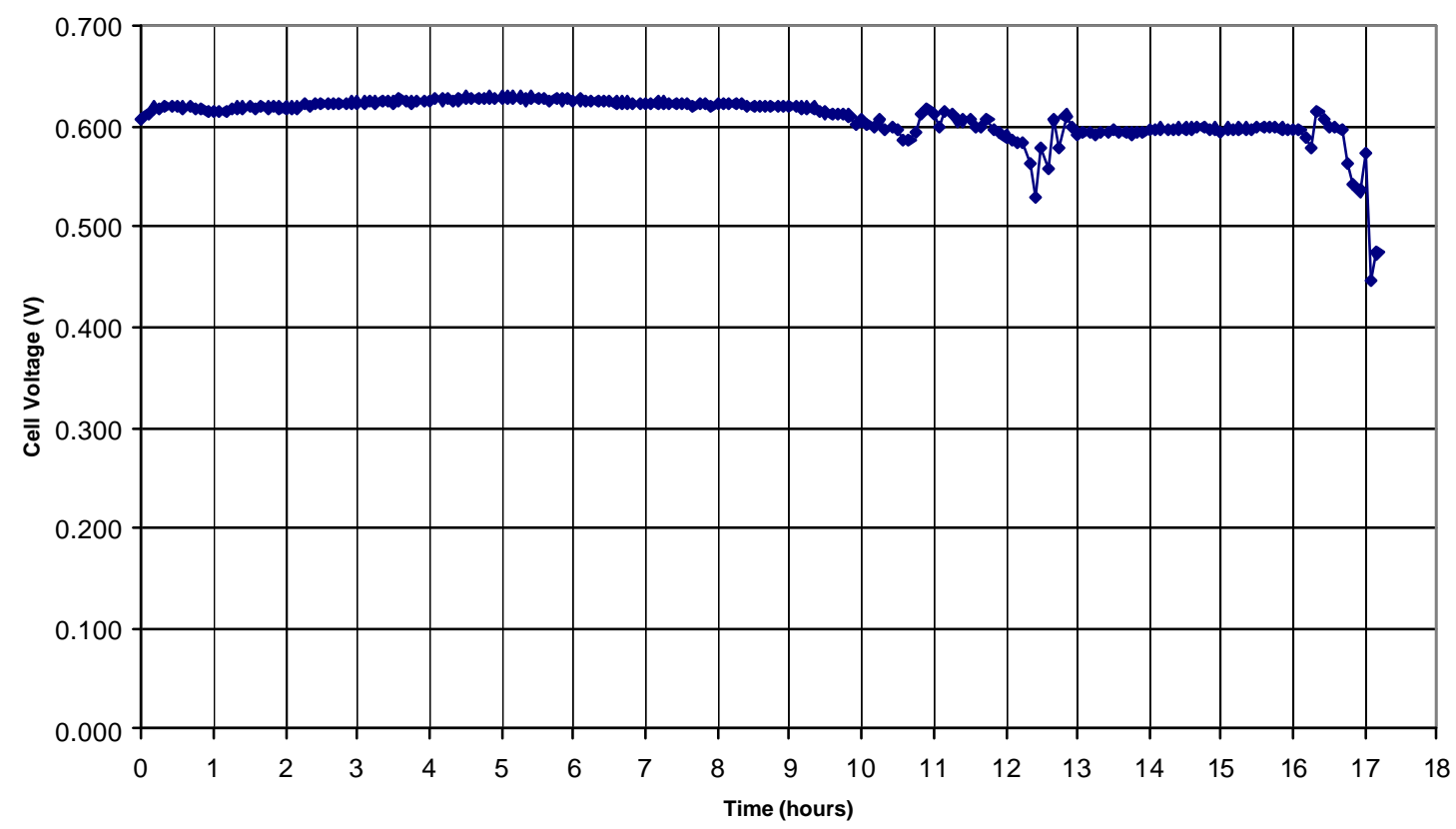

Figure 52. Long-Term Results for Graphite Experiment Subject to Condition of Run \#1

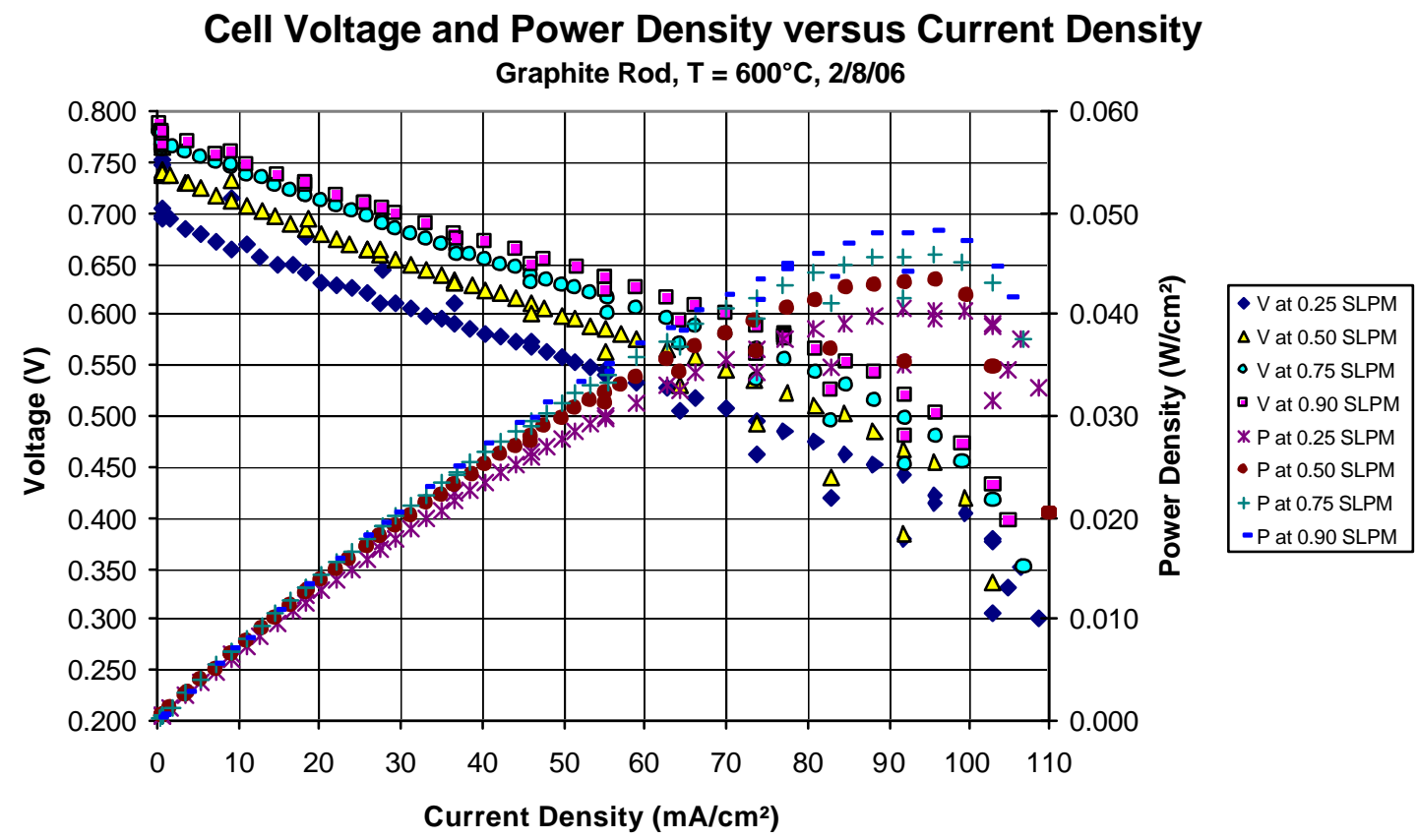

Figure 53. Results of Graphite Experiment Subject to the Conditions of Runs \#1, \#2, \#3, and \#4 


\section{Cell Voltage and Current Density over Time}

Graphite Rod, Flow $=0.50$ SLPM, $\mathrm{T}=600^{\circ} \mathrm{C}, 2 / 08 / 06-2 / 09 / 06$

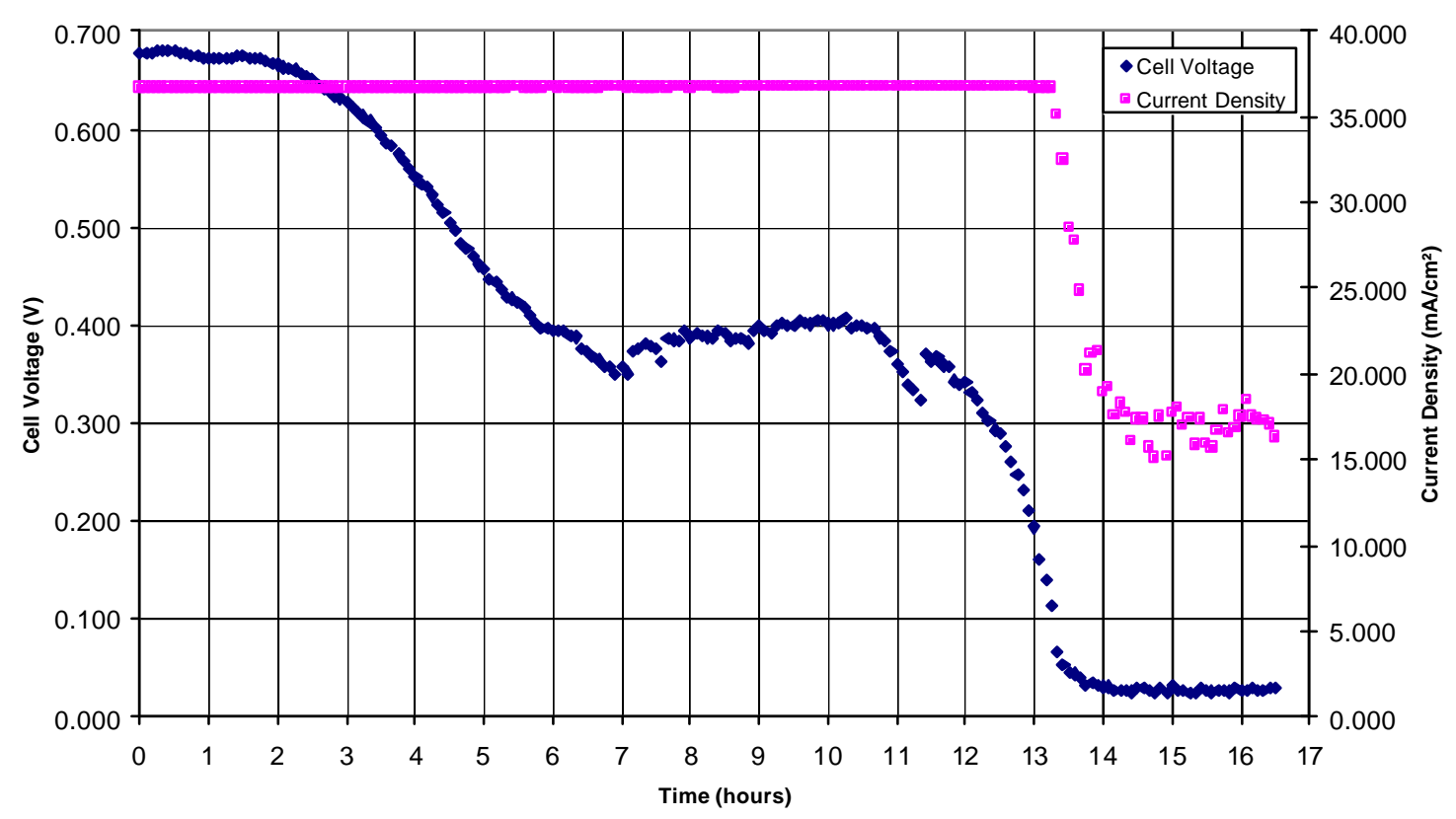

Figure 54. Long-Term Results of Graphite Experiment Subject to the Conditions of Run $\# 2$

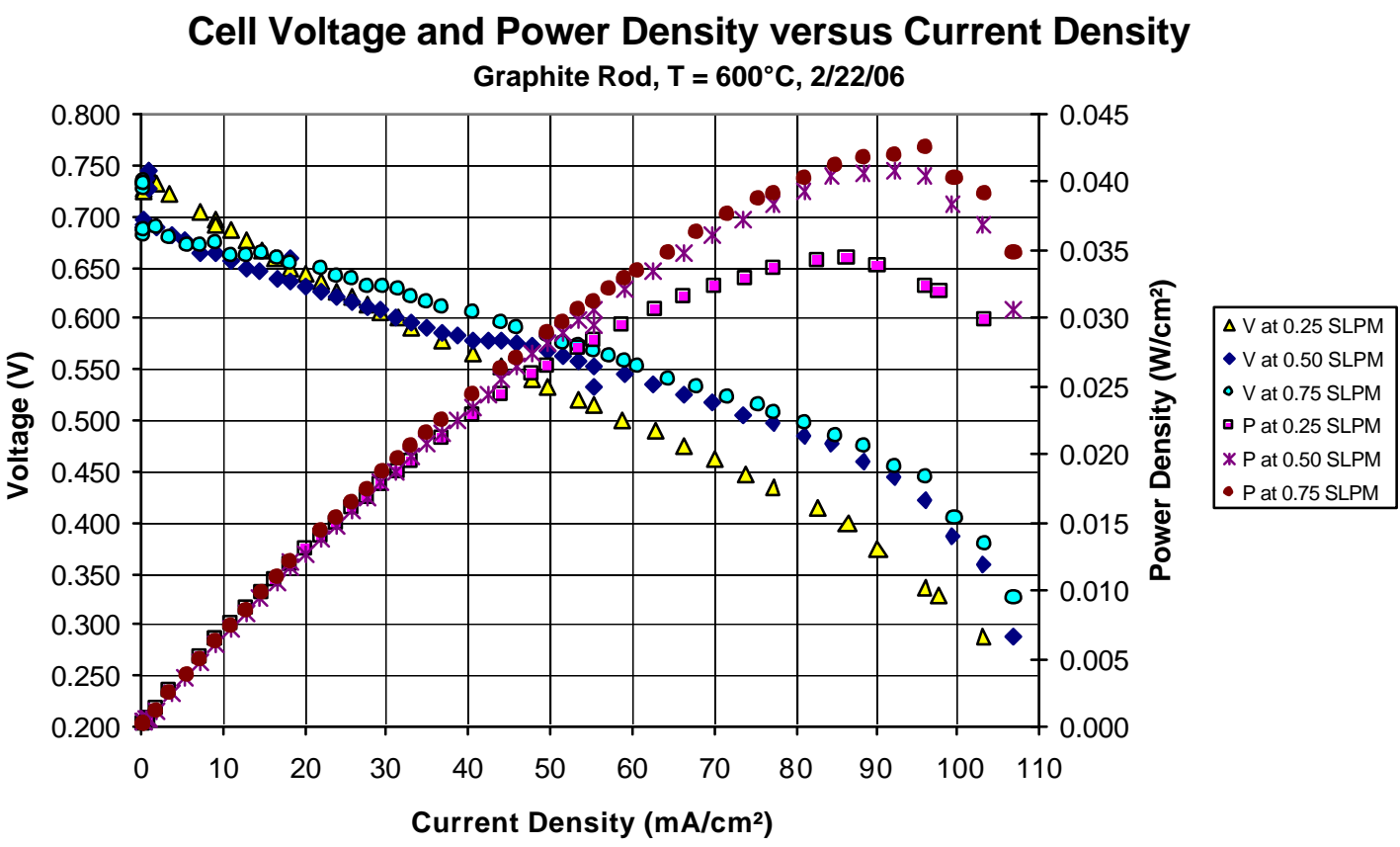

Figure 55. Results of Graphite Experiment Subject to the Conditions of Runs \#1, \#2, and \#3 


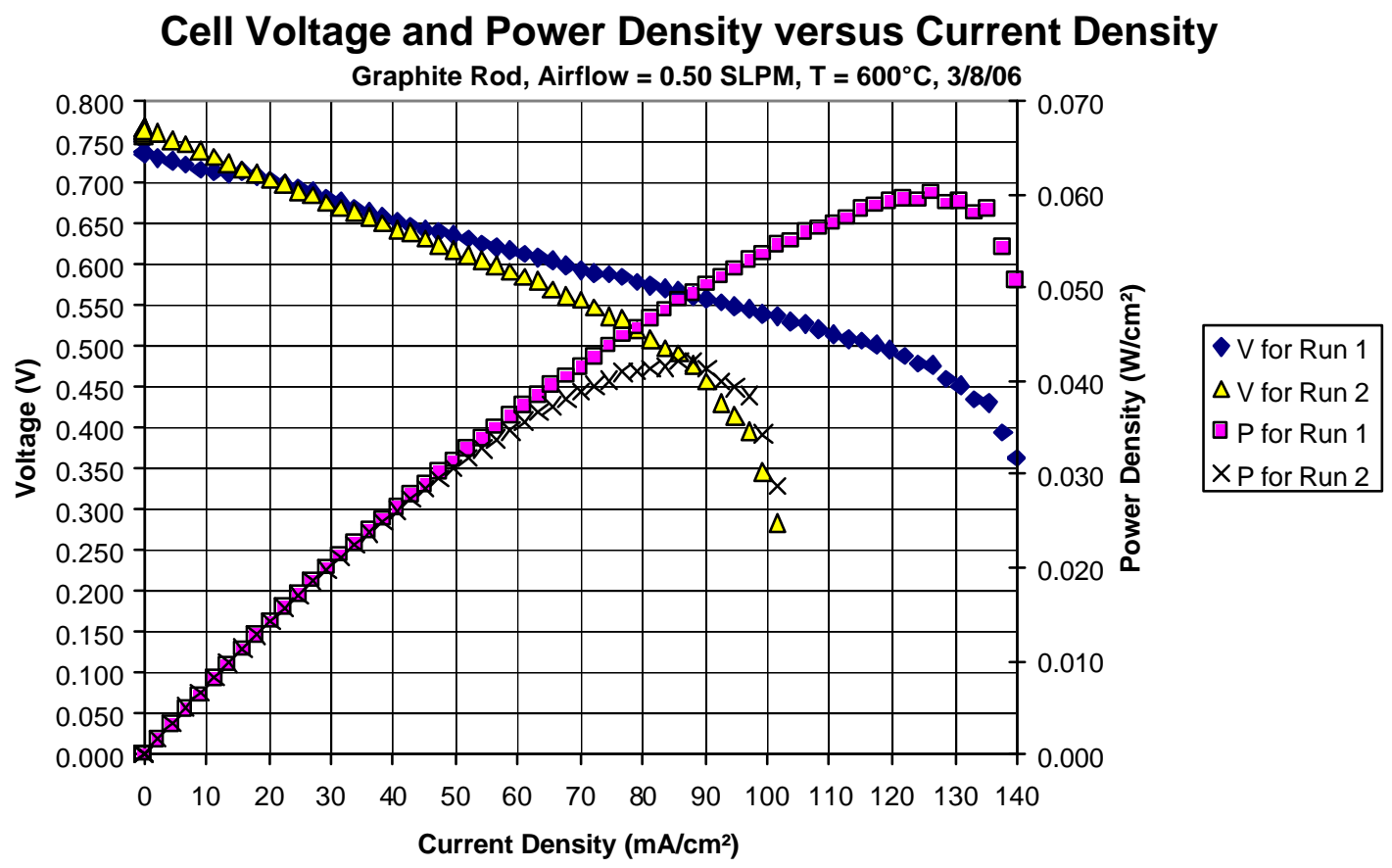

Figure 56. Results of Graphite Experiment Subject to the Conditions of Run \#2 


\section{Cell Voltage and Current Density over Time}

Graphite Rod, Flow $=0.50$ SLPM, $\mathrm{T}=600^{\circ} \mathrm{C}, 3 / 8 / 06-3 / 9 / 06$

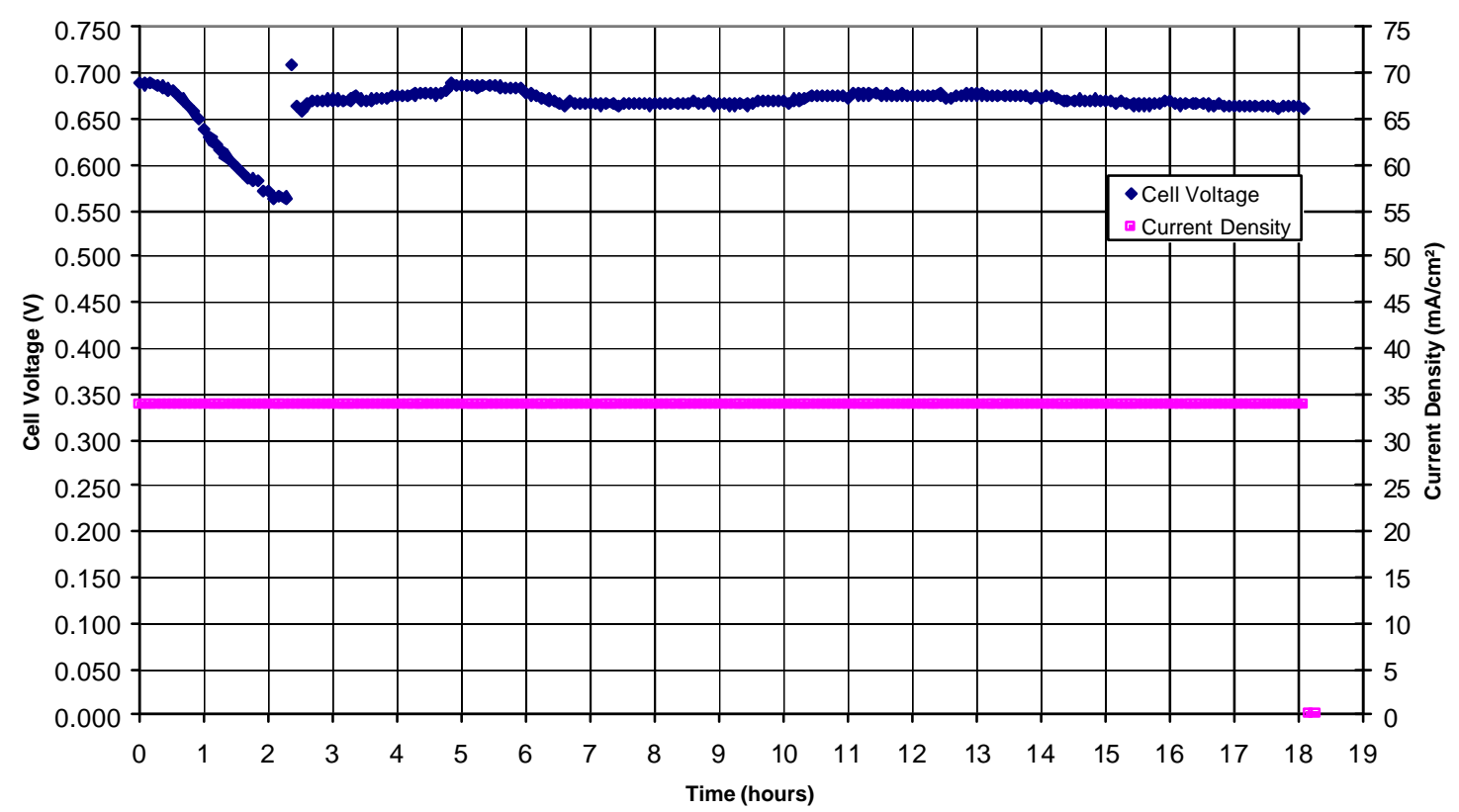

Figure 57. Long-Term Results for Graphite Experiment Subject to the Conditions of Run \#2

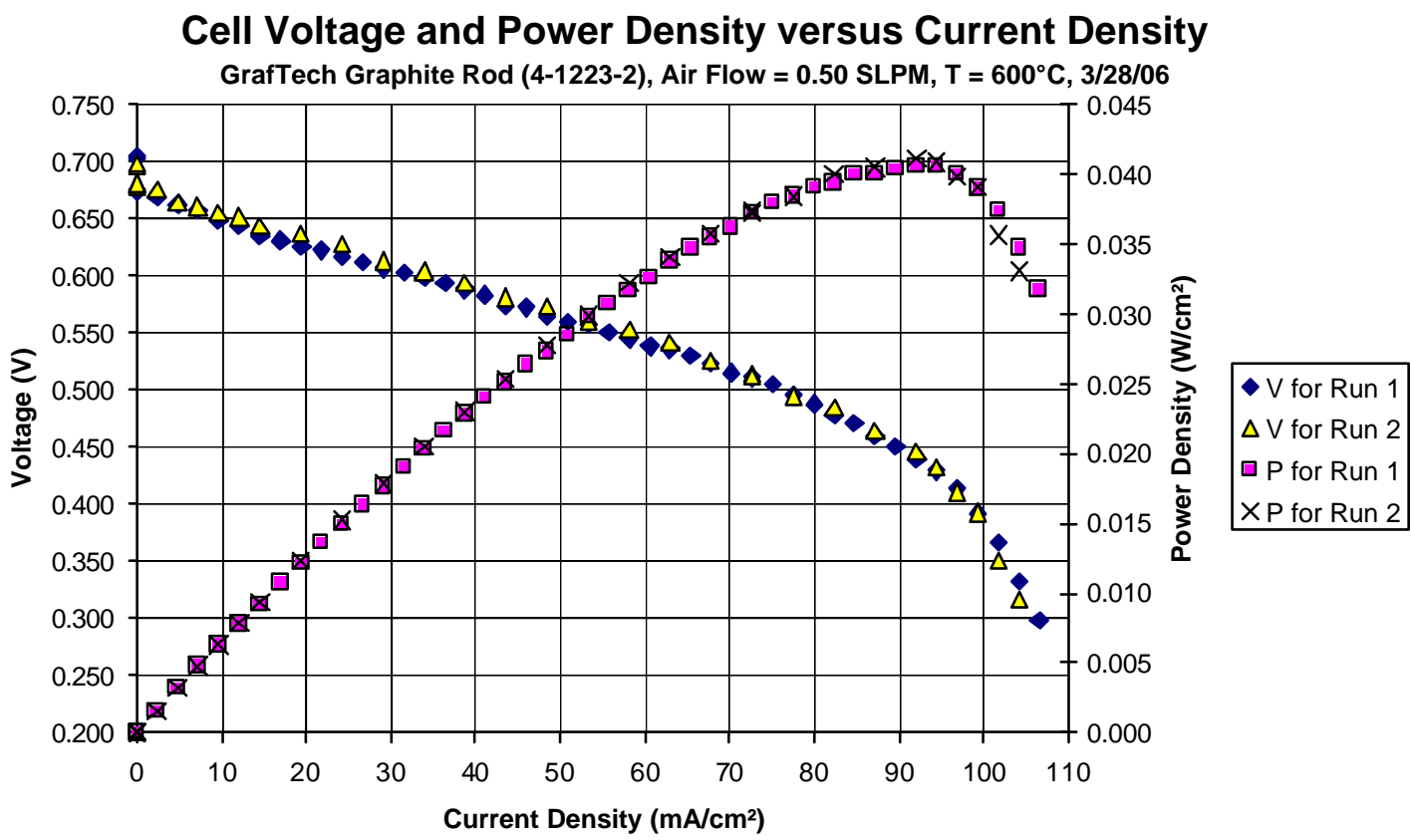

Figure 58. Results of GrafTech Graphite Rod from Run \#19 


\section{Voltage over Time}

GrafTech Graphite Rod (4-1223-2), Air Flow $=0.50$ SLPM, $\mathrm{T}=600^{\circ} \mathrm{C}, 3 / 28 / 06-3 / 29 / 06$ Long Term Run

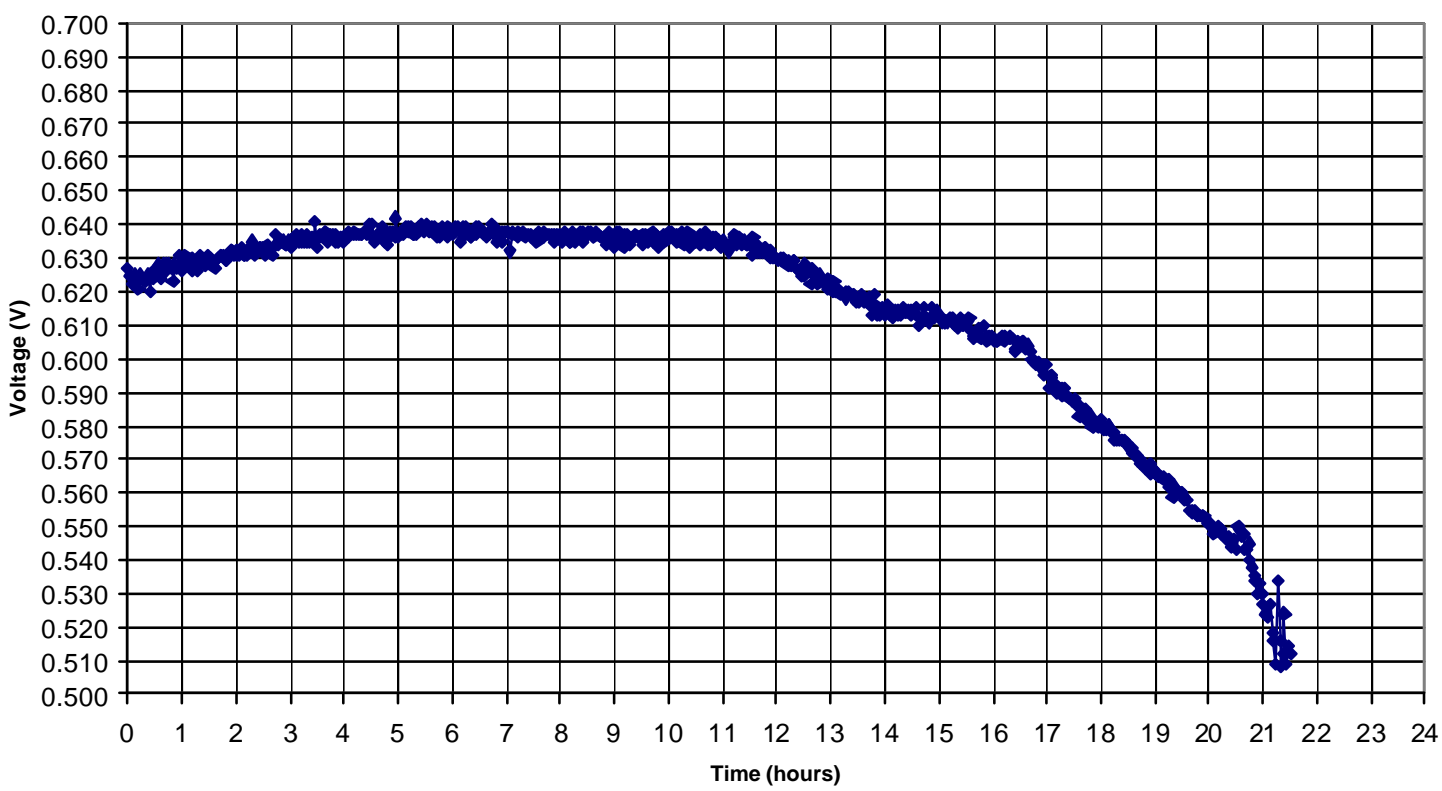

Figure 59. Long-Term Results for GrafTech Graphite Rod from Run \#19

Runs \#11 and \#12 involved an electrolyte other than sodium hydroxide. The runs did not provide any meaningful data other than the knowledge that the use of other electrolytes was unsuccessful. For both of these runs, the cell did not produce any voltage.

The GrafTech graphite rod (Run \#19) results show that the rod performance is about the same as the other graphite rods. The results of this run are given in Figure 58. The cell voltage degraded over time, as shown in Figure 59, the long term results for this experiment that were discussed above. It is unknown why the performance with this rod deteriorated so quickly. The GrafTech rods were expected to be of very high quality. Because only one of these rods were tested, it is hard to say whether or not this rod was superior. However, the point of running this rod as a separate experiment was because GrafTech is a well-known manufacturer of graphite electrodes. Therefore, because GrafTech's rod operated about the same as the other graphite rods, there is even more confidence in the results obtained from the other graphite rods.

\subsubsection{Coal-Derived Rods}

The results from the coalderived rods are show in Table 6. As can be seen, the coal-derived rods produced a higher open-circuit voltage as compared to the graphite rods. This is because the molecular alignment in the coalderived rods is not as organized as in the graphite rods and the carbon is more accessible for reaction. Therefore, there 
are more active reaction sites on the coalderived rods and hence these rods show a higher electrochemical activity.

Table 6. Summary of Results for Runs Using Coal-Derived Fuel Rods

\begin{tabular}{|c|c|c|c|c|c|c|}
\hline Run & $\begin{array}{c}\text { Open Cell } \\
\text { Voltage (V) }\end{array}$ & $\begin{array}{c}\text { Maximum } \\
\text { Current Density } \\
\left(\mathbf{m A} / \mathbf{c m}^{2}\right)\end{array}$ & $\begin{array}{c}\text { Maximum } \\
\text { Power Density } \\
\left(\mathbf{W} / \mathbf{c m}^{2}\right)\end{array}$ & $\begin{array}{c}\text { Area Specific } \\
\text { Resistance } \\
\left(\Omega \times \mathbf{c m}^{2}\right)\end{array}$ & $\begin{array}{c}\text { Active Surface } \\
\text { Area }\left(\mathbf{c m}^{2}\right)\end{array}$ & Resistance $(\Omega)$ \\
\hline 13 & 0.963 & 53 & 0.033 & 4.30 & 60.6 & 0.071 \\
\hline 14 & 0.981 & 48 & 0.032 & 4.20 & 43.7 & 0.096 \\
\hline 15 & \multicolumn{7}{|c|}{ ROD BROKE OFF AT ELECTROLYTE SURFACE } \\
\hline 16 & 0.963 & 31 & 0.020 & 8.10 & 71.7 & 0.113 \\
\hline 17 & \multicolumn{7}{|c|}{ ROD DID NOT SURVIVE EXPERIMENT PREPARATION } \\
\hline 18 & 1.044 & 35 & 0.024 & 7.55 & 66.5 & 0.114 \\
\hline 20 & 0.972 & 38 & 0.026 & 4.20 & 65.2 & 0.064 \\
\hline
\end{tabular}

The method in which the rods were produced led to a problem. The rods seemed to physically degrade in the cell. Therefore, these rods did not last as long as the graphite rods while in the electrolyte. After an experiment had been run, the electrolyte turned black. There also seemed to be a carbon buildup around the surface of the molten electrolyte clinging to the surface of the cell body. This buildup also occurred at the point on the rod that was at the top surface of the electrolyte. A portion of this buildup has been analyzed and it seems to be the electrolyte and some iron corroded from the cell body. Scanning electron micrographs of these deposits are included below as Figure 60.

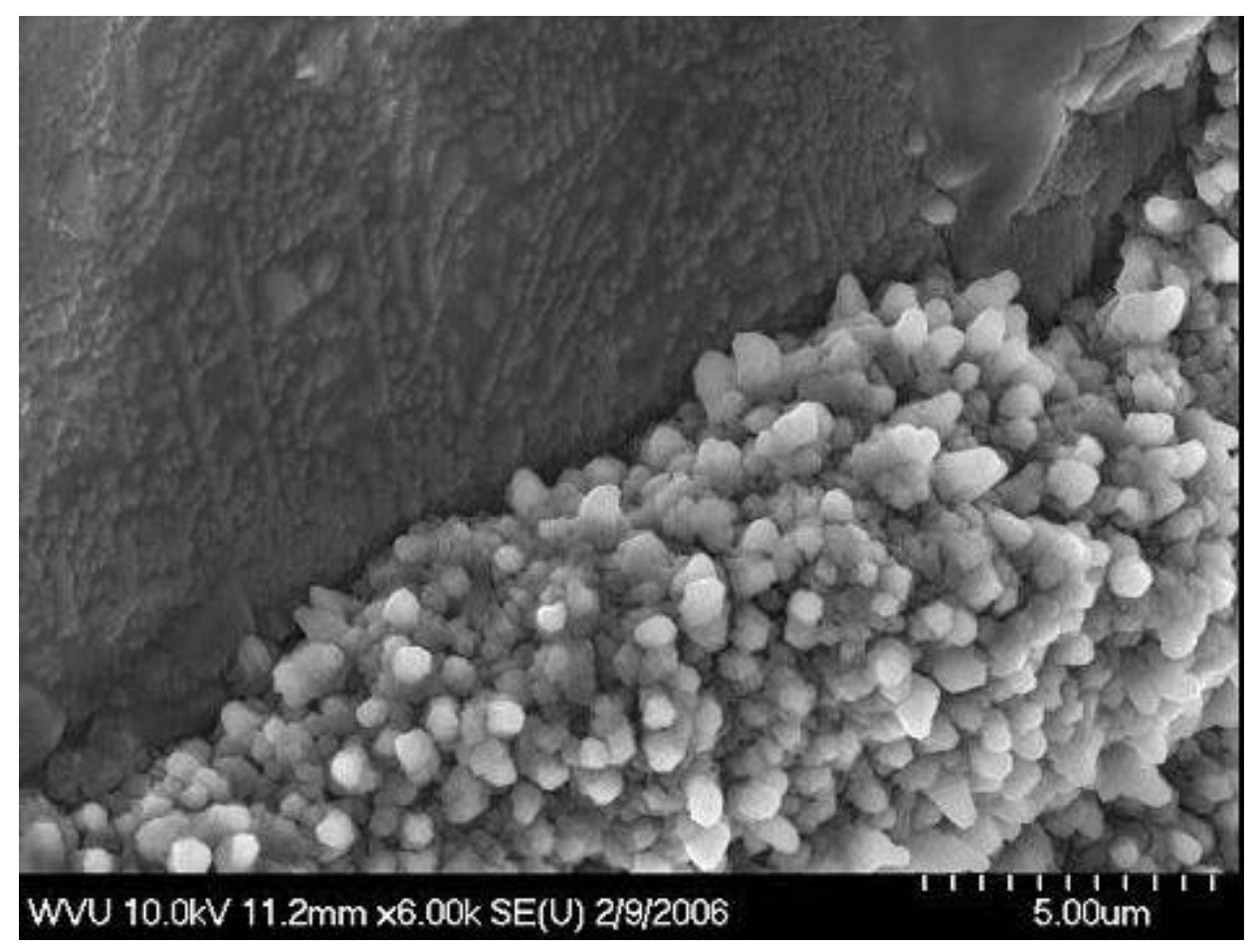

Figure 60. SEM Image of Carbon Fuel Rod with $\mathrm{C} / \mathrm{NaOH} / \mathrm{Fe}$ Buildup. 
In Run \#15, the rod did not last long enough for any data to be collected. The rod broke off at the electrolyte surface and sank into the cell, causing the active surface area to be zero. In Run \#17, no run was actually conducted. This rod did not survive the assembly process and broke before it could be inserted into the fuel cell.

The following figures are the results of the runs involving the non-graphitized coal-derived fuel rods. The results from the 100\% PetCoke rods (Runs \#13 and \#14) are given in Figure 61 and Figure 62, respectively. The results show the same trend as the experiments with the graphite rods, except for the cell voltages, which are appreciably higher, as seen in Table 6. Results for the 100\% SECO rod (Run \#18) are illustrated in Figures 63 and 64. The results for the 50\% SECO/50\% PetCoke rod (Run \#16) are given in Figures 65 and 66. The reason for there being only one run here is because the rod degraded very quickly and the other results are unreliable.

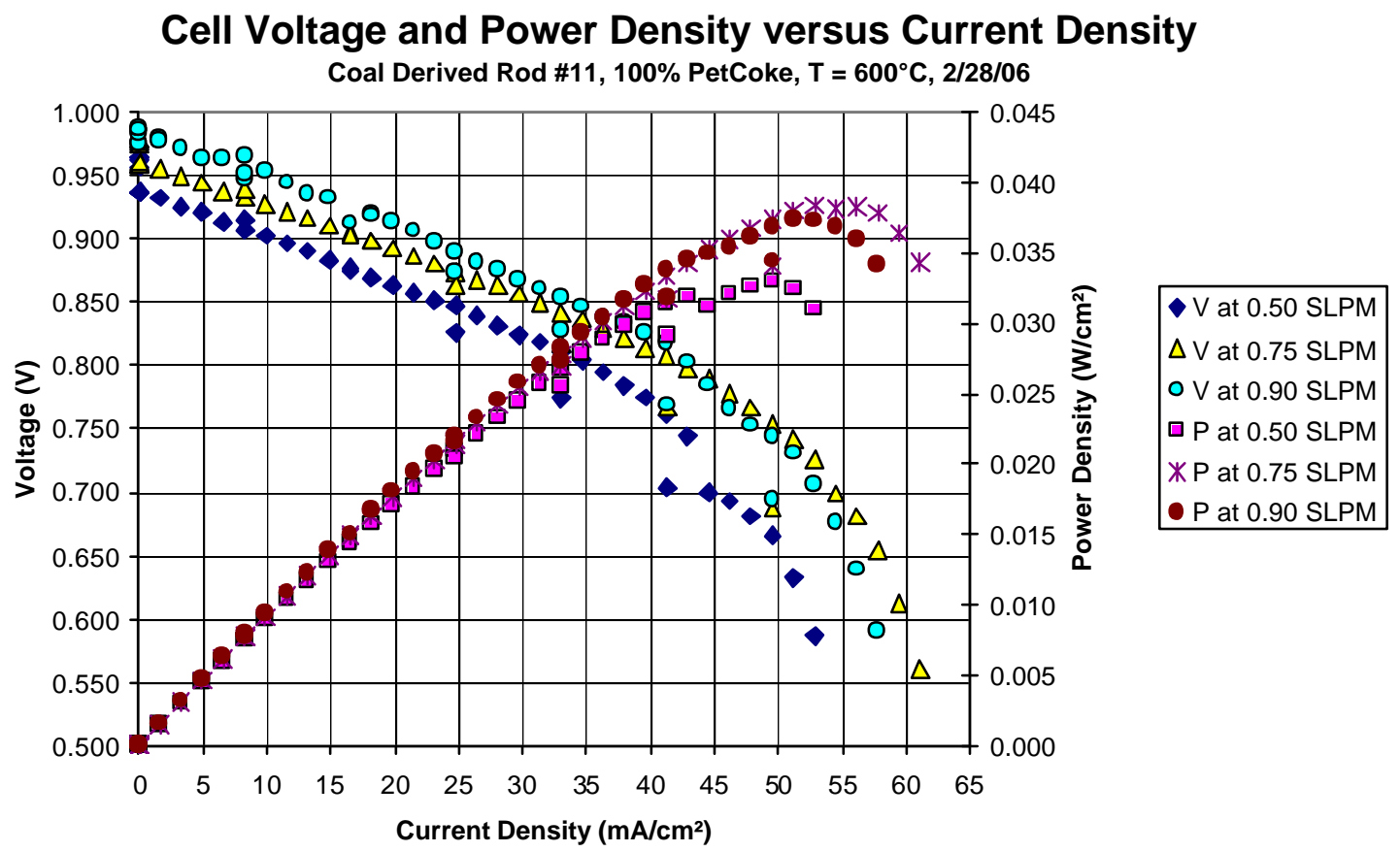

Figure 61. Results of $100 \%$ PetCoke Rod from Run \#13 


\section{Cell Voltage and Power Density versus Current Density}

Coal Derived Rod \#10, 100\% PetCoke, $\mathrm{T}=600^{\circ} \mathrm{C}, 3 / 2 / 06$

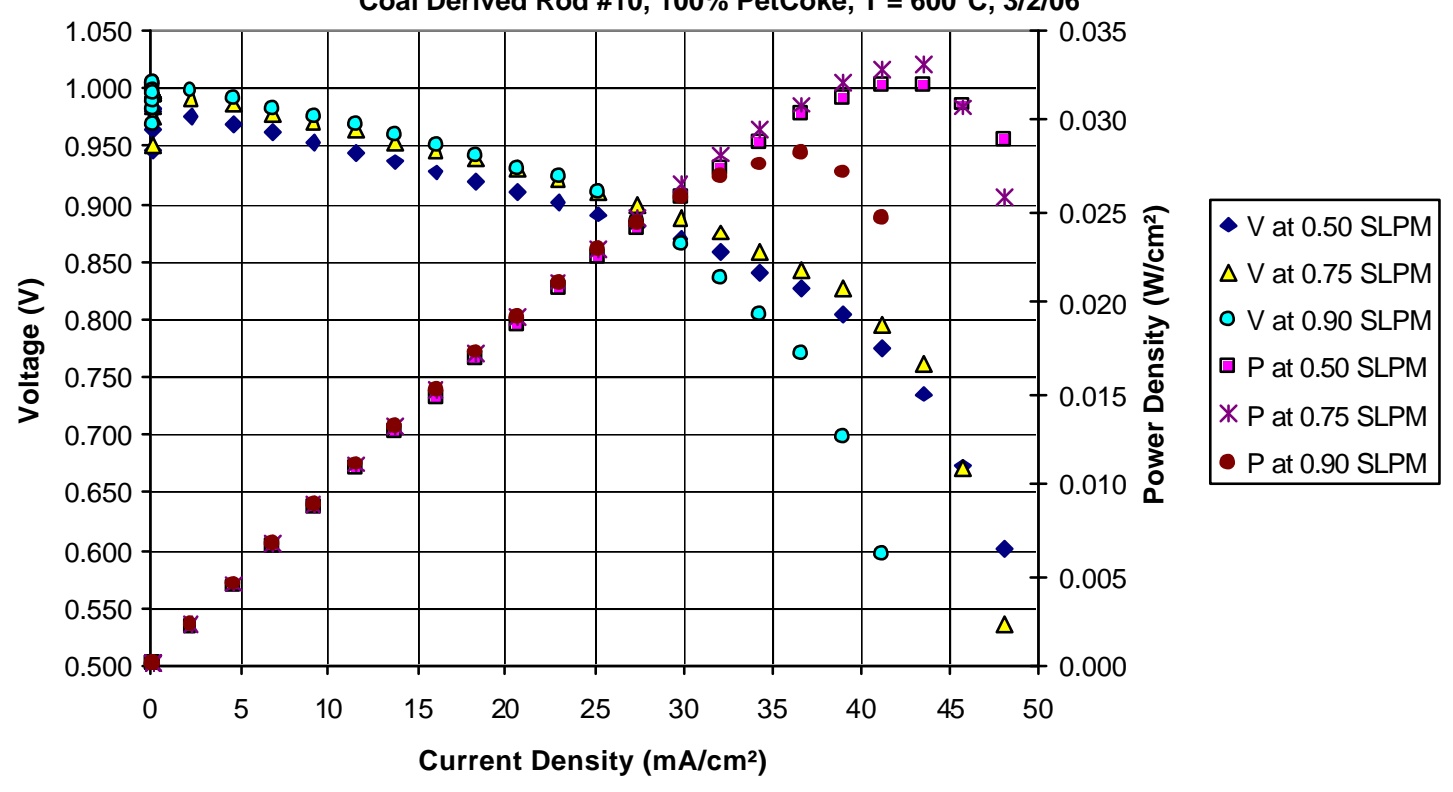

Figure 62. Results of $100 \%$ PetCoke Rod from Run \#14

Cell Voltage and Power Density versus Current Density Coal Derived Rod, $100 \%$ SECO, Air Flow $=0.50$ SLPM, $\mathrm{T}=600^{\circ} \mathrm{C}, 3 / 22 / 06$

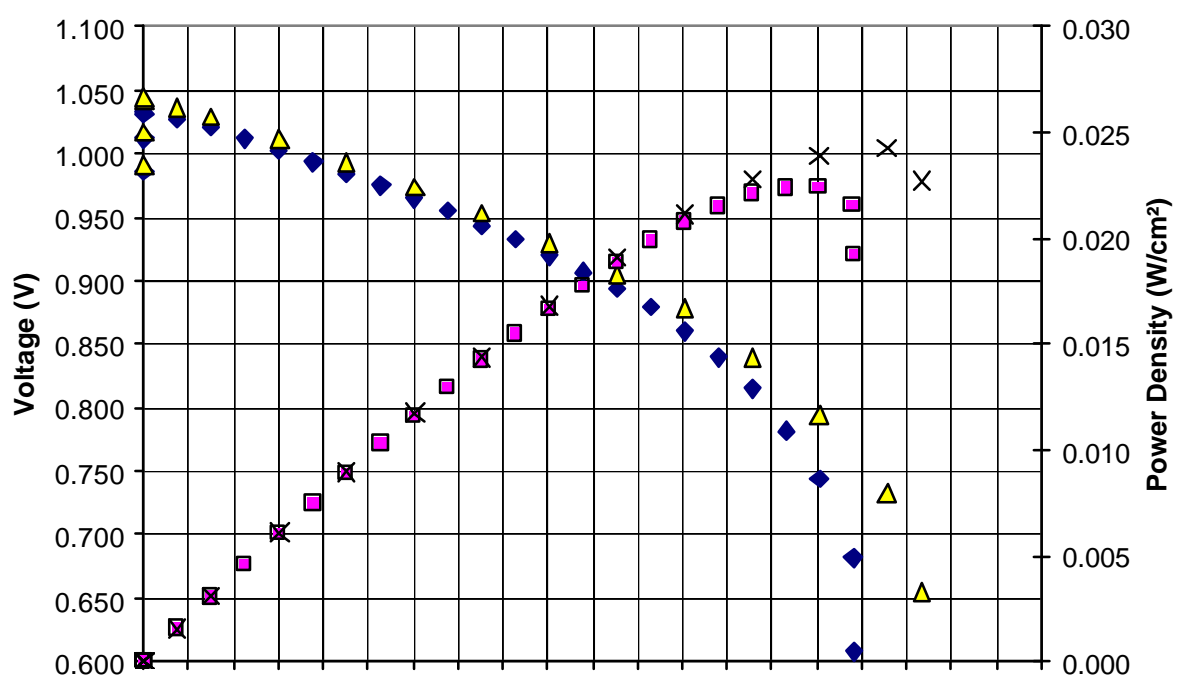

$\begin{array}{lllllllllllllllllllll}0 & 2 & 4 & 6 & 8 & 10 & 12 & 14 & 16 & 18 & 20 & 22 & 24 & 26 & 28 & 30 & 32 & 34 & 36 & 38 & 40\end{array}$

Current Density $\left(\mathrm{mA} / \mathrm{cm}^{2}\right)$

Figure 63 . Results of $100 \%$ SECO Rod from Run \#18 
Voltage over Time

Coal Derived Rod (85-15 SECO-Pitch), Air Flow $=0.50$ SLPM, $\mathrm{T}=600^{\circ} \mathrm{C}, 3 / 22 / 06$ Long Term Run

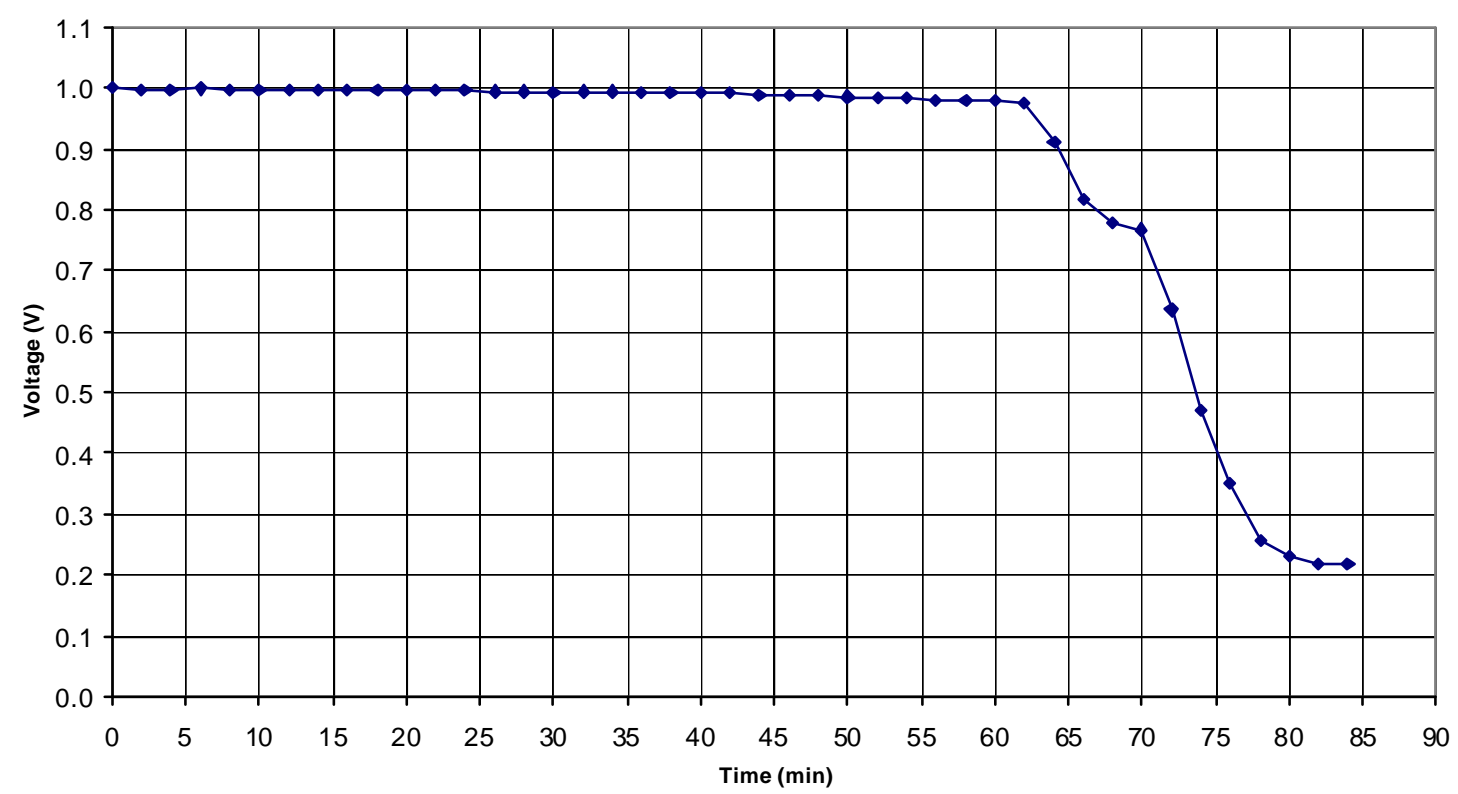

Figure 64. Long Term Results for 100\% SECO Rod Run from Run \#18

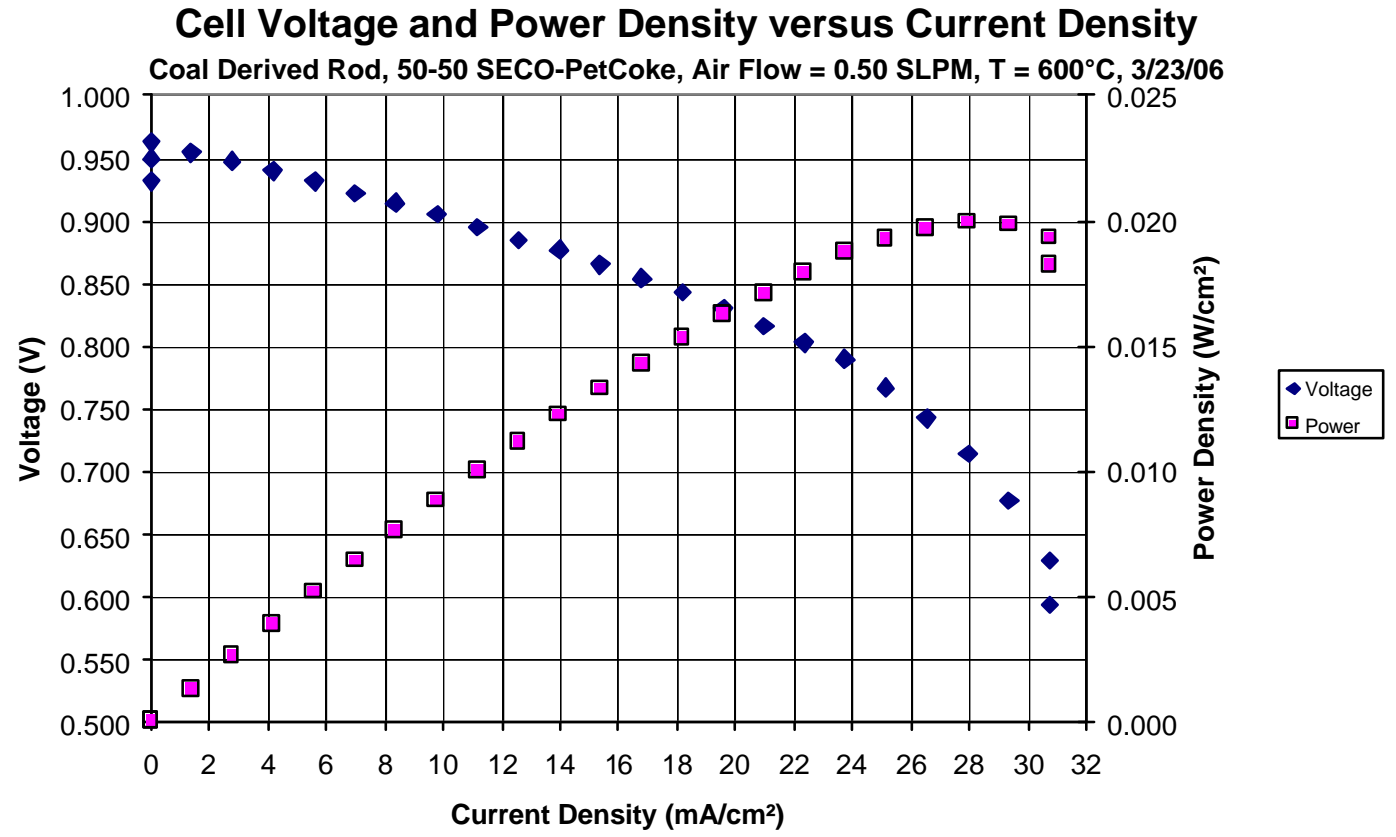

Figure 65. Results for 50\% SECO/ 50\% PetCoke Rod from Run \#16 


\section{Voltage over Time}

Coal Derived Rod (50-50 SECO-PetCoke), Air Flow $=0.50$ SLPM, $\mathrm{T}=600^{\circ} \mathrm{C}, \mathbf{3} / 23 / 06$

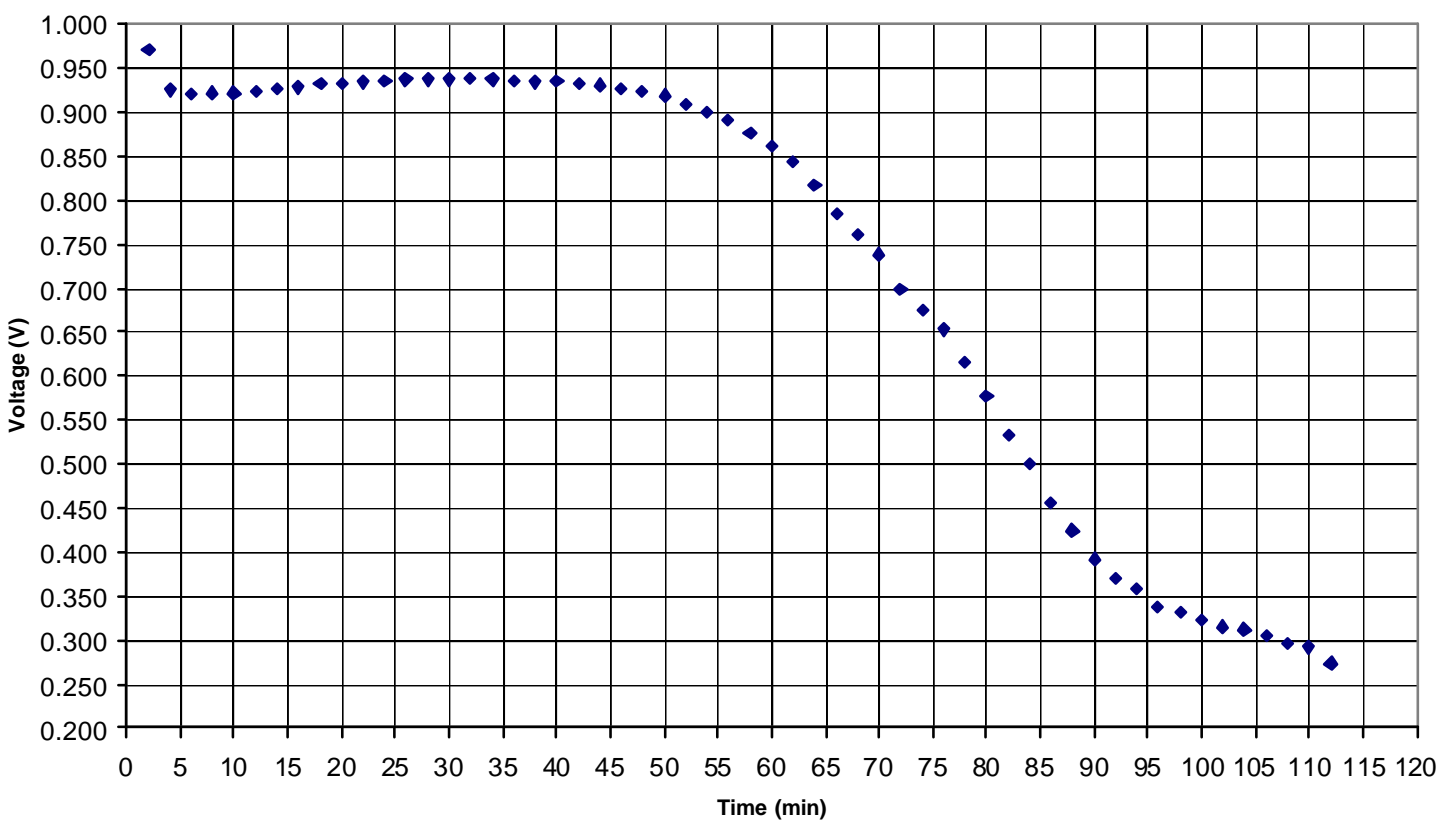

Figure 66. Long Term Results for 50/50 SECO-PetCoke Rod Run from Run \#16

Cell Voltage and Power Density versus Current Density GrafTech Coal Derived Rod, Air Flow $=0.50$ SLPM, $T=600^{\circ} \mathrm{C}, 4 / 11 / 06$

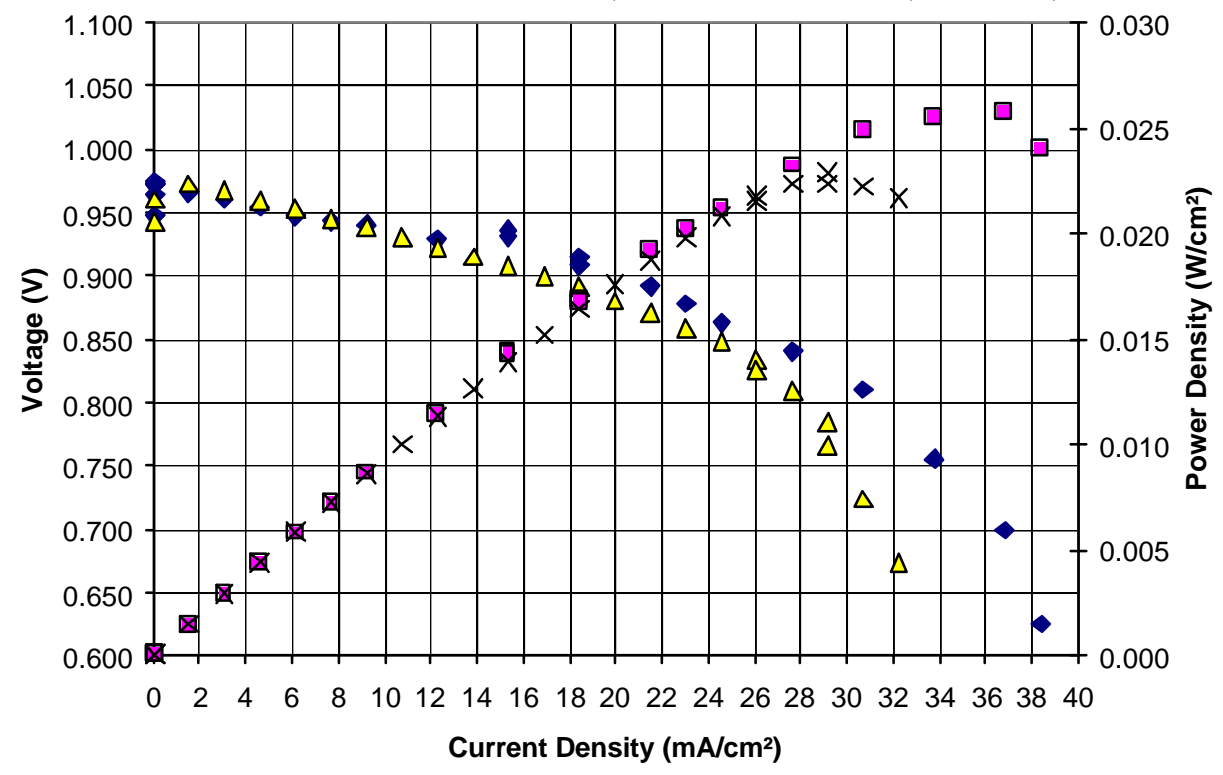

Figure 67. Results for GrafTech Baked Rod from Run \#20 
Voltage over Time

GrafTech Coal Derived Rod, Air Flow $=0.50$ SLPM, $T=600^{\circ} \mathrm{C}, 4 / 11 / 06-4 / 12 / 06$ Long Term Run

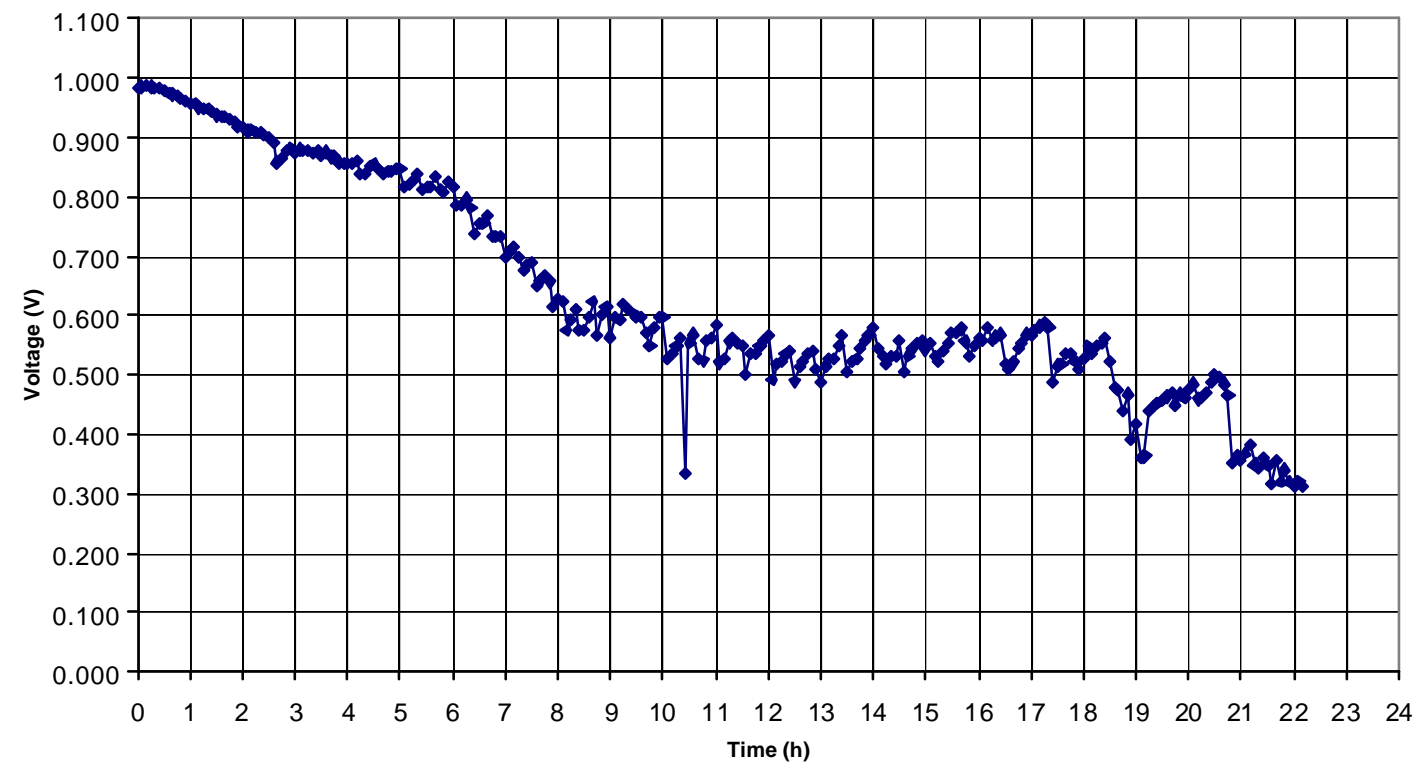

Figure 68. Long Term Results for GrafTech Non-Graphitized Rod Run from Run \#20

The resistivities of the rods are summarized in Table 7. It can be seen that the coal-derived rods have a higher resistivity than the graphite rods. The variability of the resistivity for the SECO/PetCoke rods can be due to the composition of the rods but more probably due to the technique used in their manufacture. The pressing of the rods in the laboratory was shown to be problematic and resulted in rods of inconsistent quality. Nonetheless, the resistivity of these rods is still quite low and they performed well, albeit for a shorter time, in the DCFC.

Table 7. Calculated Resistivity for Tested Rods

\begin{tabular}{|l|c|}
\hline \multicolumn{1}{|c|}{ Rod } & Resistivity $(\mu \Omega$-m) \\
\hline Graphite & 6.201 \\
\hline GrafTech Graphite & 8.670 \\
\hline & \\
\hline $0 \%$ SECO / 100\% PetCoke & 52.720 \\
\hline 25\% SECO / 75\% PetCoke & 137.250 \\
\hline $50 \%$ SECO / 50\% PetCoke & 139.920 \\
\hline 75\% SECO / 25\% PetCoke & 78.600 \\
\hline 100\% SECO / 0\% PetCoke & 81.900 \\
\hline GrafTech Baked Rod & 60.101 \\
\hline
\end{tabular}


The graphite rods show a low resistivity and the calculated values are comparable to the average literature value of $7.837 \mu \Omega-\mathrm{m} .{ }^{10}$ The resistivity of the blended rods resulted in a bell-shaped profile. The expectation was for the resistivity to increase exponentially with increasing SECO content since the SECO is coal-derived and should have a high resistance than the PetCoke. However, the PetCoke supplied from SARA is believed to be low grade material. Instead, the $50 \%$ blend resulted in the highest resistivity, and therefore had the highest ASR as shown in Table 6. The ASR for the graphite rods was about half of the ASR for coal, reflecting the higher resistivity of the coal rods.

In some cases, more current was drawn, as shown by the higher values of the current density, illustrated in Figures 69 and 70. In this series of experiments, constant cell conditions were maintained on runs conducted on different days. In the ohmic resistance region, the difference between the voltages generated for these three days is $11 \%$ at $50 \mathrm{~mA} / \mathrm{cm}^{2}$. In the unstable mass transport region, the difference was larger at $25 \%$ at $90 \mathrm{~mA} / \mathrm{cm}^{2}$. The results at the higher current densities show a larger percent difference. It is likely due to slight differences in the graphite rods (the rods were unused at the beginning of each run). Also, because the cell was taken apart after each run, the assembly and connections may have been slightly different. However, the data generated by this research are reproducible, and therefore, reliable.

Cell Voltage versus Current Density Graphite Rod, Airflow $=0.50 \mathrm{SLPM}, \mathrm{T}=600^{\circ} \mathrm{C}, 2 / 15 / 06$

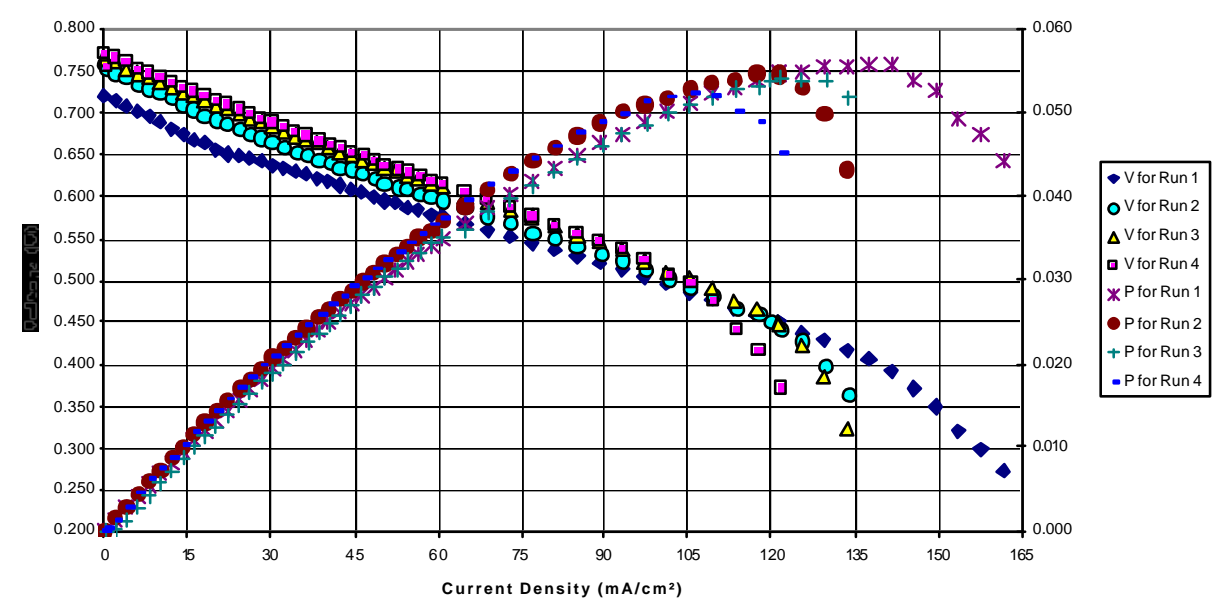

Figure 69. Reproducibility of Data Generated During the Same Run. 


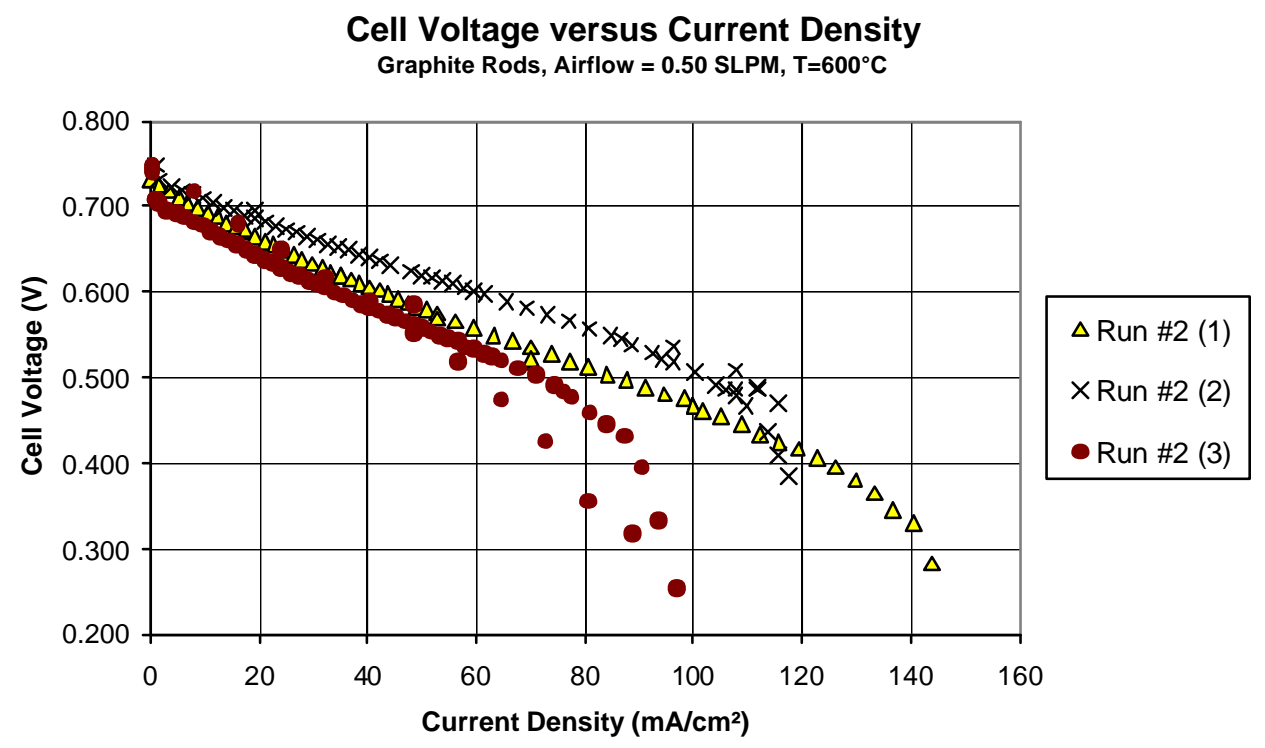

Figure 70. Reproducibility of Data Generated During Duplicate Runs

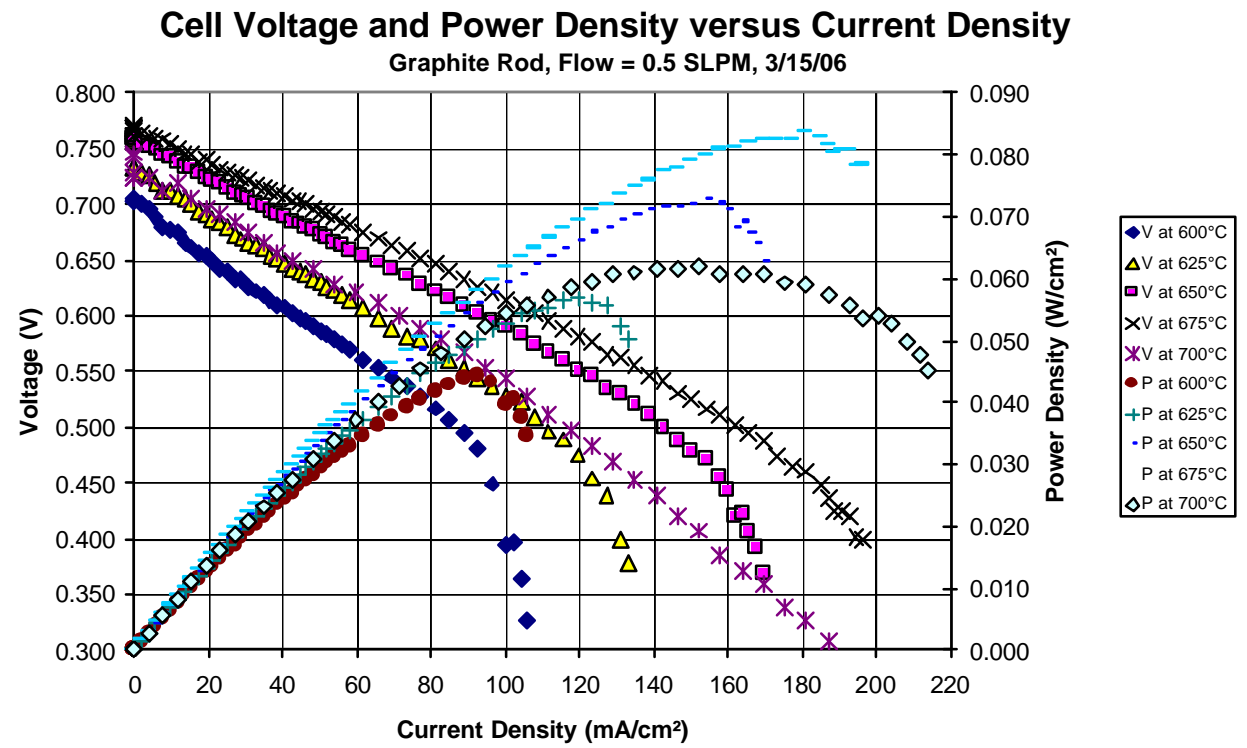

Figure 71. Effect of Temperature on Voltage Output and Power Density from Runs \#4, \#5, \#6, \#8, and \#10 (Trial 1) 


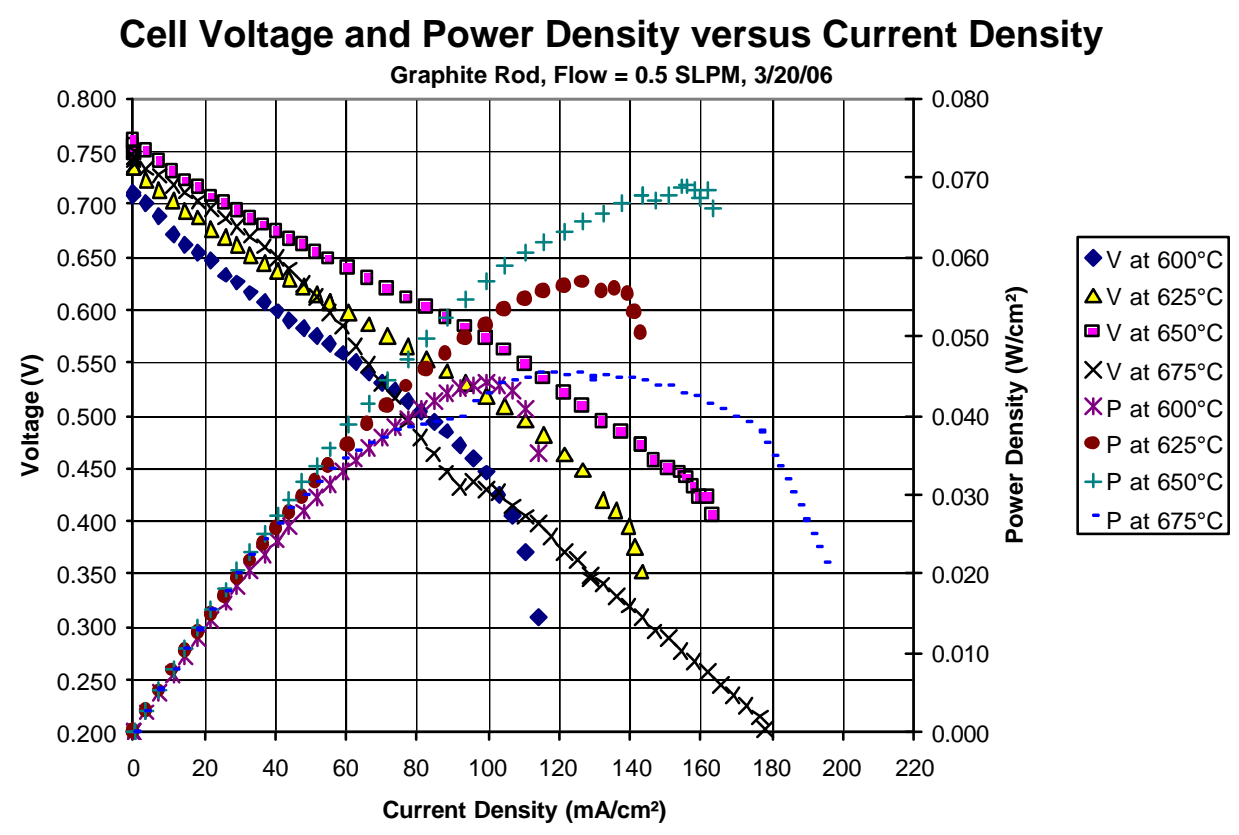

Figure 72. Effect of Temperature on Voltage Output and Power Density from Runs \#4, \#5, \#6, and \#8 (Trial 2)

The cell temperature was varied stepwise from $600{ }^{\circ} \mathrm{C}$ to $700{ }^{\circ} \mathrm{C}$ and $i$-V scans were made during a test with a graphite rods. The results indicate that the increase in temperature initially causes an increase in performance in the cell, as shown in Figure 71. However, there is a maximum temperature at which the temperature effect ceases to increase performance. It appears that the reaction is optimized at around $675{ }^{\circ} \mathrm{C}$, according to these data. Data at $700{ }^{\circ} \mathrm{C}$ show that the cell voltage is lower, even though more current is drawn than at the lower temperatures.

Although the values of $E^{\circ}$ obtained for different temperatures in Equation 8 are similar, the values for $E_{c e l l}$ obtained experimentally clearly show that temperature has more of an effect than originally anticipated. From the above equation, it seems logical that raising the temperature increases the voltage of the cell, which is seen in the increase in cell voltage from $600{ }^{\circ} \mathrm{C}$ to $675^{\circ} \mathrm{C}$. This is due to the natural log of the ratio of the partial pressures of $\mathrm{CO}_{2}$ and $\mathrm{O}_{2}$ being negative (because the partial pressure of $\mathrm{CO}_{2}$ in the inlet gas is small compared to $\mathrm{O}_{2}$, assuming a well-mixed environment. At the higher temperature, there may be more $\mathrm{CO}_{2}$ produced in the cell, which would cause the voltage output to decrease at even higher temperatures.

$$
E_{\text {cell }}=E^{\circ}-\frac{R T}{N F} \cdot \ln \frac{\left[\mathrm{CO}_{2}\right]}{\left[\mathrm{O}_{2}\right]}
$$

It should be noted that this equation holds for $\mathrm{C}$ reacting with gaseous $\mathrm{O}_{2}$ to make gaseous $\mathrm{CO}_{2}$, a situation that is not present in these experiments. However, this equation 
is frequently cited in the literature and may be relevant when using the concentrations of gaseous $\mathrm{O}_{2}$ and $\mathrm{CO}_{2}$ in the electrolyte.

A trend of how the OCV changed with respect to the temperature is given in Figure 70. The ASR shows the opposite trend of the OCV. When the ASR is at a minimum, the OCV reaches a maximum. This makes sense because when there is less ohmic resistance, the ionic and electronic conduction is higher, leading to increased cell voltage. The ASR varied in this experiment from $1.6 \Omega-\mathrm{cm}^{2}$ to $2.2 \Omega-\mathrm{cm}^{2}$, since this test was conducted using graphite rods.

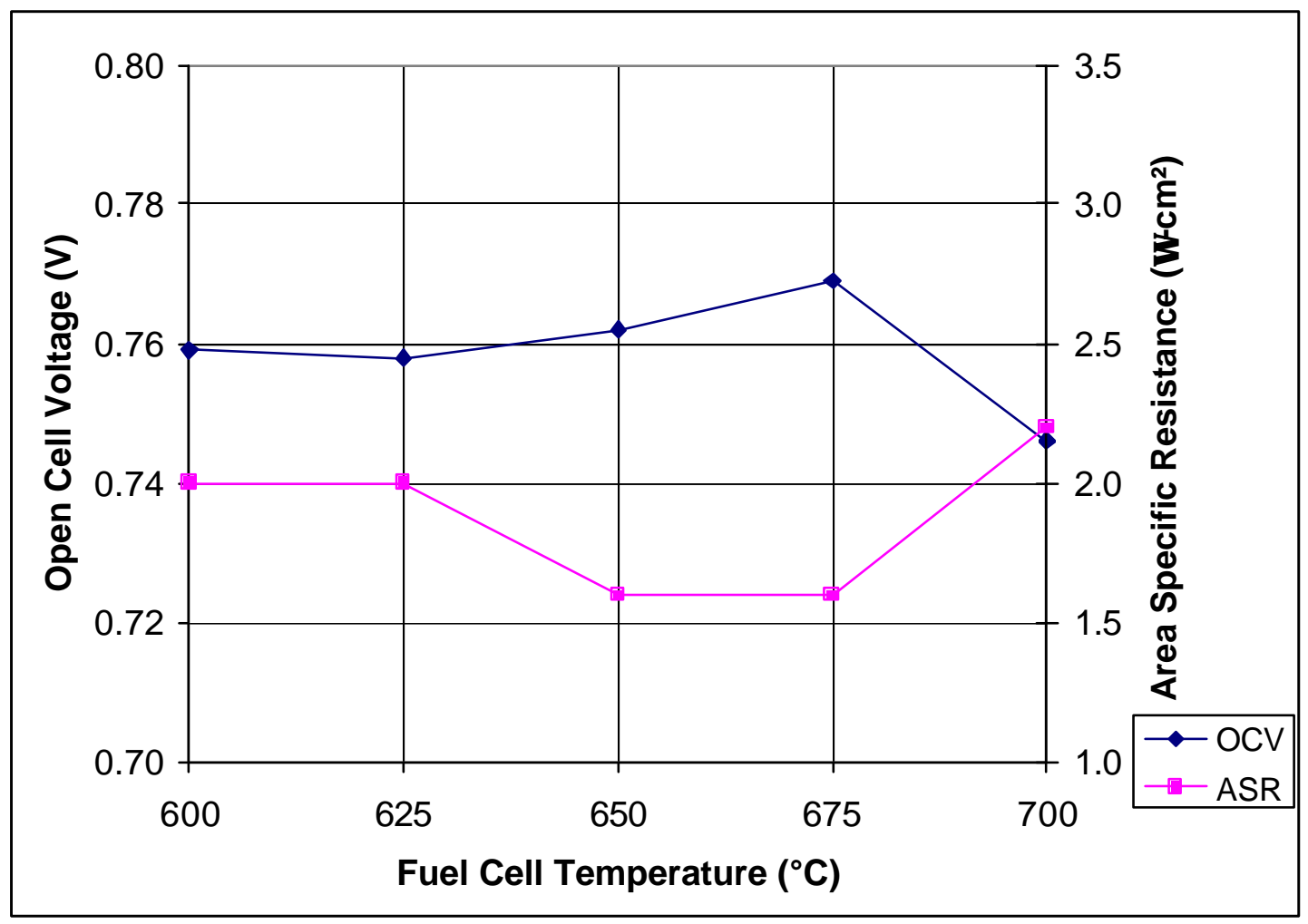

Figure 73. Trends of Open Cell Voltage and Area Specific Resistance versus Fuel Cell Temperature Using a Graphite Rod

The effect of the airflow rate into the cell influences the performance of the cell as shown below in Figure 74 and Figure 75. There is a clear peak at 0.50 SLPM where the maximum performance is obtained at $675{ }^{\circ} \mathrm{C}$, while the optimum performance at $600{ }^{\circ} \mathrm{C}$ appears to be at higher airflow rates.

At a flow rate below the optimum airflow value (0.25 SLPM), the optimum amount of air is not being supplied for the reaction. Referring to Equation 8, supplying more oxygen into the system would cause the natural $\log$ of the ratio to be more negative, causing the cell voltage to increase.

At a flow rate above the optimum airflow value ( 0.75 SLPM), the air is either flowing too quickly for the reaction to occur optimally, or it may be that the bubbles emanating from the spider are too large. This causes the surface area for the cathode 
reaction to be smaller because the air is occupying a large amount of the cathode surface, resulting in less contact between the reactants.

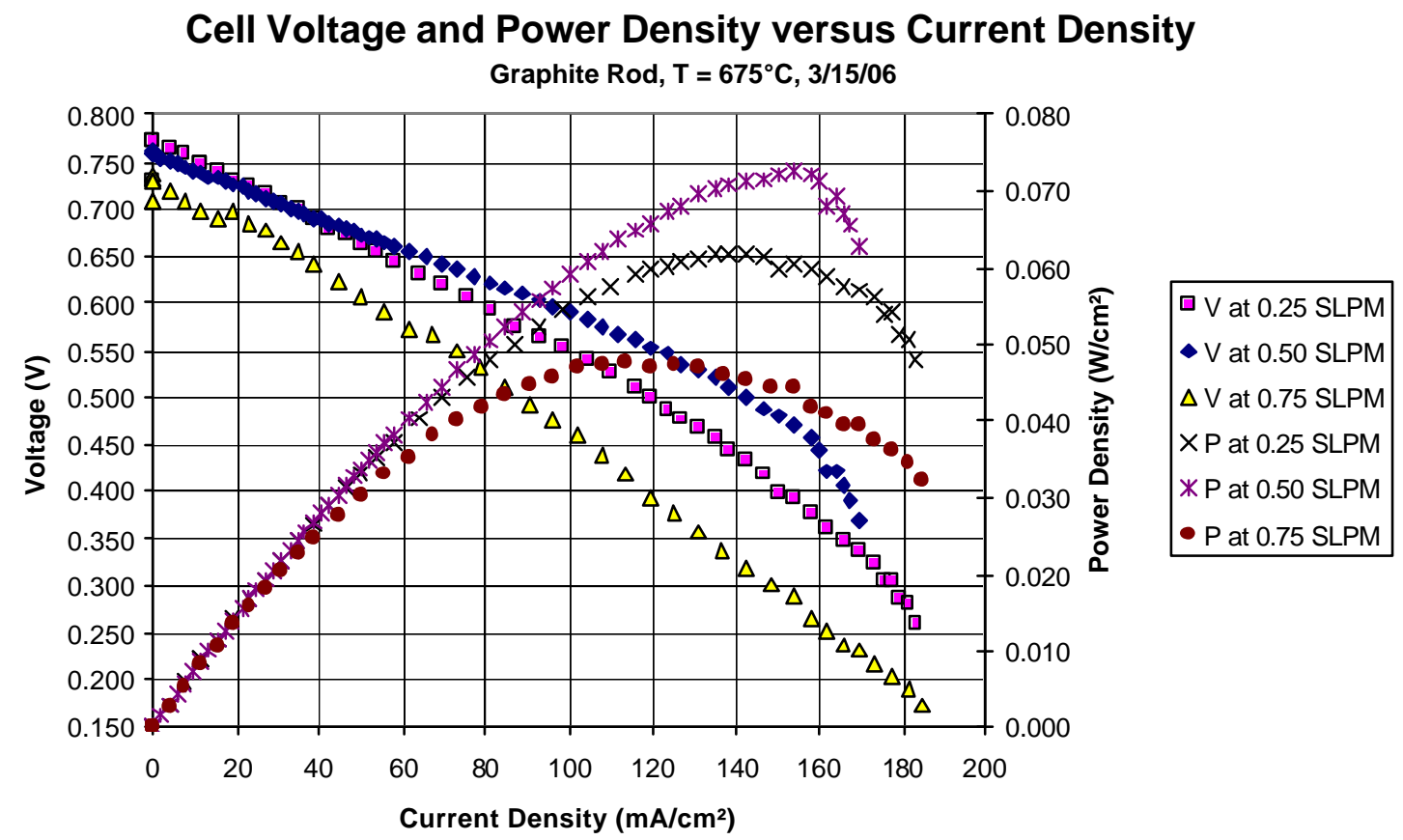

Figure 74. Effect of Airflow Rate on Voltage Output and Power Dens ity at $675{ }^{\circ} \mathrm{C}$

\section{Cell Voltage and Power Density versus Current Density} Graphite Rod, $\mathrm{T}=600^{\circ} \mathrm{C}, 2 / 8 / 06$

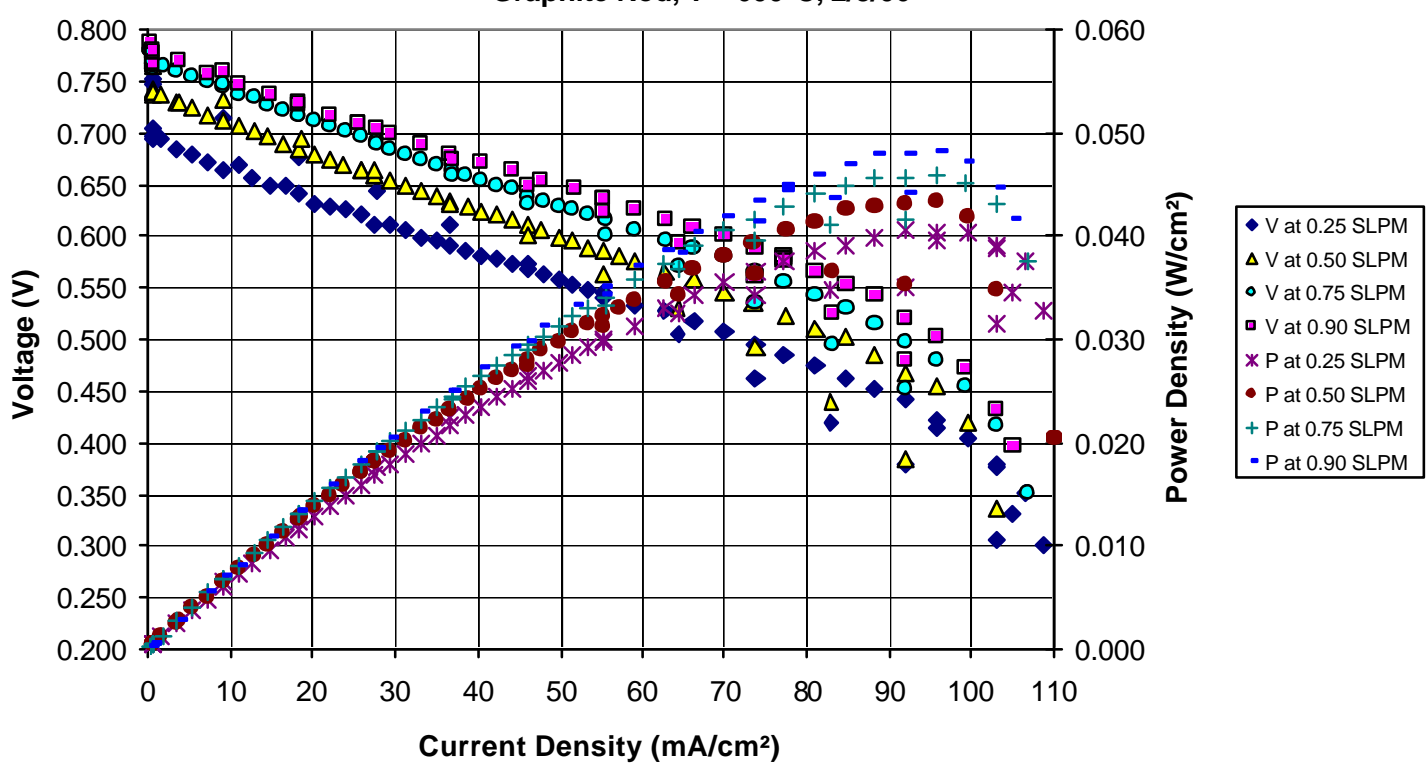

Figure 75. Effect of Airflow Rate on Voltage Output and Power Density at $600{ }^{\circ} \mathrm{C}$ 
Oxygen is required at the cathode, as seen in Equation 10, and is supplied in this process through the air feed. This equation shows that the airflow directly effects the cathode half-cell reaction. This is where the electrons are reintroduced into the system, react with the humidified air and replenish the hydroxide ions that are consumed at the anode.

$$
4 e^{-}+\mathrm{O}_{2}+2 \mathrm{H}_{2} \mathrm{O} \rightarrow 4 \mathrm{OH}^{-}
$$

The trends of OCV and ASR with the airflow rate are given in Figure 76 for the graphite rod. It can be seen here that the open cell voltage decreases steadily as airflow rate is increased. However, as shown in Figure 74, the voltage decreases faster at 0.25 SLPM than it does at 0.50 SLPM, catching up at about $35 \mathrm{~mA} / \mathrm{cm}^{2}$. The ASR shows the same trend as it did for the temperature study, with the minimum correlating to a maximum in cell voltage (not OCV, in this case). The minimum resistance is at an airflow rate of 0.50 SLPM. Further data are provided in the presentation of the graphite rod results above.

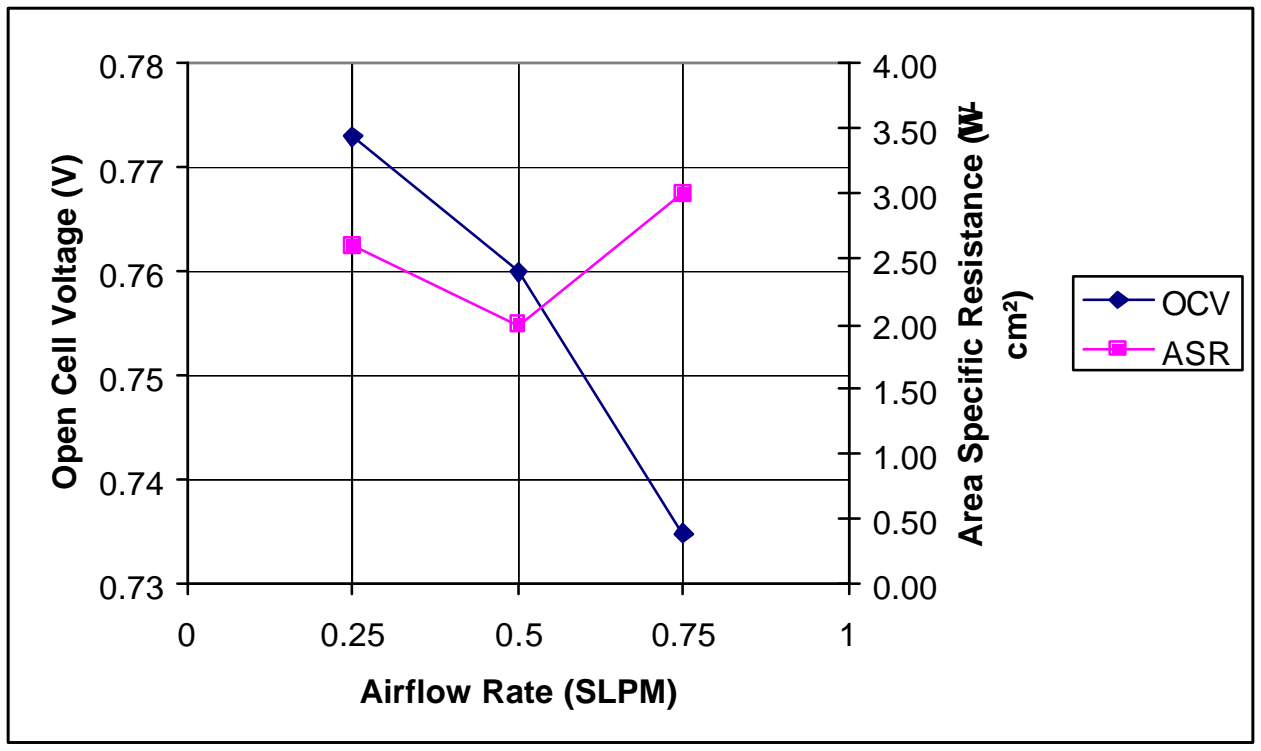

Figure 76. Trends of Open Cell Voltage and Area Specific Resistance Using a Graphite Rod when Airflow Rate is Varied (taken from data of Figure 74) 


\subsubsection{Effect of Fuel Rod Composition}

Table 8 is a summary of the main results obtained from the different fuels.

Table 8. Summary of Results by Carbon Fuel Rod

\begin{tabular}{|l|c|c|c|c|c|}
\hline \multicolumn{1}{|c|}{ Rod (Run \#) } & $\begin{array}{c}\text { Maximum } \\
\text { OCV (V) }\end{array}$ & $\begin{array}{c}\text { Maximum } \\
\text { Current Density } \\
\left(\mathbf{m A} / \mathbf{c m}^{2}\right)\end{array}$ & $\begin{array}{c}\text { Maximum } \\
\text { Power Density } \\
\left(\mathbf{W} / \mathbf{c m}^{2}\right)\end{array}$ & $\begin{array}{c}\text { Area Specific } \\
\text { Resistance } \\
\left(\Omega \times \mathbf{c m}^{2}\right)\end{array}$ & $\begin{array}{c}\text { Resistance } \\
(\Omega)\end{array}$ \\
\hline Graphite (4) & 0.788 & 230 & 0.084 & 2.59 & 0.054 \\
\hline $\begin{array}{l}\text { WVU Coal- } \\
\text { Derived (18) }\end{array}$ & 1.043 & 61 & 0.038 & 5.90 & 0.108 \\
\hline $\begin{array}{l}\text { GrafTech Baked } \\
(20)\end{array}$ & 0.972 & 38 & 0.026 & 4.20 & 0.065 \\
\hline
\end{tabular}

The best voltage output was obtained using the WVU coatderived rods, specifically, the rod used in Run \#18, composed of pure SECO. The GrafTech baked rod also reached nearly $1.0 \mathrm{~V}$. Recall that the standard potential for the oxidation of carbon is $1.01 \mathrm{~V}$. The SECO rod recorded a voltage slightly over the standard potential, probably due to reactions of some impurities or the binder pitch used in the rod.

The trends in the OCV and ASR for the SECO blend rods are given below in Figure 77. It can be seen that the OCV is the highest at about 100\% SECO content. The OCV is the lowest where the ASR is at its maximum, as expected. Once again, the ohmic resistance hinders ionic and electronic conduction in the electrolyte and electrodes, and therefore lowers cell voltage.

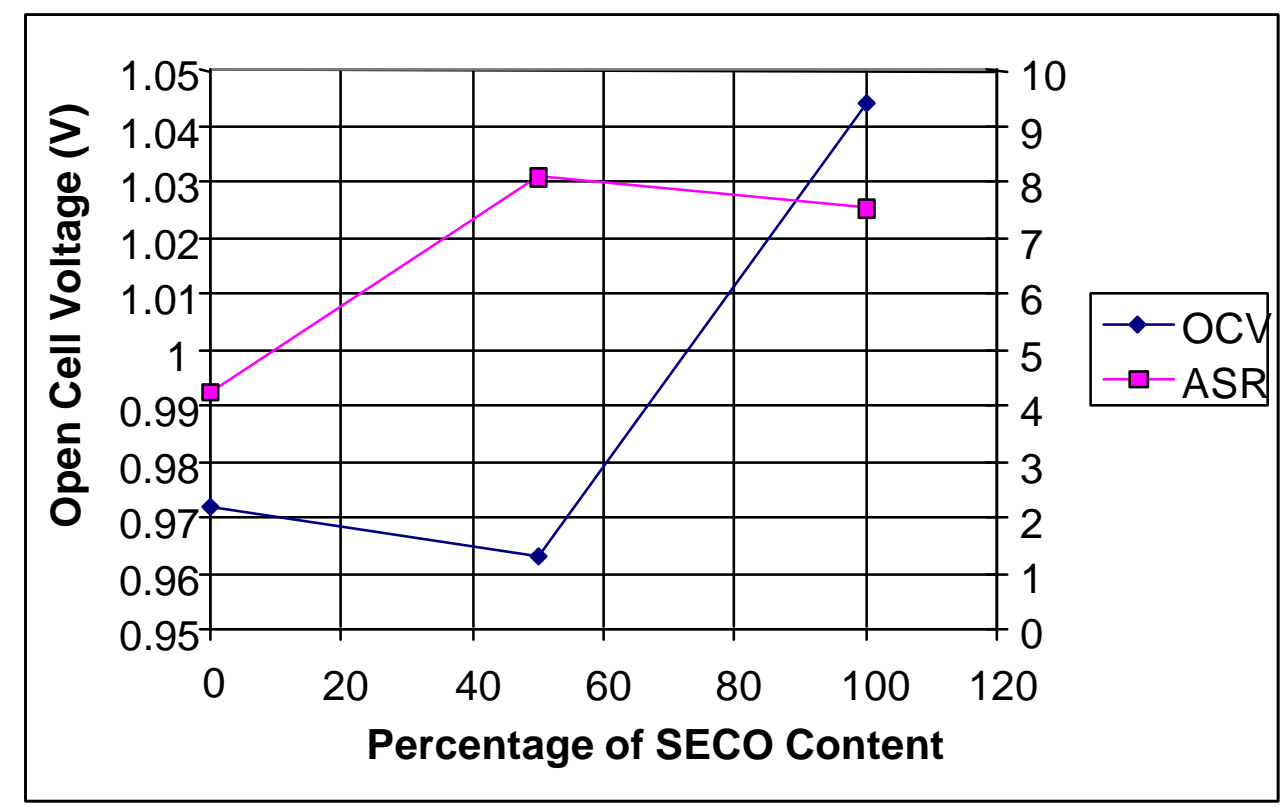

Figure 77. Trends of Open Cell Voltage and Area Specific Resistance versus Percentage of SECO Content 
More current was drawn from the graphite rods, probably due to the ordered molecular structure of graphite and the stability of the rod over time. The graphite rods clearly allow more current to be drawn per unit of surface area because of their low ohmic resistance (recall ASR is a measurement of ohmic resistance). Therefore, more power is produced from graphite rods in this case because power is the product of current times voltage. Power is the most important parameter in evaluating a fuel cell. The resistance of the coalderived rods is almost twice as much as that of graphite. Hence ohmic heating in the coalderived rods, dissipates more power, so less current can be drawn. This explains why higher current could be drawn from graphite despite the lower OCV.

\subsubsection{Carbon Electrode Conclusions}

Using carbon rods as a fuel source, direct carbon fuel cell produced electricity as predicted. The following conclusions can be drawn from the work:

The test stands provided by the U.S. Department of Energy were successfully modified for the DCFC.

Several fuel rods were used to evaluate the system, including graphite rods, petcoke carbon and SECO rods.

The effects of temperature, airflow, electrolyte, long-term exposure, and different rods were investigated and showed that cell performance peaks at about $675{ }^{\circ} \mathrm{C}$ and 0.50 SLPM with $\mathrm{NaOH}$ as the electrolyte. Graphite rods had better long-term results as they contained no binder pitch.

The fuel cell performance was evaluated via I-V curves, which can be used to investigate different types of resistances such as activation, ohmic, and transport resistances. Graphite rods produced open cell voltages of up to $0.788 \mathrm{~V}$ and current densities up to $230 \mathrm{~mA} / \mathrm{cm}^{2}$ while coalderived rods produced open cell voltages of 1.044 $\mathrm{V}$ and only $50 \mathrm{~mA} / \mathrm{cm}^{2}$ in current density. Graphite rods produced $0.084 \mathrm{~W} / \mathrm{cm}^{2}$ power density while coal-derived rods were only able to produce $0.041 \mathrm{~W} / \mathrm{cm}^{2}$ because of their higher ASR ( 4-8 $\mathrm{O} \times \mathrm{cm}^{2}$ as opposed to $\left.\sim 2 \mathrm{O} \times \mathrm{cm}^{2}\right)$.

Binder pitch is attacked preferentially in the reaction. Therefore, the baked coat derived rods crumbled over time in the electrolyte.

GrafTech baked rods were tested to investigate whether the method of manufacture influenced the behavior of the coalderived rods. These rods were not able to stand long-term runs due to the binder pitch preferentially reacting.

\subsection{References}

1 Jacques, William W., "Method of Converting the Potential Energy of Carbon into Electricity," Patent Number 555,511, March 3, 1896, Newton, MA.

2 Pesavento, Philip V., “Carbon-air Fuel Cell,” Patent Number 6,200,697, March 13, 2001, Lomita, CA 
3 Proceedings of the Direct Carbon Fuel Cell Presentation, CellTech Power, July 30, 2003, http://www.netl.doe.gov/publications/proceedings/03/dcfcw/Tao.pdf

${ }^{4}$ Lewis, G.N., and Randall, M., Thermodynamics, McGraw-Hill, New York, 1923, p. 576.

${ }^{5}$ Cherepy, N.J., Krueger, R., Fiet, K.J., Jankowski, A.F., Cooper, J.F., Direct Conversion of Carbon Fuels in a Molten Carbonate Fuel Cell, Journal of the Electrochemical Society, February 25, 2004.

${ }^{6}$ Lewis, G.N., and Randall, M., Thermodynamics, McGraw-Hill, New York, 1923, p. 576.

${ }^{7}$ Lowry, H.H., Chemistry of Coal Utilization, Volume II, John Wiley and Sons, New York, 1945, pp. 1568-1573.

${ }^{8}$ Dicks, A., Larminie, J., Fuel Cell Systems Explained, Second Edition, John Wiley and Sons, New York, 2003, Chapter 3.

${ }^{9}$ Saddawi, Abha, Carbon Fuels for the Direct Carbon Fuel Cell, Master's Thesis, West Virginia University, 2005.

${ }^{10}$ NDT Resource Center, http://www.ndt-ed.org/ 